\title{
SCHOOL LEADERS' PERCEPTIONS OF MISSOURI'S OUTDOOR LEADERSHIP EXPERIENCE
}

\author{
A Dissertation \\ presented to \\ the Faculty of the Graduate School \\ at the University of Missouri
}

In Partial Fulfillment

of the Requirements for the Degree

Doctor of Education

by
JENNI HAYES
Dr. Sandy Hutchinson, Dissertation Supervisor

May 2021 
(C) Copyright by Jenni Hayes, 2021

All Rights Reserved 
The Undersigned, appointed by the dean of the Graduate School, have examined the dissertation entitled

\section{SCHOOL LEADERS' PERCEPTIONS OF MISSOURI'S OUTDOOR LEADERSHIP EXPERIENCE}

presented by Jenni Hayes, a candidate for the degree of Doctorate of Education, and hereby certify that, in their opinion, it is worthy of acceptance.

Dr. Sandy Hutchinson

Dr. Barbara N. Martin

Dr. Bryan McDonald

Dr. Steve Ritter

Dr. Holly Jennings 


\section{DEDICATION}

I want to dedicate this work to my family_-Josh, Hunter, Parker, Sawyer, and Harper. Completing the doctoral degree process has been a family effort and it has affected each one of them. Their unwavering support and sacrifice have made this degree attainable, and they have encouraged my commitment to this challenge. Additionally, my parents, John and Paula South, and my in-laws, Roger and Shari Hayes, have cheered for me unceasingly and taken care of our children whenever it was needed. Words cannot express my gratitude to each of you. 


\section{ACKNOWLEDGMENTS}

I would like to thank Dr. Sandy Hutchinson for her encouragement to pursue this degree in order to further my development as a leader. Without her support and guidance, I would not have pushed myself to the doctoral level. Sandy embodies all I wish to become as a leader and I am so grateful for her caring influence. I would like to also thank Dr. Holly Jennings, Dr. Barbara Martin, Dr. Bryan McDonald, and Dr. Steve Ritter for their time and commitment sitting on my committee. Their support and feedback helped me grow in the doctoral process.

Further, I would like to thank Dr. Doug Miller for recognizing a need and beginning a program of leadership development for principals in Missouri. His creative thinking and lobbying for change laid the groundwork for ongoing development. I also thank Dr. Jim Masters and Dr. Paul Katnik for their continuation of Dr. Miller's vision.

The doctoral process has been a thought-provoking and exciting journey of growth. It would not have been the same without my cohort support: Elmer N. Ragus, Amanda Minear, and Lisa J. Barabas. We weathered all of the highs and lows together, and completed our journey as a team. Thanks Team Brian's Gym, I would not be here without you! 


\section{Table of Contents}

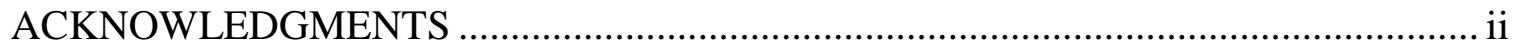

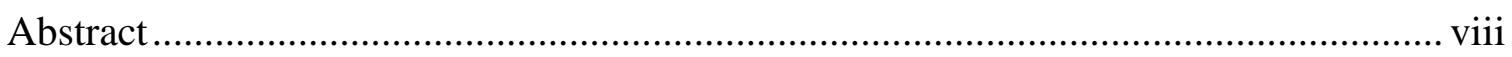

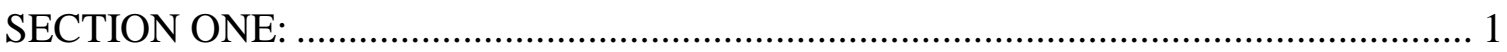

INTRODUCTION TO THE DISSERTATION IN PRACTICE .................................. 1

Introduction to the Background of the Study......................................................... 2

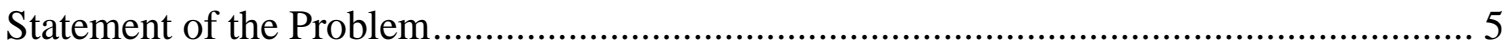

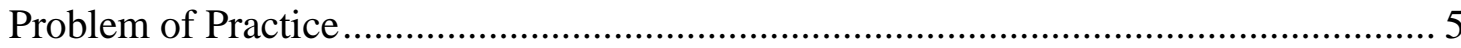

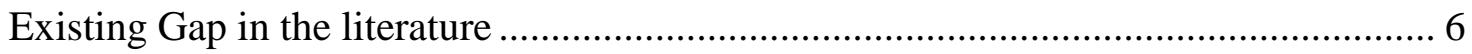

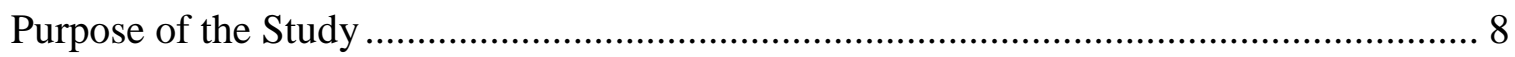

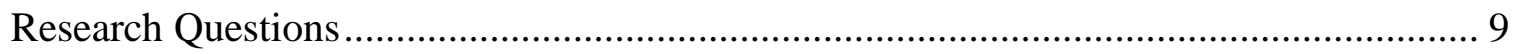

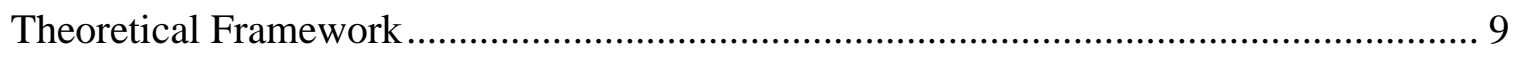

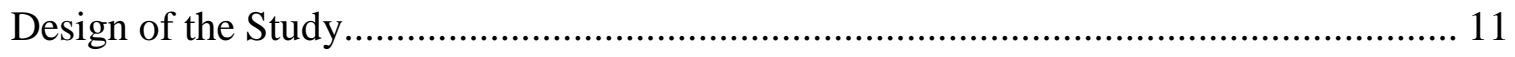

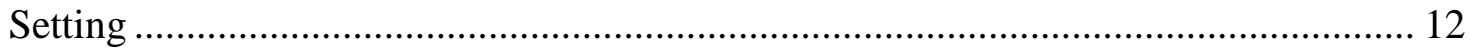

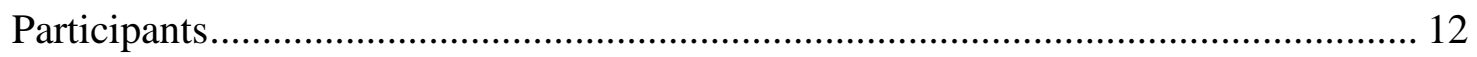

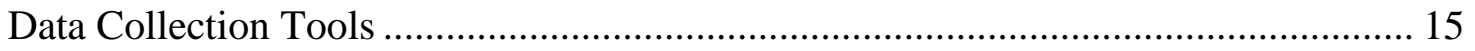

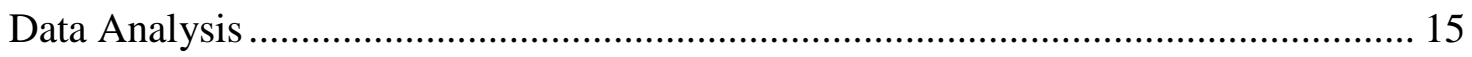


Limitations, Assumptions, and Future Research

Definitions and Key Terms

Significance of the Study 19

Scholarship. 19

Practice. 20

Findings 21

Themes. 21

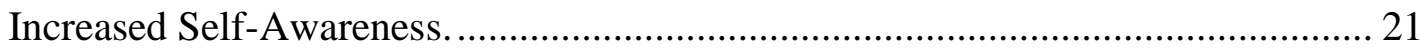

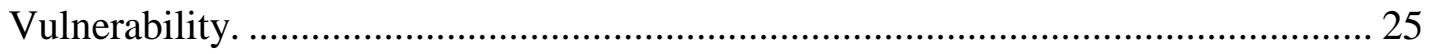

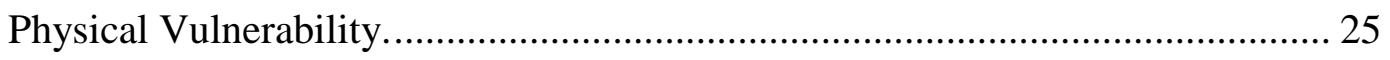

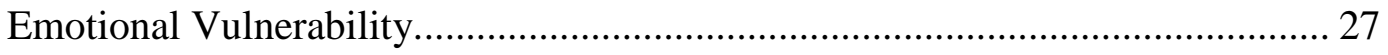

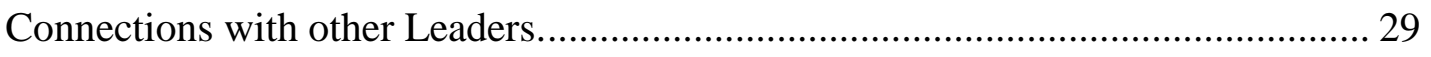

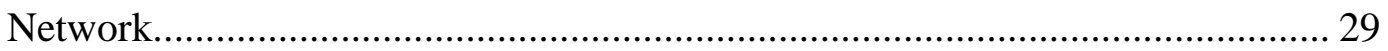

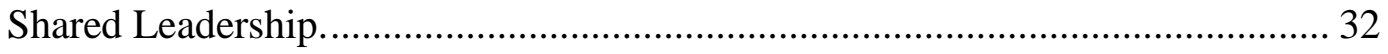

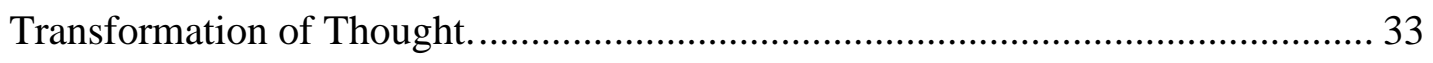

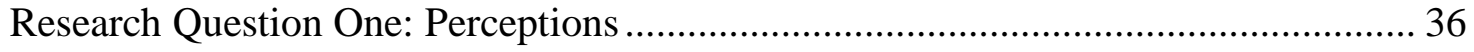

Research Question Two: Skill Implementation ................................................ 37

Research Question Three: Transformative Learning ............................................. 38

Research Question Four: Commitment to School Leadership................................. 39

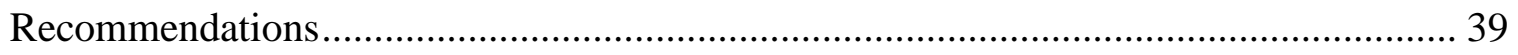


Maintain the Significance of the Hike

Advanced Outdoor Leadership Experience 40

Ensure a Forced Pause 41

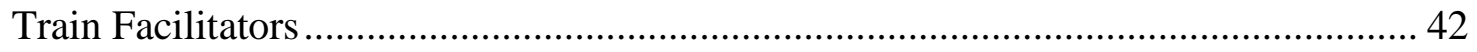

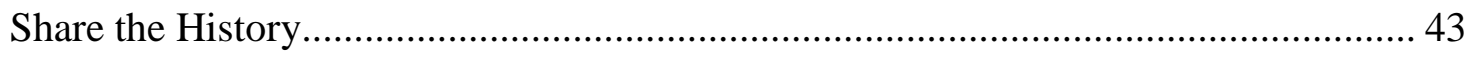

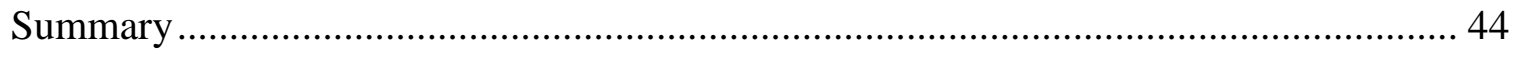

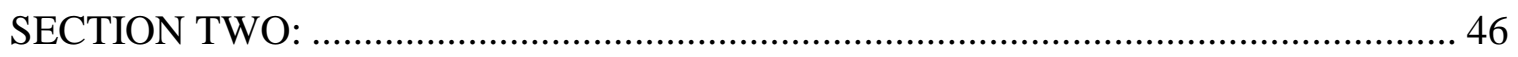

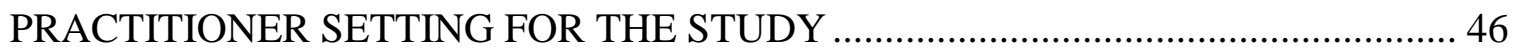

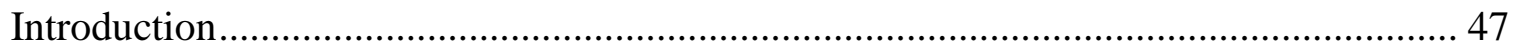

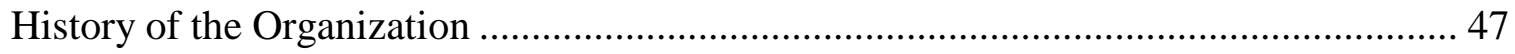

Missouri Department of Elementary and Secondary Education ................................ 47

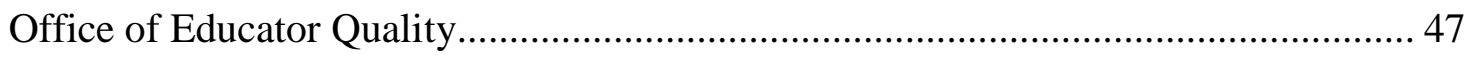

Missouri Leadership Development System .......................................................... 48

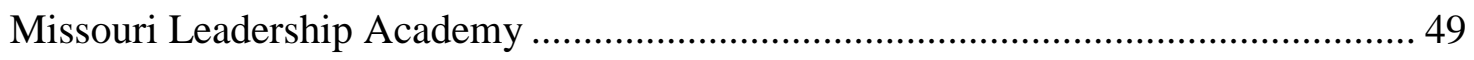

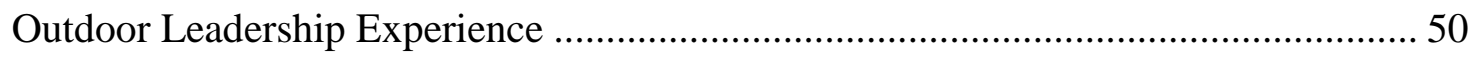

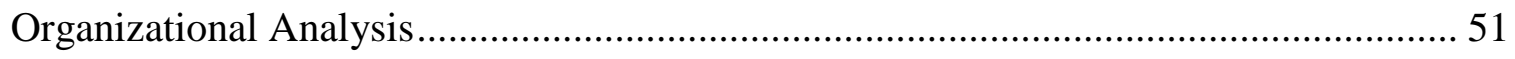

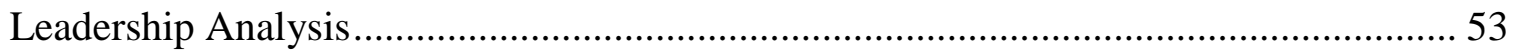

Implications for Research in the Practitioner Setting ............................................. 54 
Summary

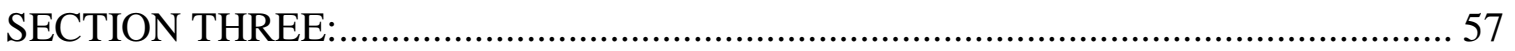

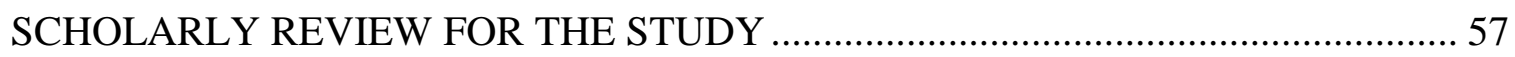

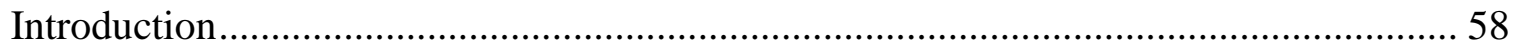

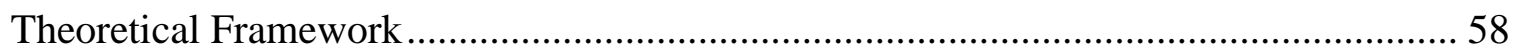

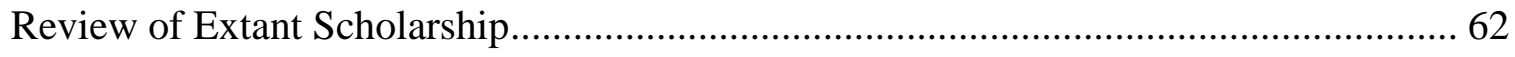

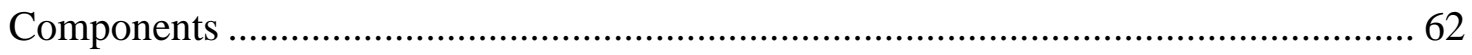

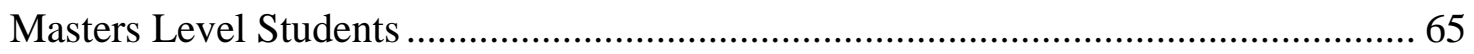

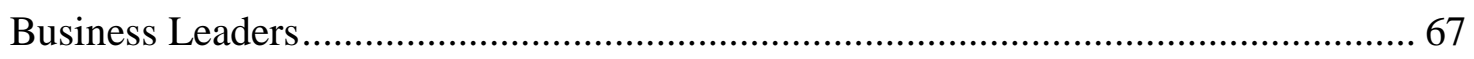

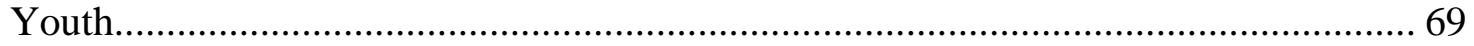

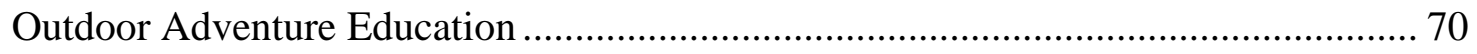

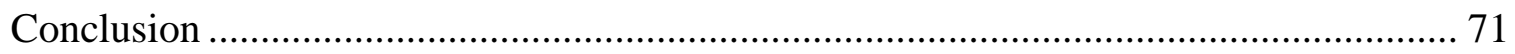

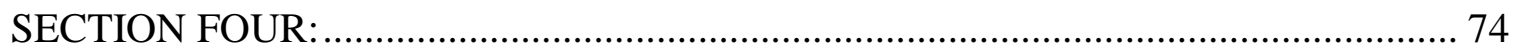

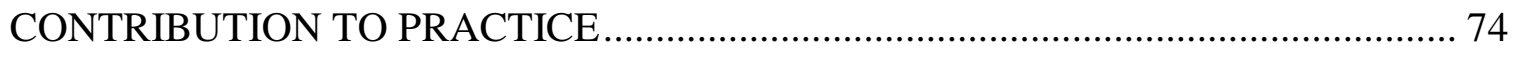

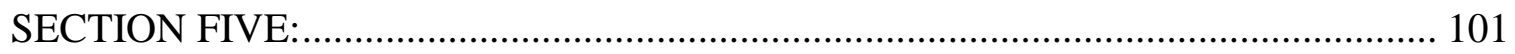

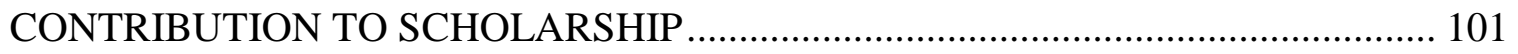

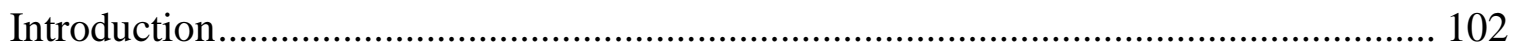

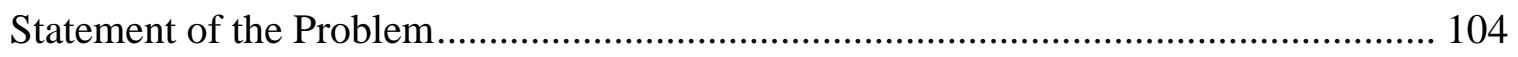


Problem of Practice

Existing Gap in the literature.

Purpose of the Study

Theoretical Framework. 108

Design of the Study. 110

Setting 111

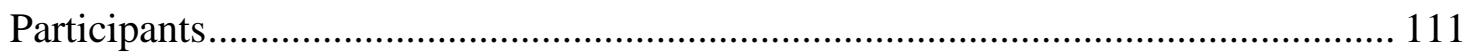

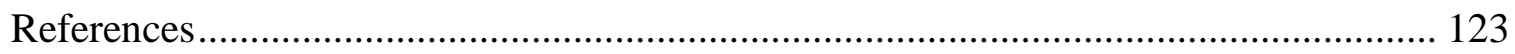

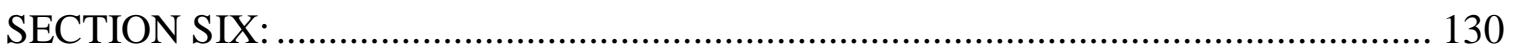

SCHOLARLY PRACTITIONER REFLECTION ................................................. 130

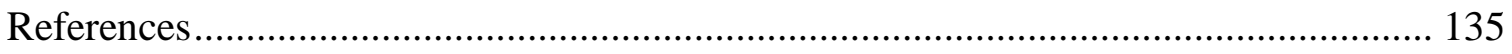

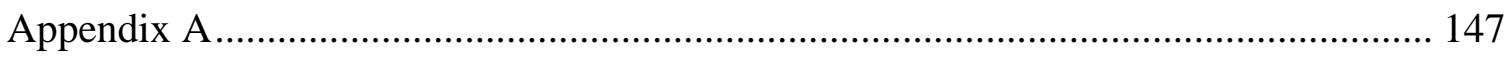

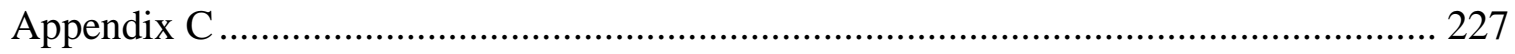

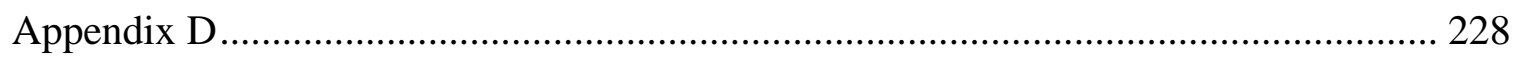

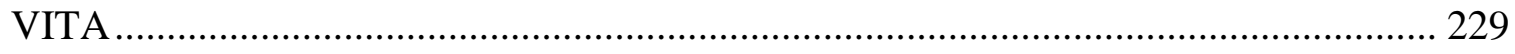




\begin{abstract}
Training school administrators to be more effective leaders through Missouri's Outdoor Leadership Experience is a unique concept that has been in place since 1987. Many other fields have used outdoor experiences for leadership training. This qualitative study discusses participants' perceptions of their experience and how it has impacted their leadership moving forward. Analysis of data was based upon Mezirow's Transformative Learning Theory and recommendations for future design of the program were made.
\end{abstract}




\section{SECTION ONE:}

INTRODUCTION TO THE DISSERTATION IN PRACTICE 


\section{Introduction to the Background of the Study}

Schools are facing escalating expectations from both parents and society, which causes many school principals to feel increasing levels of stress. Administrators are required to navigate a societal shift that is bringing both students and staff to their door with needs not seen in the school setting in the past (Elmore, 2018; Gajda \& Militello, 2008). Students are coming to school with fewer emotional skills and higher emotional needs, which adds strain to educators (Elmore, 2018). School employees are expected to meet these needs while also producing academic success.

The increased stress caused by the change in expectations results in principals not remaining in their schools or roles for a sustained amount of time. "The average principal now spends only two to three years in each school. Nearly $50 \%$ of new principals leave by their third year in the profession" (National Association of Elementary School Principals, 2016, para. 1). According to the National Teacher and Principal Survey (NTPS), for the 2015-16 school year, 75\% of school principals were at their current school less than five years, and $49 \%$ less than three years (National Center for Educational Statistics, 2019). Short employment periods are problematic because it takes 3-5 years for a school leader to develop school culture, which over time translates to more significant student achievement (Elmore, 2018; National Association of Elementary School Principals, 2016; Pounder \& Crow, 2005; Pounder, Gavin, \& Shephard, 2003). If schools are losing leaders before any real changes in culture or student achievement can be made, schools are unable to create a productive environment needed for the new generation of learners (Elmore, 2018). Research shows that student test scores often drop in the year after a leadership change (National Association of Elementary School 
Principals, 2016). Principals must stay in their position long enough to create a lasting impact on the students, teachers, and educational system.

Leaders cite a variety of reasons for moving schools or leaving the profession. Gadja and Mitello (2008) found practicing principals planned to vacate their current positions due to job stress, low salary in relationship to the responsibilities of the position, and job complexity and time demands. These results are comparable to national results found by the Educational Research Service (Gadja \& Militello, 2008). Although not all principals who left positions left the field completely, the mobility rate of principals is decreasing their impact on the schools they serve.

Developing the leadership skills of principals should increase their ability to cope with the stress and complexity of the principalship (Cranston, 2008) and decrease principal turnover (Kafele, 2018). Leadership skill development is vital to the effective support of school principals (Cranston, 2008; Nelsoney \& Welcome, 2017; Peterson, 2002). Riggio (2013) stated, “organizations believe that leadership development is important and worth the investment of resources and their time to work on their leadership development. There is a shared belief that leadership development works" ( $\mathrm{p}$. 12). Therefore, this leadership development is vital to the future of our students. The instability of a school's climate and culture based on ongoing administrator turnover ripples down to teachers and then to students.

Missouri's Department of Elementary and Secondary Education (DESE) has recognized the need for leadership development and is creating a blend of leadership supports into the Missouri Leadership Development System (MLDS) (Masters \& Katnik, 2019). As part of the new MLDS, a multi-year program of support is being developed. In 
year three of the MLDS program, leaders will attend the Missouri Leadership Academy (MOLA) (Missouri Department of Elementary and Secondary Education, 2019b). MOLA is a program that has been in place since 1985 and was initially designed to develop leadership skills and provide support for Missouri school administrators and aspiring administrators (D. Miller, personal communication, June 11, 2019).

The Outdoor Leadership Experience (OLE) has been a part of MOLA since 1987. OLE is one of the four statewide meetings and is an integral part of the program (Missouri Department of Elementary and Secondary Education, 2019a). Based on his extensive research and training, MOLA designer Dr. Doug Miller purposefully placed the OLE in the program to develop skills that cannot be learned in any other environment (D. Miller, personal communication, June 11, 2019). Miller studied the necessary components of outdoor education with Hank Schafermeyer at the acclaimed Underway Adventures program located at Southern Illinois University Outdoor Lab (D. Miller, personal communication, June 11, 2019). The Underway Adventures program designed a leadership development program based on the success of the Outward Bound Program (Southern Illinois University, 2019). The Outdoor Lab, also known as Touch of Nature, continues to be a thriving center with extensive programs in the field of outdoor education for students and adults (Southern Illinois University, 2019).

Basing his design for the OLE on the successful principles of Southern Illinois University's practicing program led Dr. Miller to create a sustainable plan for OLE which has been in place for 34 years. Researchers have found outdoor leadership training can teach a high level of transferable skills through high adventure activities and reflection (Ewert \& Overholt, 2010; Speelman \& Wagstaff, 2015). The training of educational 
leaders utilizing outdoor leadership skills through the OLE is an innovative program in Missouri that has not yet been duplicated in other states (Kensler \& Uline, 2019).

\section{Statement of the Problem}

The continued pressure society places on schools, and specifically school administrators, are creating a high principal turnover. Miller (2013) and Rangel (2018) stated this creates a situation that is detrimental to the improvement of schools and impacts student success. The discussion to decide the most effective methods for the development of principals created a need for more research on what is currently in place.

\section{Problem of Practice}

Ineffective training for leaders can lead to principal turnover (Kafele, 2018;

National Association of Elementary School Principals, 2016; Pounder \& Crow, 2005). Principal turnover is problematic because of the pivotal role that principals play and are expected to play in leading the time-consuming task of school improvement (Rangel, 2018). In other words, constant principal changeover can make it hard for schools to implement new policies and programs and to commit to improvement (Miller, 2013; Rangel, 2018). Principals indirectly affect student learning through hiring quality teachers, setting the vision and expectations for the school, creating a positive culture, supporting teachers' learning, and providing strong instructional leadership (Rangel, 2018). The School Leaders Network (2014) found the consequences of high principal turnover are a financial burden to districts: it costs districts at least $\$ 75,000$ to develop, hire, and train a single principal. The ability to retain effective principals is directly related to supporting them in their leadership development (Goldring, Taie, \& Owens, 2014). While the need to retain highly qualified administrators is recognized, the problem 
is the most effective method for leadership training has not been established. This study will examine one leadership development model to evaluate the perceptions of effectiveness of the program for training school leaders, which potentially leads to reducing principal turnover.

\section{Existing Gap in the literature}

As previously stated, Missouri has placed several components into a leadership development program to train school administrators to increase the principal retention rate (Masters \& Katnik, 2019). One aspect in year three of this training program is the Outdoor Leadership Experience (OLE). Very little research has been found to support outdoor education programs to develop school leaders. However, an abundance of research exists on outdoor education programs at many levels.

Employing outdoor adventure to develop business leaders is a practice that has been in place for many years (Brymer, Gray, \& Cotton, 2011). Whether the method is high adventure or low ropes courses, the outcome of leadership development is consistent (Hinge, 2016; Kanengeiter \& Rajagopal-Durbin, 2012, Myers \& Doyle, 2020). Business leaders who complete outdoor leadership development programs have higher retention than those who do not (Brymer et al., 2011; Williams, Graham, \& Baker, 2003).

Outdoor education programs have also been utilized by masters-level students in a variety of majors. Graduate students in the field of engineering, business, executive management, and recreation learn leadership skills transferable to their future careers in these programs (Judge, 2005; Kass \& Grandzol, 2011; Owen, 2015; Saulnier, Bagiati, \& Brisson, 2014). Often these programs are a semester in length, with a culminating outdoor experience as part of an overall class (Judge, 2005; Kass \& Grandzol, 2011). The 
transference learning from the masters-level students results in well prepared graduates who have leadership skills sought by employers.

Youth programs such as Outward Bound and the Chesapeake Bay Foundation's educational harbor programs focus on teaching the outcomes of character, leadership, and service. These programs result in students who are more confident and have the ability to interact and work effectively with others (Outward Bound, 2019b). Additional youth programs are found in many other states including Missouri, Virginia, Delaware, and several east coast states (Covitt, 2002; Experiential Education Exchange, 2019; O’Neil et al., 2020; Pigza, 2015; Roberts \& Suren, 2010). The programs focus on utilizing short, yet intense, outdoor learning experiences for youth leadership development of environmentally aware citizens (Covitt, 2002 Experiential Education Exchange, 2019; O’Neil et al., 2020; Pigza, 2015; Roberts \& Suren, 2010).

The training of outdoor adventure leaders includes outdoor education programs. However, those classes also include specific instruction on how to lead (Ballard, Shellman, \& Hyashi, 2006; Ewert \& Overholt, 2010; Hayashi \& Ewert, 2006; Speelman \& Wagstaff, 2015). Outdoor adventure leaders must be effective leaders to safely lead a group through an excursion (Speelman \& Wagstaff, 2015) and leadership development is a pivotal piece of their programs (Ewert \& Overholt, 2010). Outdoor adventure programs embed leadership into high adventure skills training to increase effectiveness (Ballard et al., 2006; Ewert \& Overholt, 2010; Hayashi \& Ewert, 2006; Speelman \& Wagstaff, 2015).

Braymer, Gray, and Cotton (2011) cite the benefits of outdoor leadership training are hard to define; however, outdoor learning experiences have become a popular and 
effective medium for generic leadership skill development. A lack of understanding or research exists regarding OLE's impact on leadership development in, and the potential retention of, Missouri's administrators. The gap in the literature shows a scarcity of studies within the education profession specific to utilizing outdoor leadership training programs to develop leadership.

\section{Purpose of the Study}

The purpose of this qualitative study was to understand how the skills learned at the outdoor leadership experience are perceived to impact school leader effectiveness. Principal effectiveness is cited as a leading factor in the retention of quality teachers (Vekeman, Devos, Valcke, \& Rosseel, 2018), as well as the effectiveness of a school (DuFour \& Marzano, 2011). The growth of a principal's effectiveness increases their likelihood to remain satisfied in their job and retain their role.

The researcher studied the impact of outdoor adventure education on the leadership skills of school leaders. The study focused on this through the context of the Missouri Leadership Academy (MOLA), specifically the Outdoor Leadership Experience (OLE) (Missouri Department of Elementary and Secondary Education, 2019a). The researcher studied the skills utilized at OLE that have also been found useful with varying levels of students and business leaders. The researcher examined the impact of a leader's transfer of these skills to their practices.

The value of outdoor leadership training was described by Ewert and Overholt (2010) as "involve[ing] active and direct experiences with many of the components associated with leadership such as decision-making, assessment, motivation, and goalsetting" (p. 40). Sharing learning experiences that establish a common base for reflection 
and discussion creates opportunities for participants to act on new insights and practice transformative learning (Taylor, 2008). The transformation of skills and ideas can then be applied to increase the effectiveness in their roles as leaders, as well as continue to create meaning of the experience and embed emergent stories into their daily lives (Ballard et al., 2006).

\section{Research Questions}

The research questions guiding this study are:

1. What are the perceptions of the participants of Missouri Leadership Academy who attended the Outdoor Leadership Experience?

2. How do participants implement the leadership toolkit skills developed through the Outdoor Leadership Experience in their daily role as Missouri school leaders?

3. How does transformative learning theory relate to the perceptions of the participants' experience?

4. How does the Outdoor Learning Experience impact the participants' commitment to remain a school leader in Missouri?

\section{Theoretical Framework}

This study was examined through the lens of transformative learning theory. As the seminal researcher in this area, Mezirow's 1978 transformative learning theory explained how adults make sense of their experiences and how influences affect this development (Mezirow, 1997). The process involves transforming frames of reference through critical reflection of assumptions, validating contested beliefs through discourse, taking action on one's reflective insight, and critically assessing it (Mezirow, 1997). Two frameworks for transformative learning exist. The first emphasizes personal 
transformation and change, with critical reflection and critique of assumptions as points of emphasis; and the second emphasizes social change as well as personal change, and the link connecting these two changes (Ettling, 2012). For this study, the focus was placed on the first framework.

Transformative learning theory asserts that learning can occur gradually or from a sudden, powerful experience, and changes the way people see themselves and their world personally, socially, and professionally (Baumgartner, 2001; DeCapua, Marshall, \& Frydland, 2018). Whether the learning takes place over time or from an intense experience, reflection and dialogue are the pieces of the experience critical to transformation (Merriam, 2004). Reflection takes time, structure, and intention to create a transformation of learning (Merriam \& Bierema, 2014; Mezirow, 2009; Taylor, 2009).

Transformative learning theory continues to be a growing area of study within adult learning and has significant implications for the practice of teaching adults (Baumgartner, 2001; Hoggan, 2016; Merriam \& Bierema, 2014; Mezirow, 2009; Taylor, 2009). The growth is so significant that it seems to have replaced andragogy as the dominant educational philosophy of adult education, offering teaching practices grounded in empirical research and supported by sound theoretical assumptions (Taylor, 2008). As such, Hoggan (2016) defined transformative learning as "processes that result in significant and irreversible changes in the way a person experiences, conceptualizes and interacts with the world" (p. 71).

Cranton and Taylor (2012) asserted that learning could only be called transformative if a fundamental change occurred at a deep level. Designing a program to foster transformative learning which reaches a deep level requires a safe and trusting 
relationship to be built, engaging the learner in discovery while overcoming fears or preconceived ideas, and acknowledgment of the learner as a whole person (Taylor \& Snyder, 2012). The Outdoor Leadership Experience (OLE) was designed to create a transformation of perspective and skill through reflection, discussion, and facilitated activities (Missouri Department of Elementary and Secondary Education, 2019a).

\section{Design of the Study}

The methodology of a study should be chosen based on the most effective manner by which to answer the research questions (Creswell, 2016). This study sought to understand participants' perceptions of their experience at the Outdoor Leadership Experience (OLE). The purpose of data analysis in qualitative research is to understand the data (Merriam \& Tisdell, 2016). The goal of qualitative research is to answer the research questions which is achieved through the process of data analysis. Therefore, a qualitative study was designed to gather information about participants' perceptions.

The research methods chosen were consistent with the qualitative case study design of Creswell (2016), as well as Merriam and Tisdell (2016). The components included in the design of this study are participant sampling, site description and selection, methods, and coding procedures. The methods chosen for this qualitative study for data collection and triangulation included historical data from the Missouri Department of Elementary and Secondary Education, interviews of participants, and focus groups of facilitators. These methods are characteristic of effective qualitative studies (Creswell, 2012; Creswell, 2016; Seidman, 2013).

Interviews were conducted until saturation was reached (Seidman, 2013), with a total of 22 participant interviews. Merriam and Tisdell (2016) stated interviews are the 
most common form of data collection for qualitative studies and were the primary source of data for this study. The interviews were approximately 30-60 minutes, with a conversational style to explore the participants' views. The interviews were based on a set of flexible questions to allow for a more natural flow of conversation.

A total of three focus groups consisting of 11 participants were formed to explore the experiences of participants who became facilitators for the OLE. The focus groups followed a similar questioning pattern to the interviews, again with flexibility, to ensure a natural and honest discourse of the participants' experiences. Focus groups allowed the researcher a unique insight into common perceptions of facilitators, as well as detailed information and personal narratives (Kruger \& Casey, 2009).

\section{Setting}

The Outdoor Leadership Experience (OLE) is a four-day experience focused on developing leadership skills in school administrators by placing leaders in an environment outside their normal routine. Facilitators guide them through outdoor adventure, team building activities, and reflection designed to develop leadership skills that can be implemented when they return to their roles. The OLE took place at Camp Rising Sun at Missouri's Lake of the Ozarks from its inception in 1987 until it was moved in 2014 to the YMCA Trout Lodge in the Mark Twain National Forest near Potosi, MO. The OLE has been in place for 34 years, and at this time the impact of leadership skills learned has not been studied.

\section{Participants}

Because the Outdoor Leadership Experience (OLE) has been part of Missouri Leadership Academy (MOLA) for 34 years, there was a large pool from which to seek 
participants. Participants were purposefully selected, which meant the researcher selected individuals who helped to understand the research problem and questions (Creswell, 2014). Participants from each of the three decades of operation were contacted. Past participants and facilitators were sent an email describing the study and inviting them to participate in interviews and focus groups to be held at their convenience. Due to COVID 19, interviews and focus groups were held electronically. Potential participants were contacted via email, from a list procured through DESE's Office for Educator Quality that coordinates the Missouri Leadership Development System (MLDS), MOLA, and the OLE. Additionally, the Missouri administrator organizations (Missouri Association of Elementary School Principals, Missouri Association of Secondary School Principals, and Missouri Association of School Administrators) were a resource for soliciting participants.

Participants were current practicing administrators with varying levels of experience, whether they were facilitators or past participants of the OLE. The researcher realized some administrators from the early years of OLE were no longer active principals, but their participation provided valuable information about the early years of the program and their perceptions of the effect of OLE on their leadership throughout their career. Participants were sought from rural, urban, and suburban schools throughout the state. The researcher was seeking as much diversity in experience, gender, ethnicity, and location as possible. Participants who attended the OLE only once as an attendee were interviewed individually (See Table 1). Facilitators who have led groups through the OLE were interviewed in three focus groups of three or four participants (See Table 2). A total of 33 school leaders were interviewed. 
(Table 1)

\begin{tabular}{|c|c|c|c|c|c|c|c|c|}
\hline Psuedonym & Year of Participatid & Years as a Leader & Region: & Gender: & Population: & Role@ attendance & Current Role & Kolbe Results \\
\hline Blake & 1989 & 3 & NW & $\mathrm{M}$ & Rural & Principal & Retired & Fact Finder \\
\hline Brady & 2008 & 0 & HOM & $\mathrm{M}$ & Urban & Teacher & Teacher & Fact Finder \\
\hline Cindy & 2008 & 0 & C & $F$ & Rural & Teacher & Principal & Quick Start/Fact Finder \\
\hline Daniel & 2006 & 3 & SW & $\mathrm{M}$ & Rural & Principal & Principal & Mediator \\
\hline Greg & 2011 & 7 & SE & $\mathrm{M}$ & Rural & \begin{tabular}{|l|} 
Principal \\
\end{tabular} & Principal/Curriculum & Can't Remember \\
\hline Janice & 2010 & 5 & $\mathrm{SC}$ & $F$ & Suburban & Curriculum Direct & Asst. Superintendent & Fact Finder/Follow Through \\
\hline Joey & 2019 & 6 & $\mathrm{KC}$ & $\mathrm{M}$ & Urban & Principal & Principal & Fact Finder/Follow Through \\
\hline John & 2012 & 6 & NW & M & Rural & Asst. Principal & Curriculum director & Quick Start \\
\hline Lacey & 2013 & 2 & C & $F$ & Rural & Principal & Principal & Quick Start \\
\hline Luke & 2014 & 4 & SE & M & Rural & Principal & Principal & Quick Start/Fact Finder \\
\hline Lydia & 2007 & 2 & C & $F$ & Rural & Assst. Principal & Higher Ed. & Quick Start \\
\hline Marcia & 2010 & 10 & $\mathrm{KC}$ & F & Urban & Principal & Princpal & Fact Finder/Follow Through \\
\hline Ron & 2014 & 2 & $\mathrm{SC}$ & $\mathrm{M}$ & Suburban & Asst. Principal & Principal & Fact Finder \\
\hline Ross & 2018 & 5 & STL & M & Urban & Asst. Principal & Principal & Fact Finder/Follow Through \\
\hline Stephanie & 2012 & 2 & NW & $F$ & Rural & Principal & Principal & Follow Trhough \\
\hline Trent & 2011 & 1 & C & M & Rural & Principal & Superintendent & Fact Finder \\
\hline Tricia & 2006 & 2 & SE & F & Rural & Principal & Superintendent & Quickstart \\
\hline \multicolumn{2}{|c|}{ Average years of Experience: } & 3.43 & & & & & & \\
\hline
\end{tabular}

Regions (of Missouri): $\mathrm{C}=$ Central, $\mathrm{HOM}=$ Heart of Missouri/Columbia, $\mathrm{KC}=$ Kansas City,

$\mathrm{NE}=$ Northeast, $\mathrm{NW}=$ Northwest, $\mathrm{SC}=$ South Central, $\mathrm{SE}=$ Southeast, $\mathrm{STL}=$ Saint Louis,

\section{SW=Southwest}

(Table 2)

\begin{tabular}{|l|c|l|l|l|}
\hline Pseudonym & Years Facilitated & Region: & Gender: & Population: \\
\hline Mitch & 10 & STL & M & Urban \\
\hline Jamie & 12 & C & F & Suburban \\
\hline Chad & 3 & SC & M & Rural \\
\hline Tim & 5 & SE & M & Rural \\
\hline & & & & \\
\hline Skip & 14 & STL & M & Urban \\
\hline Judah & 17 & STL/KC & M & Urban \\
\hline Harley & 3 & C & F & Rural \\
\hline Jonah & 5 & NE/SE & M & Rural \\
\hline & & & & \\
\hline Austin & 14 & SW & M & Suburban \\
\hline Casey & 17 & HOM & M & Rural \\
\hline Tyler & 5 & STL & M & Urban \\
\hline & & & & \\
\hline Avg. Years of OLE experience: & 9.55 & & & \\
\hline
\end{tabular}

Regions (of Missouri): C=Central, HOM=Heart of Missouri/Columbia, $\mathrm{KC}=$ Kansas City,

NE=Northeast, NW=Northwest, $\mathrm{SC}=$ South Central, $\mathrm{SE}=$ Southeast, $\mathrm{STL}=$ Saint Louis,

SW=Southwest 


\section{Data Collection Tools}

Interview and focus group questions were created based on the literature review on transformational learning theory, the Outdoor Leadership Experience toolkit strategies, and outdoor leadership development programs. Interviews lasted approximately 30-60 minutes. The recommended interview length was based on Creswell's (2014) suggestions. Seidman (2013) asserted interviews must be audio recorded to ensure proper transcription is made. Therefore, the researcher audio recorded and transcribed all interviews, as well as the focus group sessions.

\section{Data Analysis}

Transcripts from the interviews and focus groups were coded with open and axial coding. Merriam and Tisdell (2016) defined open coding as the initial thoughts repeated when studying transcripts. Axial coding was defined as the grouping of the open codes initially found in open coding (Merriam \& Tisdell, 2016). Common themes based on the skills participants employed in their role post-OLE were grouped and coded. Bias was limited by reflexivity. Creswell (2014) defined reflexivity in terms of researchers' reflection on how their personal biases and values impact the interpretation of data.

\section{Limitations, Assumptions, and Future Research}

Care was taken to ensure the study addresses ethical concerns and limits the researcher's bias (Merriam \& Tisdell, 2016; Seidman, 2013). The researcher is a 2014 Outdoor Leadership Experience (OLE) participant and has been an OLE facilitator for the past five years. The researcher was also a facilitator for the Central Region Missouri Leadership Academy (MOLA) group for the 2019-20 Academy. As an active member of the OLE and MOLA, the researcher has personal connections to some past participants. 
Creswell (2014) cautioned against leaders interviewing followers and encouraged as much professional distance between the interviewer and the participants as possible. Therefore, the researcher avoided interviewing participants she has led through the outdoor leadership experience in the past.

A serious limitation to this study was the data base of the past participants and facilitators. Demographic data were kept electronically from 2006 to the present time. Information listing participants from 1987-2005 was not accessible to the researcher. The researcher was able to gain information from a few participants from 1987-2005 through current OLE leadership and past facilitators. However, the researcher was only able to make contact with and interview two participants from the early years of the program.

As a leader in the program, the researcher believes in the program's goals and success. Assumptions regarding this study centered on that belief, as well as the belief that leaders have an innate desire to be transformed. Therefore, this consideration of bias is noted, and steps were taken to ensure equitable and ethical research. Despite the steps that were taken to limit impact on the data, Merriam and Tisdell (2016) stated the researcher will have an effect.

Validity is defined as the researcher checking the accuracy of findings. Validity is increased when data are triangulated and peer debriefing is used (Creswell, 2014). To increase validity, a peer debriefer and an external auditor, the researcher's advisor, reviewed the study. Triangulation was completed by studying historical data from the creation of the program, past participant survey information, as well as the interviews and focus groups the researcher conducted. 
Future research topics that emerged from this study were specific to the components of the experience. Many participants cited the hike as a significant event for them. There are several aspects of the hike that could be explored in order to determine which portion was the most impactful. The aspects that could have impacted participants are the uncomfortable environment, the team building skills taught by the facilitators, and the reflection through processing aloud and journaling. Each component was cited by various participants as impactful, but it was unclear which was most impactful in a transformation of the participants' leadership.

\section{Definitions and Key Terms}

The following terms are defined for the purpose of this study:

Challenge by Choice- The encouragement of participants to participate in challenges to the level that they feel comfortable.

Department of Secondary and Elementary Education (DESE)- The Department of Elementary and Secondary Education is primarily a service agency that works with school officials, legislators, government agencies, community leaders and citizens to maintain a strong public education system. The Department of Elementary and Secondary Education is the administrative arm of the State Board of Education.

Kolbe A Index- An assessment tool given to all Missouri Leadership Academy participants. It measures the instinctive way people make decisions and categorizes them into four categories: Fact Finder, Follow Through, Quick Start, Implementor.

Missouri Leadership Academy (MOLA)- A program designed to give Missouri school administrators leadership development support. This program has been in place since 1985 , with very few major changes in design. 


\section{Missouri Leadership Development System (MLDS)- A four-year program}

designed to support the development of Missouri school administrators. This program was implemented in 2017 and has incorporated the Missouri Leadership Academy into year three of the program. It continues to refine its organization and streamline the incorporation of Missouri Leadership Academy.

NOLS- Originally created in 1965 , the National Outdoor Leadership School is a school to train adult outdoor leaders how to lead expeditions; NOLS has transformed to encompass high school students through adult learners. The school is a multifaceted wilderness school focused on teaching leadership in many contexts (NOLS, 2019b).

Orienteering- The navigation of the outdoors using a map and compass to guide direction in order to find designated checkpoints.

Outdoor Leadership Experience (OLE)- A four-day experience, created in 1987 for the Missouri Leadership Academy by Doug Miller, in which participants go on an extended hike using orienteering. Participants also have the opportunity to rock climb, rappel, canoe, and complete team building initiatives.

Outward Bound- A program designed for the development of youth leadership utilizing outdoor experiences founded in 1934 in Scotland. It has been utilized in the United States since 1961 (Outward Bound, 2019c).

Regional Professional Development Center (RPDC)- Area centers organized in the eleven regions of Missouri by DESE. These centers organize teacher and principal professional development for their region based on recommendations and guidance from DESE. Including, but not limited to, regional groups of Missouri's Teacher Academy, Leadership Academy, and Leadership Development System. 
Toolkit Strategies- Strategies of decision-making, based upon the work of Tom Leahy, taught to leaders at the Outdoor Leadership Experience to enhance their leadership abilities.

\section{Significance of the Study}

\section{Scholarship}

There is general agreement in research that leadership development now needs learning opportunities from multiple disciplines and aspects; it is not enough to learn or practice leadership in isolation from context (Owen, 2015). To train our educational leaders in a variety of disciplines, evaluation of the impact of leadership development programs must occur. "Outdoor settings offer the types of hands-on and diverse experiential leadership development that is often lacking in other leadership development realms" (Ewert \& Overholt, 2010, p. 45). However, it is not known at this time if Missouri's Outdoor Leadership Experience (OLE) is more or less effective than other Missouri programs that do not lead participants through a physical journey or engage in guided reflection.

Bennis and Thomas (2002/2011) stated leadership is honed when dealing with adversity, and the skills required to overcome and emerge stronger are what create extraordinary leaders. The OLE places participants in difficult situations to hone these skills and utilizes reflection to encourage administrators to move toward what Magolda (2009) described as self-authorship of their leadership. The goal is to transform school leaders through this process, with transformational leadership as the final ambition. A transformational leader leads in such a way the organization is transformed to become influential and life-changing in both the short and long term (Rooke \& Torbert, 
2005/2011). To have a transformational leader in each school in Missouri is the goal of the creator of OLE (D. Miller, personal communication, June 11, 2019).

\section{Practice}

The Outdoor Leadership Experience (OLE) places leaders in situations that cause a transformation of belief through being outside their comfort zone and then leading them through reflection and skill-building. Hinge (2016) referenced crucible situations in which character and leadership are forged by citing Abigail Adams' letters to her son in 1780: "It is not in the still calm of life...that great characters are formed. The habits of a vigorous mind are formed in contending with difficulty. Great necessities call out great virtues" (p. 38). Evaluation of the effectiveness of utilizing the crucible situation of outdoor adventure experience to train leadership skills will allow for insight into an unexplored area in education.

The purpose of this study and subsequent article was a worthwhile undertaking to provide valuable information for Missouri's Department of Elementary and Secondary Education (DESE) Office of Educator Quality who implement the OLE as part of Missouri Leadership Academy (MOLA). Participants' perceptions of the OLE are essential to validate the outcome of the experience, as well as the cost to implement. Seeking information regarding how participants apply the leadership toolkit skills developed through the OLE in their daily role as leaders will provide information on how to enhance the structure of the experience. Studying how participation in the OLE impacts a leader's day-to-day role will provide feedback as to how the skills taught can be honed and developed. Additionally, school districts can utilize this research to validate 
the time and money spent sending principals to outdoor leadership experiences for leadership development.

\section{Findings}

After analysis of the interview and focus group transcripts, multiple themes emerged as significant. Each participant shared with the researcher their perceptions of the Outdoor Leadership Experience (OLE) and the impacts the experience had on them as leaders. Within these conversations, rich descriptions of their thoughts provided the researcher with a comprehensive and multifaceted perspective of their experiences.

\section{Themes}

The participants' poignant descriptions allowed for several themes to arise through analysis. Although not every interviewee perceived the experience as transformational, the majority of participants were impacted in some way. The participants and facilitators shared perceptions of increased self-awareness of their leadership style and skills, vulnerability, lasting connections with other leaders, and a transformation of thought.

Increased Self-Awareness. Goleman (1996/2011) highlighted self-awareness as one vital component of emotional intelligence. He defined self-awareness as "knowing one's emotions, strengths, weaknesses, drives, values, and goals — and their impact on others" (Goleman, 1996/2011, p. 4). Participants and facilitators repeatedly stated an increase in self-awareness as a significant result of the Outdoor Leadership Experience (OLE). Peter summarized the experience as "one of the more meaningful opportunities in leadership to really discover more about yourself and about others." Casey claimed, "You will come back with a whole new appreciation of who you are, who others are, and 
working together to accomplish a goal." The lens through which each person reached a level of self-awareness varied.

Chad's view was of the overall experience. He related, At the end of the experience to just see and talk to the participants: this is a powerful thing. It's beneficial. Obviously, not everybody walks away and says, 'Man that was great.' But the majority do. And I think they would all say, 'Yeah, I had some growth through this experience.'

Jason said,

I learned more intrinsically about myself from those three days than arguably, any other time during my educational career. It wasn't until probably two to three weeks after the experience that everything I learned really sank in. I had to process. And then the caveat of that is once you know who you are, recognize your weaknesses and how to work with others.

Daniel asserted that OLE developed his "perspective, attitude, and beliefs" throughout the weekend. He believes it is important to have empathy and recognize when others were struggling.

Recognizing that as a leader you are there for your team, not to just go; it's not about you being the fastest or the best or the strongest or the smartest. It's more about working with the team to be stronger together. When you're a young leader, you're picking up on those things and it's helping to shape your leadership philosophy. But until you really internalize those and practice those in a situation like OLE, it's not solidified. 
As a teacher leader, Phoebe discovered a revelation during reflection at the campfire.

I was doing a lot of leadership within teaching when I went the first time. But when we were sitting around the fire in 2011. They had us all come up and we had to share some thoughts and it was when I was sharing those thoughts that it clicked for me. That I do want to make a bigger impact. I do want to go into administration and so that became my goal.

Tricia's self-awareness came through the ability to embrace her leadership strengths.

It really helps you to connect with your own leadership style and understand the leader that you are. Not being this other person but knowing I have a lot of gifts and things that I offer from my perspective, gifts and talents. I think it helps you connect with yourself and your leadership style. It helps you to not really compare yourself to others anymore.

Stephanie believed the theme of OLE is to become More comfortable with my leadership qualities that I bring to the table. Being there at OLE and recognizing everybody's different qualities, to get to know who you are, and what traits you bring to the team. Understanding that you are a part of the team and that you have a valuable piece to the team. You have to be cohesive and collaborative, and recognize the strengths and sometimes the weaknesses and opportunities for improvements in yourself and in other people as well. 
Many leaders stated the increase in self-awareness made them more effective in their leadership roles. Ross said, "Knowing your own strengths and weaknesses is important. You have to know yourself to really maximize your leadership potential. So what I took away from that is: it's important for me to think about what I say and how I do things and how it's going to impact others." Additionally, Luke realized he reframed how he thinks about situations. "Stopping and thinking about my initial reaction. But from a different perspective, some people may take it this way or it may be viewed this way. So in problem solving, especially just think of taking the time to step back and then look at it from multiple lenses."

John said he learned "more about myself as a leader. Before, I think I would make a decision and assume that everybody would get on board and figure it out. Because that's what I do. So now, I think I've had to be more reflective about those people who are the fact finders. I've had to be more thorough about creating plans and communicating with others. I'm valuing people's opinions more after that experience, and knowing that I need to surround myself with people who don't just think like me." Jonah also cited "personal awareness and development" as important.

Ron changed how he saw his role as a building leader through gaining selfawareness. He found, "before OLE I think I would have handled it more from an aggressive stance. I'm worried about the bottom line. I'm not worried about my feelings towards you or your feelings towards me. Let's just get the job done. I think now it's much more of a coaching aspect that I approach it with. I'm going to give you every opportunity to be successful and I'm going to give you the tools that I think you need to be successful. Understanding that everybody has their strengths. The more that we 
embrace those, the better off we're going to be as a team." Greg had a similar experience. He reflected, "It helped me to evaluate myself personally in regards to my take as a leader. How I present myself as a leader, what my role in a leadership team is. Not always having to take the lead, but being able to step back and take perspective from other directions. That was very beneficial from those team building activities." Whether from the overall experience or a specific portion of the experience, participants stated the overall changes in self-awareness had a significant impact on their leadership.

Vulnerability. The majority of participants shared the importance of allowing themselves to be vulnerable throughout the experience in a variety of ways. Being vulnerable physically by being in an environment outside of their comfort zone, as well as being emotionally vulnerable through reflection, was noted as pivotal. The notion of being open to being uncomfortable was repeatedly expressed as necessary for growth.

Physical Vulnerability. The majority of participants noted that being out of their normal environment was an effective component of OLE. Brady summarized it succinctly by stating, "None of us had ever been tasked with anything like that before. We were thrust into a group of people that you don't really know that well to do this big thing, so everything is a brand new experience and it's the novelty of us all experiencing this together."

This physical vulnerability came through the hike, rappelling, and rock climbing. Jeanie and Marcia both transferred this learning to their role as leaders. Jeanie said, "In that moment of being put in a situation (rappelling), you really did have to trust someone other than yourself. And the value of that. There are lots of things in our jobs that we may not like doing. But from that we have the confidence to do difficult things." When Marcia 
went rock climbing, she noted, "I felt like that part was similar to the job when we have hurdles. I didn't want to be the one to let people down, so I went outside of my comfort zone to do some things." Peter noted that everyone talks about the hike. "It actually pulls you out of a place that you feel pretty confident and now you have to navigate some uncharted waters."

The notion of the unique environment is described by Skip as a "great equalizer in that it's not our normal workspace. You find people who enjoy the outdoors, whether it's a couple of folks hiking or going into the woods for a hunting weekend. But then you have a group of $12-15$, and it creates a very different dynamic for those of us who are comfortable in the outdoors." Janice noted this took away the posturing that can happen with a group of leaders. "It brings leaders from across the state in different roles, we're not all assistant superintendents, we're not all principals. We come from all roles together; we actually live, eat, and play together. And so I think it brings a rich conversation to leadership." Harley noted the "vulnerability of coming into an atmosphere like OLE. I remember coming in, not really knowing exactly what it was going to consist of, and being very worried because it was outside of my realm of comfortableness."

Cindy said, "It just gets you out of your mind space, and really gets you to see things from a different perspective." Austin believed OLE developed "vulnerability based trust because it's all about getting out of your comfort zone.” Ross described the environment provoking his learning. "How often do you get a couple of days of uninterrupted professional development or uninterrupted time with peers and colleagues where you can really focus on leadership and learning from other people?" Phoebe said 
the best part was the "chance to get away and do something I don't normally get to do. I had to make decisions but it wasn't the same. I got to slow down and reflect on my practice and my leadership."

Through the environment, many participants learned about themselves and developed new skills. Lacey claimed, "we school leaders get to be together and not worry. So it's okay to take that hat off for a minute and just talk about my strengths or weaknesses." Lydia kept returning to how the environment expanded her empathy. "I was in a group with a lot of people from urban districts. And they would just look up at the stars and go, 'Isn't this beautiful?' And I'm like 'yeah, yeah, yeah, let's go!' So I became more empathetic with what really drives people" and developed an "appreciation for differences of others." Trent really enjoyed helping people on the hike, but thought the process was inefficient. This caused him to realize that if his "best people aren't doing what they're good at you waste a lot of time." Jason learned a similar lesson from the hike. "It was dark and we were lost. Our guide said, 'trust your instincts and go anyway.' Looking back, that tip of advice from the lady with the GPS was so true. Things always seem farther in the dark when you don't exactly know where you're going, you don't exactly know where you're at. But she said, 'don't let them get scared. Just keep going."” He noted that this is also true in his role as a leader.

Emotional Vulnerability. Many participants stated they were able to truly embrace uncomfortable situations because of the trust that had been built within the framework of OLE. They felt safe to share and take risks in their discussions or input within team decisions because of this emotional safety. Luke noted it was important to 
"lose your inhibitions and let your guard down." He labeled himself as slow to "warm up and feel comfortable putting himself out there in front of people or trusting them."

The ability to be emotionally vulnerable came through in Jeanine's reflection that the emotional safety embedded in the framework of OLE "provided the space for folks who might not be one of those powerful people to really show you where they are coming from and that they have value in that thought process.” This emotional safety naturally leads to an environment of trust. This trust led Greg to realize and understand "that you don't have to do everything yourself. You have to trust in others, you have to build a team around you that has similar goals and similar vision as yours." Joey said the vulnerability of his team and all of the "stuff we went through really helped bond us and really grew a trust in just three days that many of us didn't have with our administrative team that we've worked with for a year or more."

Blake believes that being uncomfortable is part of the process. He said, "you might be uncomfortable but you need to go ahead and do those things. It'll be alright. You'll survive." Phoebe believes this is part of the design of OLE and the process is "constantly putting people into uncomfortable positions on purpose so that you can see how you will work through it." Marcia agreed. She said that when one person got tired, "we had to rely on others, which is important in leadership. There's going to be times where you have to allow other people around you to help you. We just have to be vulnerable."

Brady, Jamie, and Mitch all relayed a story of a teammate who struggled with being vulnerable. In each story, the participant had never been put in a position of struggle or vulnerability. In each event, the teammate realized it was going to take more 
than just themselves to find success and others may be carrying your stuff or encouraging you to have a voice when you felt unsure and they embraced that. Tyler also discussed "understanding risk-taking and vulnerability as an exploration of self and the impact that has on the community." This emotional vulnerability stretched each participant to grow. Greg affirmed this saying, "the whole reason behind leadership is to make you feel a little bit uncomfortable. To put you in some uncomfortable situations. I think part of being leaders is staying in a state of uncomfortability, but being able to manage that. To make sound decisions and to gain input."

Connections with other Leaders. Participants and facilitators overwhelmingly noted that the OLE created deep connections with the other leaders. These connections came through a strong network and the development of shared leadership. Peter noted OLE is designed to "build trust with other people within the profession. A lot of people actually aren't great at networking, they network through proximity. And OLE is a space that allows you, because of the design, to connect with somebody out of St. Louis, and it allows you to connect with somebody in Northwest Missouri that has a school district of 200. It helps build perspective, a lot of different relationships."

Network. The connections that are forged when people go through what Hinge (2016) called a crucible moment can be deep and lasting. Ron agreed, stating the team that went through the entire experience together became "extremely close and bonded deeper than you would ever think that you could get to know somebody in the course of three days.” Tricia, Lydia, Marcia, Greg, Ron, and Joey all noted their connections were so deep that they could reach out to anyone on their OLE team still today and ask for assistance with a problem or give support at any moment. Janice 
affirmed "in that short amount of time. I am still tight friends with some people from across the state that I only spent a weekend with. I'm talking about deep relationships. How did that happen? How do I have this much respect for that person out of such a short time? Our feelings were naked, our conversations were naked. We spoke personally, and sometimes we work with people for years and never do that." Tim also asserted, "I don't think we can ever overstate the importance of the networking that takes place, laughing and crying, spending those days at OLE, it creates a network that just isn't broken. When people see each other that they've been through this with, their eyes light up with a different sparkle than in their contact with others over their years of experience as a leader. I also think that it builds this commitment, that camaraderie that we need to be supportive of each other."

Participants also spoke to the expansion of their network to create diversity in their connections. Skip attested:

I get the opportunity to interact and learn from and share with administrators across the state and across demographic groups. In conversations at campfire or on a long hike, you really find how much more commonality there is in the issues we have. Whether its poverty and resources, or the needs we have around testing, all those things are so much more common. There are commonalities that you don't recognize if you're in an urban or suburban or rural district, until you find that we're all working to grow human beings, and we have common needs, common support for each other.

Connecting with other leaders helped Luke expand his knowledge through expanding his Twitter network. Ross noted those connections allowed him to feel less "insulated from 
other school districts. I learned a lot from the different people and I've got people that I can reach out to get perspective." John made connections with leaders he "wouldn't normally have gotten a chance to interact with. I think it's just helped me be able to look past our local neighbors here and actually look at what people are doing across the state. It's been a good experience to talk to people who see things way differently than we do."

Some connections were deeper than others. Daniel, Phoebe, Stephanie, and Brady all noted that their connections were deep for several years after their experience, but gradually waned over time. They all valued those connections and believed those connections helped them develop as leaders. Brady professed, "I think there were some professional connections that were used. The only reason we had that little, tight community, for even that little window of time in our life, was because of the OLE." Lacey utilized her connections to share her passion with other schools and leaders. "They have continued to reach out for things. It's given me the opportunity to teach what I'm so passionate about to so many different people. I've been at school districts all over the state. And then just through my own network I got to do some nationwide speaking but I would have never had that unless I'd gone to OLE." Trent also noted that there is a connection with OLE participants other than his immediate team. "I think there's some camaraderie with other people who have done it. Maybe having a shared bond with some people." Harley feels less alone now, "I felt being in a very small rural district I was on an island by myself. After going to OLE, it was just life changing for me."

Unfortunately not every participant made deep connections with their OLE team. Cindy, Jason, and Max claimed that they did not keep in contact with their team. Jason 
claimed that this was "by my own fault. I allowed those networks to dissolve by my own accord. It's not something I'm proud of, but had I put in any effort, I think I could still have very strong networks. I just didn't. I allowed them to dissolve. I take full responsibility for that. The opportunity was there." Max and Cindy contended that they valued the statewide connection, but there were not lasting contacts.

Shared Leadership. For the purposes of this study, shared leadership was defined as collaboration to problem solve and build a team in order to move in a positive direction. The idea of shared leadership was valuable for the participants because, as Lacey alleged, "we went back and we were trying to burn our lights all by ourselves. There was a connection that we had made but when you get in your own district you tend to not ask for help very often. But you will ask a stranger that you have made this connection with for more help." Shared leadership was displayed at OLE through teamwork. Max, Lydia, Joey, Ron, and Blake all noted that teamwork was an important function of OLE. Cindy learned "building consensus, knowing that I can't really move forward unless I have everybody on the same page," was important for success. Marcia agreed, "because if you wanted to get done you had to rely on each other." John believed this shared leadership was intentionally wrought. "I think they probably intentionally paired you with people who were quite [the] opposite than you. It just seemed like we were a good mix of different personalities, different strengths." Stephanie knew "as we went on our little journey everybody brought something different to the table. Everybody has a different personality and brings something positive to the team. That's what makes a good, cohesive team." 
Brady, Casey, and Tyler all shared a specific story of when their team reached a moment of frustration and they could not move on until everyone was on the same page. Jason shared that he learned his role as a leader was "not to make people follow you. The goal is to grow as a leader. In the beginning, there was clearly a divide between me and my group. And that went away by the end of the hike." Janice learned she had to "give up the ownership and allow other people to have input as well. It all happened through OLE. I can remember very clearly the interactions of OLE and how everyone was very, very collaborative and allowed other people to lead." Jeanie asserted the concept of team became solidified "because of the setting, it was an opportunity to really develop that team concept and we're stronger together. I'm actually going to take some real serious, powerful learning back with me in whatever role I'm in."

Transformation of Thought. Participants had a variety of transformations from their Outdoor Leadership Experience. Many had an increase in confidence, but that increase came from a variety of experiences at OLE. Lydia gained confidence from the rock wall. "Have confidence in yourself that you can do something that looks pretty big. Climbing that rock wall and thinking I couldn't do it and then I did it. I decided if I can climb a rock wall, then I can be a leader." Lacey gained confidence in her place in leadership. "Tables turned for me at that point [of reflection]. I became a different person among leaders. It was the first time I stepped up amongst my peers and thought I might be good enough to do something. And it just gave me a surge, allowing myself to be what I want it to be. That was a moment that's made a big impact in the latter part of my career." 
Jason, Marcia, Harley, Phoebe, Tricia, and Jeanie had a transformation that was significant. Jason said, "It has rearranged my perspective of leadership. I thought a leader stood at the front of the line and blazed a trail for others to follow. OLE taught me that no, that is not necessarily what a leader does. You empower others to blaze their own trail. I think that is what a true leader does now. And OLE helps you understand the why behind it. It probably sped up the process of my development." Marcia asserted, "I think it's a life changing experience because you're outside your comfort zone and you realize you can do things that you never thought you could do. I accomplished something bigger than myself." Phoebe also said it was life changing. She noted, "it changes how you lead. I think it's your responsibility to go as a leader, because you need to always be learning." Jeanie went a step further to state that OLE "probably saved lives. I'm glad that Missouri stepped out and decided to try this, because I think it's good for administrators and for leaders. It was lifesaving." Tricia said it changed her because "it made me more secure in who I was as a leader and more confident in who I was. One of the best things I've ever done as far as leadership goes." Austin said as a facilitator "it's a life changing experience, and to have a small part in doing that for other people, that's really what it's all about. I mean we're all in this job to be life changers and that is a way to do it for your fellow administrators."

Prior to attending OLE, Joey felt like he had to have all the answers. When he "went to OLE I found out about the idea of failing forward. I really embraced that." Acknowledging that he will make mistakes, but "we're going to learn from it and we're going to get back on track. As a leader, you don't have to carry the weight on your own, but you have to build the capacity of those around you so they can help carry the weight." 
Ross had a similar revelation and acknowledged, "if it doesn't work, we'll turn around and go back the opposite direction. That wasn't necessarily my predominant leadership style or my personality, but ultimately your toolbox is going to get fuller because of that." Jamie believes OLE is designed for this purpose.

I think part of OLE is that we set them up to fail in certain ways because they need to experience that. I think we have to experience that to be forced to remember what it feels like. Because it's so important for our students to fail forward. That's what life's all about, we're going to fail. But what do you do when you fail? I think that's one of the top things that has to be instilled in everyone. Cindy and Greg both applied their new skills to their roles as building leaders. Cindy was "pushing beyond boundaries. It showed that you could conquer and do things that you probably didn't expect yourself to do. Seeing things from a different perspective. It helps you take the blinders off and realize what you do here at OLE can also be applied back in your school." Greg said it "changed my leadership style. I started to do more team building activities. Once I attended the OLE, I felt like it was important to draw people together."

The design of this unique professional development experience led both Peter and John to encourage other leaders in their districts to attend. John said, "it was one of the most valuable PD experiences that I've had as a leader. It really changed my thinking because we don't often hear people process out loud." Peter noted the culminating event of OLE where

Everybody speaks into the individual's life of what they saw in that person. That was super powerful, lots of tears. We spoke into each individual and the impact 
that had on each individual's life. To give them the courage, to give them the affirmation that is needed to say 'I'm a leader.' I think it is a microcosm of what we try to do on a continual basis as school leaders. They're able to grow in a lot of ways that they've never grown before in their life. It becomes way more transferable. It's really good instruction to allow us to experience it physically, but also mentally by processing through it.

Facilitators had a unique perspective of the transformation of thought that participants described. Judah noted that the transformation is at the root of experiential education. "It's an experience that's both visceral and academic that carries with you. I think it's an igniter, not only of ideas but a passion. You can process that experiential education piece there, but then extrapolate that to your home setting." Tim claimed that "as far as the outdoor transfer from non-school activities to school activities, OLE is unmatched anywhere.” Although Jonah has been retired and away from OLE for many years, he could recall how transformational the experience was. "It pushes us out of our comfort zones, but yet it's such a safe environment. You go there and everybody is uplifted, they're positive, they're supportive. That is such a life giving experience that buoys you up for forever. I still carry that and I haven't seen anybody for a long time. It changes your heart, really. It opens up your mind to what real leadership and what relationships are all about in an informal way but then it carries over."

\section{Research Question One: Perceptions}

The first research question asked about the perceptions of the participants. As each individual and facilitator shared their perceptions of the Outdoor Leadership Experience (OLE), the vast majority stated the experience shifted their perceptions of 
themselves as leaders. Additionally, they spoke of vulnerability, which in turn promoted growth. They also spoke of the diverse groupings as well as being out of their usual environment and how those factors impacted them as leaders. The fact that they were out of their element allowed the participants to focus on their learning and develop their skills as leaders.

Of the 33 study participants, only two had differing perceptions. They stated a lack of connection or transformation through their experience. However, both of these participants voiced an aligned vision of the goal of OLE and stated several positive perceptions from the experience. Max shared,

I enjoyed it for the most part. I'm a pretty private, quiet person; I like to observe more than participate in a lot of things. I got frustrated with my group not following what I thought we should do. So I can't say from that experience that I went back and changed how I behaved or how I act or anything like that. There were some positive things about it, but it's just not who I am as far as like being open and sharing and that type of thing. But I did enjoy it and I do like the outdoor stuff.

\section{Research Question Two: Skill Implementation}

The second research question asked how participants implement the leadership toolkit skills developed at the Outdoor Leadership Experience (OLE) in their daily role as Missouri school leaders. Participants listed numerous instances of skills they developed and implemented through the OLE. Participants stated an increased capacity in teamwork, reflection, self-awareness, confidence, listening, and shared leadership. Learning to fail forward, build consensus, and develop skills in others were specifically 
listed as impactful. Ross noted "to be able to have those tools and articulate that here's how we're going to do things and why we're doing it this way" was impactful. Daniel said he was aware of some tools prior to attending, "but until you really internalize those and practice those in a situation like OLE, it's not solidified." Tyler noted that "there's always these things that are intentionally challenge by choice. There's low challenge by choice and there's high level challenge by choice but you learn from them." The majority of participants also noted that the skills they developed not only made them better leaders, but improved their teams.

\section{Research Question Three: Transformative Learning}

Research Question Three asked about the relationship of Transformative Learning Theory to the participants' perceptions of the OLE. Nearly every participant claimed a transformation in some way. Some stated a life-changing transformation, while others merely had a transformation of certain skills or thought processes. Transformative Learning Theory asserts that an event must cause a shift in thinking that is significant in order to be transformational. The majority of interviewed participants and facilitators cited a change in thinking after attendance at OLE, confirming the relevance of Transformative Learning Theory.

Jason stated that moments of struggle impacted his transformation. "That boiling point is crucial. It forced implementation in a longer setting so it could come to a boil and go over and I had to deal with it." Ross stated the experience reinforced his belief in his abilities. "If I want to do something I can make it happen. You know maybe you have a little more swagger." Tricia, Marcia, and Phoebe all used the words "life-changing" when reflecting on the OLE confirming a transformation of thought. 


\section{Research Question Four: Commitment to School Leadership}

The fourth research question asks how the OLE impacted the leaders' plans to stay in school leadership in Missouri. Every single participant stated a desire to stay in Missouri school leadership or revealed that they retired after a long career in educational leadership. Many participants had advanced in their leadership role since their attendance at the OLE. For those who had retired from school leadership, many had moved on to a state level leadership position with Missouri's Department of Elementary and Secondary Education or a Regional Professional Development Center. Many participants cited the impact OLE had on their leadership roles as significant in their growth as leaders and their passion to stay in education. Joey responded that "it's ever evolving. The one thing that I think I have decided after OLE is not to pigeonhole myself into one place. Something to do with education for sure; even if it was just to be the principal here the rest of my career, I'd be more than happy." Lacey passionately claimed, "I will stay in school leadership because I'm not done yet with what I came to do."

\section{Recommendations}

Interviewing both participants and facilitators about their perceptions of the Outdoor Leadership Experience (OLE) led the researcher to several recommendations for the future of the OLE. Due to the fact that the OLE has been in place for 34 years, a conclusion can be made that the overall design is effective. This conclusion was confirmed by the study participants. Overwhelmingly, the participants stated their belief that each piece of the experience was impactful regardless of the year or site of participation. However, the facilitators and participants who were interviewed had some 
memories and unique perceptions. The data led the researcher to suggest

recommendations for future designers of the OLE.

\section{Maintain the Significance of the Hike}

The comparison of the OLE in the more rustic site at Camp Rising Sun versus the updated site at Camp Lakewood was based more on the hike experience than the camping accommodations. Recollections of the hike from participants and facilitators who attended both sites stated the length of the hike was key. To be out in the woods after dark was an impactful experience and interviewees stated the need to keep this portion consistent. The majority of interviewees stated the hike was pivotal to their growth and application of skills. Cindy cautioned, "Don't take out the hike and orienteering. It brings you back to being a learner."

For those who had attended OLE more than once, or were facilitators, there is a comparison point between the two sites. Having the right location is important to consider when designing an impactful hike for teams of adults. The recommendation for the hike is to choose a site that is safe, yet allows for extended time in the woods to ensure that the orienteering portion does not get shortened or watered down based on location or bureaucratic constraints. Casey noted, "I just worry about [the hike] for the future and for it to continue to be viable and as impactful as it was."

\section{Advanced Outdoor Leadership Experience}

Interviewees repeatedly noted that they desired another OLE experience. Several mentioned wishing they could go every year and take that time for quality professional development. Having the opportunity to experience the OLE, with an added layer of depth based on previous experience, will allow for advanced leadership development. 
Furthermore, as leaders gain experience, the depth of learning that could occur is vastly expanded. It was noted by many that OLE was the best professional development they had ever experienced. Daniel claimed the "impact of that over typical professional development is lightyears ahead." An overwhelming majority of interviewees stated a desire to complete the experience again. Although the logistics and cost involved must be a consideration, participation numbers for a weekend of advanced OLE is predicted to be high.

\section{Ensure a Forced Pause}

Another recommendation is to keep or expand the reflective nature of OLE which requires busy leaders to take a forced pause. Creating a journal, having an entire hour of solo reflection time, and processing aloud during team activities are key points that were noted as impactful by participants. These elements contribute to the forced pause created within the experience. The reflection is the piece that brings all of the experiences together and creates a meaningful impact. Marcia said the reflection during the "alone time in the woods because we got time to write in our journals. I thought, 'Oh my gosh, that was so important because here we were busy, busy, busy and I just needed a little bit of time to collect my thoughts and gather myself."' Judah noted that the processing time "around a common purpose makes it all above and beyond anything else I've experienced, because it's not in isolation. You can learn a skill in isolation, but it's not going to be visceral, it's not going to stick and you're not going to have the application breadth that you're going to have with a common purpose of educators like you have at OLE." Jamie expanded on the theme of reflection. She discussed how facilitators give the participants "time for reflection, we reflect with them. We do a lot of reflection and I 
think that's one of the things people comment on all the time. They say they are not good about reflecting because we don't take the time. And I think it forces them to take the time and realize how powerful it is." Tyler brings it back to nature. "There's nothing better than a canoe crossing at sunset to bring your mind back to a certain place." Interviewees observed that staying the entire length of the experience is important. Ensuring that participants and facilitators are supported by their districts and can commit to staying from Wednesday afternoon through noon on Saturday is necessary. Additionally, participants need to make the commitment to stay the entire time which will allow them to truly focus on their development. Tim stressed how important this is for participants. "It's really frustrating when people are leaving earlier and earlier every year. I think they're missing out on some of the experiences that you can have.

We'd rather wait until next year, or a time that you could be there the entire time. Because it seems like the world is not slowing down any. And we need them to slow down for three days and ignore everything that's going on around them. And that's easy for us to say, but there are not a lot of school districts that will say that same thing." A commitment to a forced pause will ensure the experience is all it could be.

\section{Train Facilitators}

It was noted that OLE facilitators at one point in history had a required training weekend. The current model of interning for one year with current facilitators has varied levels of effectiveness. Shadowing a pair of current facilitators can give an intern a model to emulate, but not necessarily specific training of facilitator expectations. Facilitation of adult learning requires skill. Jonah noted "working with adults, there's something to that besides having passion, you've got to have a level of expertise." Having consistent 
training and expectations for facilitators will ensure consistency of the experience for participants. Casey suggested the organizers of OLE "are just relying that they go as a participant, they come back as an intern, and that's the training they get. I think we need training in order to ensure the viability of the experience into the future."

Extended training for facilitators will also ensure consistency of the shared history and program expectations. Tyler wants to "leave leadership better than the way you found it. I'd rather dedicate my time to this type of mission than a lot of other things. It's a give and take, I get as much as I hope to give. Leave this place better than you found it, in terms of leadership. If people are committed to all those processes and those things that take place at OLE, and they can dive into it, you will be better. If it makes you better and it makes other people better, it's a win-win type of situation. There is no negative."

\section{Share the History}

The history of the origin of OLE is in danger of being forgotten. The intentionality of design and the passion of the designers to develop administrators in Missouri cannot be lost. Many noted that they recognized the intentionality of the design and the facilitators expanded on the why behind most of the activities, but did not have a deep understanding of the history. Although the program has been in place for 34 years, an acknowledgement of the history is necessary to inspire future leaders to carry on with minimal changes to the design. Updates are necessary for every program to be sustainable long term. However, the updates must be made without changing the true nature of the program. Skip noted, “There's a history of OLE that is not contingent upon a place. I think being cognizant of how to structure it in such a way to capture who we are as an entity is important. There are those who have given us so much in the past, and for those 
will come after us. And even then... who's coming next? I don't know, but I want to be there to make sure that somebody else has those same tools that were freely given to me to be a better human being."

Generally the history of OLE is shared at the campfire experience. Therefore, designing the campfire to be intentional and impactful will create the opportunity to give depth to the history. One suggestion is to have a campfire more than one night or with each team in a smaller setting so that the connection is deeper. Helping everyone understand how the history of OLE, as well as the connection to nature, creates a bond with all participants through the years.

Interviewees who mentioned the campfire either thought it was inspirational and reflective or it was hokey and turned them off. Those who thought it was hokey were turned off by the singing and the feeling of it being forced. Those who found it inspirational truly reflected on the experience and had an open mind to growth. The hope is that in creating more opportunities for the campfire(s) to be meaningful and more personal, participants will embrace the history and call to leadership that is intended.

\section{Summary}

Research of leadership development utilizing outdoor programs has been completed in many other settings, yet it is lacking in the field of educational leaders. The gap in the literature shows a scarcity of studies within the education profession specific to utilizing outdoor leadership training programs to develop leadership. The study concluded that Missouri's Outdoor Leadership Experience is more effective than other Missouri programs that do not lead participants outside their comfort zone or through a 
transformational experience. OLE's impact on leadership development in, and thereby retention of, Missouri's administrators can be confirmed as positive.

Educational leaders need practical leadership training and support now more than ever. "Being a school leader in any role is hard, gratifying, and a gift of love" (DragoSeverson \& Blum-DeStefano, 2015, p. 38). The stress of leadership can cause principals to leave the profession or constantly move to find a more supportive role. Leaders are often left "wondering whether or not they can see themselves continuing this work for the next five to 10 years" (Kafele, 2018, p. 23). This unhealthy mindset can be detrimental to schools because the principal sets the tone of the school. Whitaker (2012) stated, "If the principal sneezes, the whole school catches a cold" (p. 36). The effect of a school leader is far reaching and significant. Having a well-developed leader, who stays in their role long enough to affect real change, is vital to the success of our students.

The Outdoor Leadership Experience (OLE) places leaders in situations that cause a transformation of belief through being outside their comfort zone and leading them through reflection and skill-building. Hinge (2016) referenced crucible situations in which character and leadership are forged through adversity. Evaluation of the effectiveness of utilizing the crucible situation of an outdoor adventure experience to train leadership skills allowed for insight into an unexplored area in education. The purpose of this study and subsequent article provided information for state-level officials who wish to continue or discontinue the Outdoor Leadership Experience as part of Missouri Leadership Academy and the Missouri Leadership Development System. 
SECTION TWO:

PRACTITIONER SETTING FOR THE STUDY 


\section{Introduction}

Public schools across the nation are struggling to hold onto quality administrators (Goldring, Taie, \& Owens, 2014). Principal turnover negatively affects student growth (Miller, 2013). As Missouri's Department of Elementary and Secondary Education (DESE) seeks to address this issue, the most effective methods to support and develop leaders need to be studied. This study sought to address the needs of DESE and can be applied to leadership development of school leaders in other states as well.

\section{History of the Organization}

\section{Missouri Department of Elementary and Secondary Education}

The Department of Elementary and Secondary Education (DESE) is the state of Missouri's guiding agency for the public K-12 school system. DESE consists of two main divisions: The Division of Learning Services and the Division of Financial and Administrative Services. The Division of Learning Services has six offices: The Office of Quality Schools, the Office of Educator Quality, the Office of College and Career Readiness, the Office of Special Education, the Office of Data System Management, and the Office of Adult Learning and Rehabilitation Services (Missouri Department of Elementary and Secondary Education, 2019c). Of these six offices, the researcher focused on the Office of Educator Quality.

\section{Office of Educator Quality}

The Office of Educator Quality has many roles. This office is responsible for the following tasks: evaluation of educator preparation programs, the issuance of certificates or licenses, the design of innovative professional development programs for educators (teachers and administrators) at the state level, assisting in the development of educator 
standards, and the development evaluation models for school personnel (Missouri Department of Elementary and Secondary Education, 2019c). Under the task of developing innovative professional development for administrators, the Office of Educator Quality has created the Missouri Leadership Development System.

\section{Missouri Leadership Development System}

Missouri's Department of Elementary and Secondary Education (DESE) has recognized the need for leadership development and created a blend of their leadership supports into the Missouri Leadership Development System (MLDS) (Masters \& Katnik, 2019). Dr. Margie Vandeven, DESE's Commissioner of Education, described MLDS this way: "Through the implementation of the Missouri Leadership Development System, we choose to cultivate improved leadership practice by engaging our principals in relevant and meaningful learning over the course of their entire career" (Missouri Department of Elementary and Secondary Education, 2019d, para. 2). The intentional design of this program speaks to the value DESE has placed on leadership development.

As part of the new MLDS, a multi-year program of support has been developed. New school administrators are encouraged to become a part of the initial four-year program. However, leaders of any level can participate in the MLDS program. The initial levels of support are labeled in the following manner: year one-Aspiring; year twoEmerging; year three-Developing; year four-Transformational (Missouri Department of Elementary and Secondary Education, 2019d).

In years one and two, school leaders are given a mentor and attend meetings to develop skills that are outlined as highly effective in the Professional Standards for Educational Leaders (Missouri Department of Elementary and Secondary Education, 
2019d). In year three of the MLDS program, the developing level, leaders will attend the Missouri Leadership Academy (MOLA), where they will continue to complete MLDS modules (Missouri Department of Elementary and Secondary Education, 2019b). In year four, the Transformational level, leaders will complete MLDS modules designed to create sustainability of their leadership skills and create a plan for continued professional development and support.

\section{Missouri Leadership Academy}

Missouri Leadership Academy (MOLA) is a program that has been in place since 1985 and was initially designed to develop leadership skills and provide support for Missouri school administrators and aspiring administrators (D. Miller, personal communication, June 11, 2019). MOLA consists of six to seven regional meetings throughout the year, as well as four statewide meetings. The statewide meetings consist of: Kickoff in June, Outdoor Leadership Experience in October, Winter Meeting in January, and Graduation in June. At the regional meetings participants complete a variety of activities ranging from book studies to hot topic discussions and from MLDS modules to team building. Each region has unique meetings; however, they all follow a specific program of instruction agreed upon by the Regional Professional Development Centers (RPDC).

The statewide meetings give participants an opportunity to enlarge their professional learning network through engaging in activities with leaders around the state. Depending on the size of each MOLA class, this network will consist of 90-120 leaders. The Outdoor Leadership Experience (OLE) is one of the statewide meetings and 
is designed to bring small groups (consisting of 12-16 participants) from a variety of areas across the state into deep connection and learning.

\section{Outdoor Leadership Experience}

The Outdoor Leadership Experience (OLE) is a four-day experience that is focused on developing leadership skills in school administrators by placing leaders in an environment outside their comfort zone. Facilitators guide participants through outdoor adventure, team building activities, and reflection designed to develop leadership skills that can be implemented when they return to their administrative roles.

The OLE has been a part of Missouri Leadership Academy (MOLA) since 1987. Based on his extensive research and training, MOLA designer Dr. Doug Miller purposefully placed the OLE in the program to develop skills that cannot be learned in any other environment (D. Miller, personal communication, June 11, 2019). Miller studied the necessary components of outdoor education with Hank Schafermeyer at the acclaimed Underway Adventures program located at Southern Illinois University Outdoor Lab (D. Miller, personal communication, June 11, 2019). The Underway Adventures program designed a leadership development program based on the success of the Outward Bound Program (Southern Illinois University, 2019). The Outdoor Lab, also known as Touch of Nature, continues to be a thriving center with extensive programs in the field of outdoor education for students and adults (Southern Illinois University, 2019).

Basing his design for the OLE on the successful principles of Southern Illinois University's practicing program led Dr. Miller to create a sustainable plan which has been in place for 34 years. OLE is one of the four statewide meetings and is an integral part of the MOLA program (Missouri Department of Elementary and Secondary 
Education, 2019a). Unfortunately, usually due to fears about outdoor adventure, not all MOLA participants attend OLE. However, over 4,000 educators of every imaginable description, physical ability, and level of experience, representing schools from across Missouri, have participated in OLE (Missouri Department of Elementary and Secondary Education, 2019b).

Researchers have found outdoor leadership training can teach a high level of transferable skills through high adventure activities and reflection (Ewert \& Overholt, 2010; Speelman \& Wagstaff, 2015). OLE activities include, but are not limited to, rappelling, rock climbing, orienteering, canoeing, and multiple team building initiatives. These experiences are designed to bring effective leadership practice into focus and to challenge participating leaders to think and act beyond their typical framework.

Challenge by choice allows leaders to stretch themselves past their current limits to go beyond their current skill mastery levels. The training of educational leaders utilizing outdoor leadership skills through the OLE is an innovative program in Missouri that has not been duplicated in other states.

\section{Organizational Analysis}

Bolman and Deal's (2013) four frames of organizational analysis include structural, human resource, political, and symbolic. The implementation and analysis of an organization's structural frame is based upon the desired outcome. The human resource frame's key assumption is that "individuals find meaningful and satisfying work, and organizations get the talent and energy they need to succeed" (Bolman \& Deal, 2013, p. 117). Analyzation of an organization within the political frame focuses on power - who has it and who wants it. Bolman and Deal (2013) encouraged selection of 
the symbolic frame when an organization focuses on how humans make sense of the chaotic, ambiguous world in which they live. Meaning belief, and faith are its central concerns. The Missouri Leadership Academy (MOLA) and, thereby, the Outdoor Leadership Experience (OLE) as an organization, function primarily within the human resource frame for overall function. However, when the designers are formatting the experience for participants, the focus lies squarely within the symbolic frame.

MOLA's function within the human resource frame makes connections between leadership theory and investing in people. The power of understanding people - their strengths and foibles, reason and emotion, desires and fears-is significant to how each piece of the MOLA and OLE are designed. Bolman and Deal (2013) claimed "a skilled and motivated workforce is a powerful source of competitive advantage" (p. 133). The human variables inherent to professional development through MOLA and OLE will impact the research. Bolman and Deal (2013) stated organizations exist to realize the established goals. Therefore, the designers of MOLA and OLE were tasked with creating a shared vision for the desired outcomes. OLE is based on trust between members. Trust is the belief that intentions are pure and allows team members to become comfortable being vulnerable, which builds the foundation for a properly functioning team (Lencioni, 2002). The use of team building techniques helps leaders manage conflict and be more constructive (Levi, 2017). Many leaders fail because they do not focus enough on relationships (Bolman \& Deal, 2013).

For the participants of MOLA and OLE, the organization relies on symbolic function. Bolman and Deal (2013) asserted that symbols carry powerful intellectual and emotional messages; they speak to both the mind and the heart. Within the symbolic 
frame, what is most important is not what happens but what it means. OLE participants are asked to reflect on the meaning derived from the experiences and how this can improve or change how they lead.

The reflective design of OLE, with the powerful focus on internal development and self-awareness, creates a culture of symbolism. Events and actions have multiple interpretations based on one's experience, which include values and vision. Vision, defined as a core ideology or sense of purpose, is turned into an image for the future. These values and vision are realized in a culture and form the superglue that bonds an organization, unites people, and helps accomplish desired ends (Bolman \& Deal, 2013). The leaders of OLE must be aware of the symbolic meaning people place on things to be equipped to lead in that environment.

\section{Leadership Analysis}

The rapidly changing world needs leaders who can integrate theory and application, intuition and knowledge, tradition and innovation (Owens, 2015). The drive for updated thought in leadership requires programs that embrace this need in unique ways. To that end, the innovation of Dr. Doug Miller resulted in the foundation of the Missouri Leadership Academy (MOLA) where he crafted the Outdoor Leadership Experience (OLE) as an integral component of MOLA. However, the current leadership of Jim Masters and Paul Katnik in the Office of Educator Quality at the Missouri Department of Elementary and Secondary Education (DESE) have elevated OLE to the present level of effectiveness and success.

While there are many definitions of leadership and the encompassing factors, Masters and Katnik embody the characteristics of authentic, adaptive, servant, and 
transformational leaders. Effective leaders are authentic when communicating with staff (authentic leadership) (George, Sims, McLean \& Mayer, 2007/201) and adapt to situations by encouraging followers to confront challenges and solve problems (adaptive leadership) (Northouse, 2016). Servant leaders lead by example and behave ethically, encouraging staff to be more than they thought they were capable of being (Northouse, 2016). A transformational leader leads in such a way that the organization is transformed to become influential and life-changing in both the short and long term (Rooke \& Tolbert, 2005/2011). The leaders of OLE strive to create opportunities for the organization to transform Missouri school leaders and embody the mission of the organization.

Providing professional development for school leaders that transforms their practice displays the leadership of OLE and embodies George, Sims, McLean, and Mayer's (2007/2011) declaration: “Leadership principles are values translated into action" (p. 170). Masters and Katnik continuously refine the design of OLE to ensure that the values enacted in the events and reflections epitomize the leadership principles proven to be most effective.

\section{Implications for Research in the Practitioner Setting}

Merriam and Bierema (2014) described the need for adult learners to be fully engaged through a variety of activities, for leaders to value their contributions, and to create an environment that allows for adults to learn from each other and gain personal experience. The Outdoor Leadership Experience (OLE) is a professional development event that seeks to transform the practice of Missouri school leaders. Through seeking the perceptions of the participants, the researcher will gain knowledge of activities and 
strategies which were most effective and transformational to the participant. This knowledge will be useful to the designers of OLE for future planning. Ettling (2012) reminds transformational instructors to self-evaluate for strengths and weaknesses, be mindful to create a trusting environment for learners, and engage in critical reflection with learners. When creating the transformational experience of OLE, the designers keep these key aspects in focus.

Additionally, the impact of OLE is measured in the skill development of the leaders who have completed the experience. If their leadership has been improved through the implementation of the skills learned, as well as an ongoing development of their decision-making style and self-awareness, then the goal of OLE has been achieved. The goal of the designers of OLE is for Missouri administrators to feel supported through this training, networking and skill development (D. Miller, personal communication, June 11, 2019).

As a professional development aspect of the Missouri Leadership Academy (MOLA), OLE is designed to give participants a variety of skills to rely upon in their leadership roles. Discovering how these skills impact leaders' feelings of success and job satisfaction provided designers with valuable information on OLE as a professional development tool. This information also assisted the researcher in discovering how the participants' commitment level to remaining a school leader in Missouri was impacted.

\section{Summary}

The longevity of the Outdoor Leadership Academy (OLE) implies value in the program. However, to date there have been no studies completed to verify this 
implication. The reflective nature of the current leadership of OLE, as well as the organizational structure, lends itself to be open to study and feedback. 
SECTION THREE:

SCHOLARLY REVIEW FOR THE STUDY 


\section{Introduction}

Outdoor leadership training is described by Ewert and Overholt (2010) as “involve[ing] active and direct experiences with many of the components associated with leadership such as decision-making, assessment, motivation, and goal-setting” (p. 40).

Sharing learning experiences that establish a common base for reflection and discussion creates opportunities for participants to act on new insights and practice transformative learning (Taylor, 2008). The transformation of skills and insights can then be applied to increase effectiveness in participants' roles as leaders, as well as continue to create meaning of the experience and embed emergent stories into participants' daily lives (Ballard et al., 2006).

\section{Theoretical Framework}

This study was examined through the lens of transformative learning theory. Merriam and Bierema (2014) informed readers, "transformative learning is embedded in life experience" (p. 107). As the seminal researcher in this area, Mezirow's 1978 theory depicted transformative learning by explaining how adults make sense of their experiences and how influences affect this development (Mezirow, 1997). The process involves transforming frames of reference through critical reflection of assumptions, validating contested beliefs through discourse, taking action on one's reflective insight, and critically assessing that action (Mezirow, 1997).

Epochal transformations are defined as transformative learning experiences that transform a learner's core identity or worldview, and are often sudden, dramatic, and reorient insight (Mezirow, 2012; Tisdell, 2012). Tisdell (2012) and Mezirow (1997) concurred that the transformation of thinking is different from transformation of being 
and, often, the transformation of thinking is not epochal. "There are likely many times in one's life when one has transformational experiences...But there are likely few instances of an epochal shift that transforms one's being and identity" (Tisdell, 2012). An epochal transformation is life changing (Mezirow, 1997).

Transformative learning theory asserts that learning can occur gradually or from a sudden, powerful experience, and changes the way people see themselves and their world, personally, socially, and professionally (Baumgartner, 2001; DeCapua, Marshall, \& Frydland, 2018). Whether the learning takes place over time or from an intense experience, reflection and dialogue are the pieces of the experience critical to transformation (Merriam, 2004). Reflection takes time, structure, and intention to create a transformation of learning (Merriam \& Bierema, 2014; Mezirow, 2009; Taylor, 2009). Ettling (2012) tasked adult educators with creating environments which emphasize critical reflexivity to foster transformative learning. Within the adult learning environment, an advanced cognitive development is demonstrated through a transformative learner's ability to critically reflect and have rational discourse about their experiences (Merriam \& Kim, 2012; Mezirow, 2012). A paradigmatic shift occurs through the revision of reference in conjunction with a reflection on experience (Taylor, 2008). Merriam (2004) emphasized without the critical reflection and discourse processes, it is unlikely that an act of learning will be truly transformative.

Mezirow (1997) indicated after discourse and critical reflection occur, new action and assessment should occur to complete the transformation. Pigza (2015) encouraged this cycle by stating "reflection and action upon [and with] the world to transform it... orients the study of leadership, the cycles of action and reflection in action research, the 
reflection that accompanies service, and the collaborative process of change.” (p. 47). Critical scrutiny after a shared learning experience establishes a common base from which each learner constructs meaning through personal reflection and group discussion (Tennant, 1991). Action followed by reflection is seen as an explicit reassessment of the meaning of structures and fosters transformative learning (Taylor, 2008).

Ettling (2012) described two frameworks for transformative learning. The first framework prioritizes personal transformation and change, with critical reflection and critique of assumptions as points of emphasis. The second framework emphasizes social change as well as personal change, and the link connecting these two changes. When the research is focused on individual transformation, the first framework is utilized.

Transformative learning theory continues to be a growing area of study of adult learning and has significant implications for the practice of teaching adults (Baumgartner, 2001; Hoggan, 2016; Merriam \& Bierema, 2014; Mezirow, 2009; Taylor, 2009). The growth is so significant that it seems to have replaced andragogy as the dominant educational philosophy of adult education, offering teaching practices grounded in empirical research and supported by sound theoretical assumptions (Taylor, 2008). Baumgartner (2001) explained that transformational learning theory expanded understanding of adult learning by untangling the meaning-making process. It is not what people know, but how they know that is important. Hoggan (2016) updated the definition of transformative learning as a process which culminates in "significant and irreversible changes in the way a person experiences, conceptualizes and interacts with the world" (p. 71). The more recent definition encompassed Mezirow's original theory of individual change as well as updated theory which specifies thoughts and feelings focused on social 
or organizational change and spiritual integration (Baumgartner, 2001; Hoggan, 2016). Cranton and Taylor (2012) asserted that learning can only be called transformative if a fundamental change occurs at a deep level. Transformative learning occurs when the way adults make meaning of their experience changes because the previous way of thinking cannot accommodate the new experience (Merriam \& Bierema, 2014).

Designing a program to foster transformative learning that reaches a deep level requires a safe and trusting relationship to be built, engaging the learner in discovery while overcoming fears or preconceived ideas, and acknowledgment of the learner as a whole person (Taylor \& Snyder, 2012). One of the essential factors in a transformative experience is building trust through establishing positive and productive relationships with others (Ettling, 2012). Baumgartner (2001) recommended a program design based on trust to enhance participation, collaboration, exploration, critical reflection, and feedback.

Transformative learning theory directly relates to outdoor education. Brymer et al. (2011) found that despite not being introduced to the transformational leadership model, outdoor leaders demonstrated a "higher level of transformational leadership qualities than the general population" (p. 102). Hinge (2016) believed this concept inspired research about the transformative power of experiential learning, specifically on the development of leadership effectiveness. Kass and Grandizol (2011) cited student comments that outdoor education was a transformative personal experience that is unlikely to be emulated in a classroom. 


\section{Review of Extant Scholarship}

Outdoor learning experiences have become a popular and effective medium for generic leadership skill development (Brymer et al., 2011). The learning outcomes for outdoor learning experiences are listed as leadership skills, problem-solving, team building, trust, and interpersonal communication (Williams, Graham, \& Baker, 2003).

These outcomes embody effective practices for leaders and organizations. Williams et al. (2003) stated

Leadership skills can be enhanced by challenges that require decisiveness and risk-taking. Problem-solving skills may be improved by the variety and novelty of the challenges presented. Team building may be promoted by challenges that compel team members to rely on each other to be successful. Trust can be increased by activities that expose the barriers to trust and encourage trainees to overcome them. Interpersonal communication may be enhanced by activities that demonstrate the complexity and value of effective listening. (p. 48)

The acquisition of skills through the common practices in most outdoor programs are what make these experiences effective for leadership development.

\section{Components}

The components of outdoor adventure education (OAE) programs follow a typical pattern. Ewert and Sibthorp (2014) stated the typical OAE program includes activities and experiences that "entail action, high energy, and meaningful consequences; strenuous and kinesthetic behaviors; and small groups of participants" (p. 35). OAE programs design experiences based on key principles: 
- Experiences are supported by reflection, critical analysis, and transfer of things learned.

- Learning is personal and provides a foundation for developing meaning and relevance.

- Participants are encouraged to examine their values and behaviors during and from an OAE experience.

- Participants are engaged at the physical, emotional, cognitive, and intellectual level.

- Outdoor adventure educators are active learners and engage in a process that parallels that of participants. (Ewert \& Sibthorp, 2014, p. 37)

Program design which embraces these key principles elicits both interpersonal and intrapersonal outcomes (Ewert \& Sibthorp, 2014). In order to reach the outcomes, OAE programs often have specific components. These components are critical reflection (sometimes through journaling), high adventure (hiking, rappelling, canoeing, kayaking, rock climbing, etc.), and challenge by choice (Shooter, Paisley, \& Sibthorp, 2010).

Critical reflection is defined by Seaman and Rheingold (2013) as a cognitive process for generalization and internalization which occurs after an event, called an experience. The authors believe that reflection is an essential component of learning, and it is necessary to learn from experiences. Dyment and O'Connell (2010) engaged higher education students in reflection through journaling; they stated "journals serve as a vehicle for reflection before, during, and after a learning experience" (p. 233). Similarly, Seaman and Rheingold (2013) engaged students in reflection through circle talks, which highlight the profoundly social nature of routine experiential practices and challenge the 
overly cerebral or individualist concepts of experiential learning and reflection. Timken and McNamee (2012) engaged pre-service physical education students in a semester-long cycle of written and verbal reflection after varying levels of outdoor adventure experiences. Their period of reflection resulted in deep meaning-making and a transformation of thought for their students. Circle talks and journals are utilized in conjunction with reflective conversation to create deep reflection and new meaning after OAE experiences (Dyment \& O’Connell, 2010; Ewert \& Sibthorp, 2014; Seaman \& Rheingold, 2013; Timken \& McNamee, 2012).

The high adventure portion of OAE engages participants in risk-taking behaviors which move them outside their comfort zones (Ewert \& Sibthorp, 2014). Adventure education activities situated within a supportive environment are a catalyst for change, primarily due to perceived increased risk (Timken \& McNamee, 2012). High adventure often includes camping, hiking, rappelling, canoeing, kayaking, rock climbing, and other similar activities (Ewert \& Sibthorp, 2014). When designing their innovative Outdoor Orientation Program, Wolfe and Kay (2011) labeled high adventure activities a novel setting for learning and designed the program to increase retention and success in college freshmen. High adventure activities that lead participants of every age outside normal levels of comfort bring forth skills which transform mastery and personal growth (Passarelli, Hall \& Anderson, 2010).

The concept of challenge by choice empowers students to make decisions regarding their level of participation in various high adventure activities (Speelman \& Wagstaff, 2015). Such challenge by choice activities may include rock-climbing, rappelling, or canoeing. During the group reflection period, the facilitator is responsible 
for helping everyone feel connection to the activity or experience regardless of level of participation. By working together to support each other through each member's contribution and level of comfort, groups can experience an incredible outdoor experience due to genuine teamwork (Shooter, Paisley, \& Sibthorp, 2010).

\section{Masters Level Students}

Outdoor education programs have been utilized by masters-level students in a variety of majors. Graduate students learn leadership skills transferable to their future careers through participation in outdoor education programs (Judge, 2005; Kass \& Grandzol, 2011; Owen, 2015; Saulnier et al., 2014). Often the outdoor education programs are a semester in length, with a culminating outdoor experience as part of an overall class (Judge, 2005; Kass \& Grandzol, 2011).

Bell, Gass, Nafziger, and Starbuck (2014) found "Almost 200 colleges in the U.S. and Canada use outdoor orientation programs to help students 'develop a sense of belonging and status in transition', often resulting in long term measurable increases in factors such as retention rate and GPA" (p. 37). In 2010, a program was initiated for masters-level engineering students at the Massachusetts Institute of Technology (MIT). MIT students partnered with students from a comparable master's program in Singapore to participate in a wilderness program focused on developing leadership skills (Saulnier et al., 2014). The program combined the pedagogical approaches of design-based learning and wilderness education to create a unique learning environment for masterslevel engineering students. Saulnier et al. (2014) determined wilderness education programs have the potential to provide substantial and lasting changes in a student's perception of themselves and their life perspective. 
Many parallels to the MIT program were made by Judge (2005) through an evaluation of another masters-level program involving students in an Executive MBA program. He also found experiential learning to be an effective method of leadership development. The study summarized a three-year evolution of a one-day experiential learning event focused on leadership development. Each year, after making changes, the program produced more significant results. The most notable additions to the program were a debriefing (reflection) aspect, as well as a pre- and post-evaluation by the participants' supervisors on each participants' leadership skills. The faculty was very involved in the process for the students. The researcher recognized that passive learning often does not translate into practice as quickly as experiential learning does. The final recommendation was, "if your goal is more than just conceptual awareness for your leadership development initiatives, we strongly recommend that you experiment with adventure-based experiential learning" (p. 299).

Kass and Grandzol (2011) found students from an outdoor management training program had a transformational personal experience not likely to be duplicated in a classroom. The researchers' purpose was to analyze the impact of Outdoor Management Training [OMT] on the leadership development of MBA students attending an intensive outdoor leadership experience, which was then compared to students in the same program who did not attend an outdoor experience. Participants were guided to reflect on their experiences and to transfer the skills to other situations. Students experienced real-time decision making, as well as outcomes with significant consequences, and found there were no textbook solutions. "Each student had to balance their own needs and the needs of the team, cope with physical and emotional fatigue, the ever-changing weather, the 
fear of heights, the deadline of darkness, and the unknown" (p. 47). In the end, the researchers found anecdotal and statistical evidence that the students in the outdoor training experienced more effective leadership development than those who were not in the program. The value of OMT was statistically demonstrated as a tool for leadership development, and the value derived justifies the time, effort, and expense required for such an event. The researchers recommended those wishing to implement effective approaches to leadership development consider experiential education.

\section{Business Leaders}

Employing outdoor adventure experiences to develop business leaders is a practice that has been in place for many years (Brymer et al., 2011). Whether the method is high adventure or low ropes courses, the outcome of leadership development is consistent (Hinge, 2016). "There are several reasons to expect the unique learning environment of outdoor experiential training to influence leaders and teams in a way that contributes to business results for the organizations that invest in outdoor programs" (Williams et al., 2003). These reasons are classified in the categories of complex and unfamiliar environment, transferable knowledge development, necessity of teamwork, and increased self-awareness (Baruch, 2019; Gans, 2011; Kanengieter \& RajagopalDurbin, 2012; Myers \& Doyle, 2020). By making people work collaboratively, acquire new skills, and control their outcomes, outdoor or wilderness experiences expose key facets of leadership and team interaction that might otherwise be overlooked in a more traditional setting (Myers \& Doyle, 2020).

Business leaders who complete outdoor leadership development programs have higher retention, productivity, and satisfaction than those who do not (Brymer et al., 
2011; Williams et al., 2003). Hinge (2016) studied themes of leadership effectiveness which emerged from two high stakes expeditions and demonstrated how crucibles can effectively develop business leadership capabilities. He found the transformative power of experiential learning had a significant impact on the development of business leadership effectiveness. The ability to tolerate adversity and uncertainty is a crucial leadership skill that can be honed in the constantly shifting outdoor environment (Kanengeiter \& Rajagopal-Durbin, 2012). Additionally, Kanengeiter and RajagopalDurbin (2012) stated a business leader's ability to get out of the way and let someone with more knowledge take charge is an invaluable skill transfer from the wilderness to the board room. Myers and Doyle (2020) and Gans (2011) confirmed when leaders and teams are in a more natural setting, out of the standard office roles where they are not influenced by technology, competing demands, or office politics, the wilderness distills many facets of leadership and team interaction down to their essence.

Leadership skills are also developed through becoming an active follower in an outdoor experience. All members of the team are asked to give input and are empowered in their role to contribute to the larger group vision and success (Gans, 2011; Kanengeiter \& Rajagopal-Durbin, 2012). Leaders begin to see the value in listening to others, leading from the back, and encouraging diverse ideas (Brandt, 2016; Gans, 2011; Williams et al., 2003). The ongoing opportunities to practice new leadership skills in the outdoor setting as situations continuously arise and shift, allow for the leader to solidify their new knowledge in order for it to be transferred to their corporate role (Hinge, 2016; Kanengeiter \& Rajagopal-Durbin, 2012, Myers \& Doyle, 2020). 


\section{Youth}

The Outward Bound program has been established as an effective means of training for youth through outdoor adventure education since 1941 (Hattie, Neill, Marsh, \& Richards, 1997; McKenzie, 2002; Outward Bound, 2019b). Many youth outdoor adventure programs follow the model set forth by Kahn, who founded the first outdoor learning program in England in 1941and was the model for developing the Outward Bound program in America. (McKenzie, 2002).

Kurt Hahn's goal when creating Outward Bound was to integrate intensive experience and skill-building into the fabric of education. He approached teaching and learning as centered on the belief that education should place equal emphasis on development of character and the intellect (Outward Bound, 2019a). This desire to grow youth in a unique way laid the foundation for many programs. Due to Hahn's leadership and forward thinking, the Outward Bound program is set apart from many of the other organizations that provide wilderness expeditions. The Outward Bound training brings a high level of emphasis and performance to teaching the outcomes of character, leadership, and service; these outcomes bring about the long-term effect of an Outward Bound education (Outward Bound, 2019a). “Outward Bound courses build confidence and develop students' abilities to interact and work effectively with others and can improve achievement and progress in school" (Outward Bound, 2019b).

Youth programs similar to Outward Bound are found in many other states including Missouri, Virginia, Delaware, Maryland and several other east coast states (Covitt, 2002; Experiential Education Exchange, 2019; O’Neil et al., 2020; Pigza, 2015; Roberts \& Suren, 2010). Missouri’s St. Louis Experiential Exchange program began in 
the late 1980s and, although the program has evolved and been renamed over the years, the focus on utilizing short, yet intense, outdoor learning experiences for youth development has never wavered (Experiential Education Exchange, 2019). The Chesapeake Bay Foundation runs many outdoor learning opportunities along the east coast for youth to develop leadership, autonomy, and environmentally aware citizens (Covitt, 2002). The east coast youth programs established by the Chesapeake Bay Foundation create situations for higher order thinking and leadership development in learners from $5^{\text {th }}-12^{\text {th }}$ grades (Covitt, 2002; O’Neil et al., 2020). O'Neil et al. (2020) stated the importance of contact with nature through outdoor learning experiences increases as children spend an escalating amount of time inside engaged digitally. Using urban harbors to successfully create outdoor experiential learning encourages students to take initiative, pose questions, and integrate knowledge to solve problems (O'Neil et al., 2020).

\section{Outdoor Adventure Education}

Outdoor adventure classes and outdoor education programs embed leadership into high adventure skills training to increase effectiveness (Ballard et al., 2006; Ewert \& Overholt, 2010; Hayashi \& Ewert, 2006; Speelman \& Wagstaff, 2015). Outdoor adventure leaders must be effective leaders to safely lead a group through an excursion (Speelman \& Wagstaff, 2015). Leadership development is a pivotal piece of outdoor adventure programs (Ewert \& Overholt, 2010). Wilderness education requires solutions to problems that do not have definitive right or wrong answers, and inherently include novelty, instability, and unpredictability (Collins, Sibthorp, \& Gookin, 2016). Outdoor 
learning can transform skills, knowledge, attitudes, and behaviors through reflection and connection with others and the environment (Anderson, 2019).

The training of many adult outdoor adventure leaders includes NOLS. NOLS is a non-profit organization founded by mountaineer and wilderness activist, Paul Petzoldt, in 1965 as the National Outdoor Leadership School. The published mission is to be an instrumental source and teacher of wilderness skills and leadership that serves people as well as the environment (NOLS, 2019a). 'NOLS' strength is that it provides an experience where actions have immediate and serious consequences, and where success depends on working closely as a group" (NOLS, 2019a, p. 39). NOLS has been established as the pinnacle program for training outdoor adventure leaders through their ability to create a balance between challenging experiences with personal reflection and meaning-making (Ballard et al., 2006).

NOLS has created a program which affirms a transfer of skills to future leadership situations (Kavalsky, 2018; Sibthorp, Furman, Paisley, Gookin, \& Shuman, 2011). NOLS participants come from all professions and skill sets, but they all possess a spirit of adventure and develop a unique set of leadership skills upon completion. As society becomes more digital and complex, the ability to solve intricate problems, focus on learning to lead, and build working relationships becomes increasingly valuable (Kavalsky, 2018; Rochelle, 2018).

\section{Conclusion}

Transformative learning theory and outdoor leadership experiences have deep connections to the creation of transformational leaders. Mezirow's 1978 transformative learning theory and subsequent evolutions by other researchers have created an updated 
definition of the theory. The transformative theory embraces reflection and action, which are critical components of outdoor learning experiences (Brymer et al., 2011).

Leadership is a common outcome of outdoor adventure education, yet a definition remains elusive. For research, the definition of leadership is often divided into skills considered valuable to leaders, such as communication, charisma, and problem solving (Ewert \& Sibthorp, 2014). These leadership skills can be applied in a variety of professions and skills can be transferred due to the intense nature of outdoor experiences (Hinge, 2016). The components of outdoor education that lead to leadership development are critical reflection (sometimes through journaling), high adventure (hiking, rappelling, canoeing, kayaking, rock climbing, etc.), and challenge by choice (Shooter, Paisley, \& Sibthorp, 2010).

Research in leadership development has been conducted for programs involving masters-level students, youth, and business leaders. Regardless of the age or role of the participants, the programs report higher rates of leadership development for participants than for those who did not participate in outdoor experiences (Ballard et al., 2006; Pigza, 2015; Roberts \& Suren, 2010; Williams et al., 2003). Kass and Grandizol (2011) cited comments that outdoor education was a transformative personal experience that cannot be emulated in a classroom.

There is general agreement in research that leadership development now needs learning opportunities from multiple disciplines and aspects; it is not enough to learn or practice leadership in isolation from context (Owen, 2015). To train our educational leaders in a variety of disciplines, evaluation of the impact of leadership development programs must occur. "Outdoor settings offer the types of hands-on and diverse 
experiential leadership development that is often lacking in other leadership development realms" (Ewert \& Overholt, 2010, p. 45). Brymer et al. (2011) cite the benefits of outdoor leadership training are hard to define; however, outdoor learning experiences have become a popular and effective medium for generic leadership skill development. 
SECTION FOUR:

CONTRIBUTION TO PRACTICE 


\section{Contribution to Practice}

The researcher will present the findings to the Department of Elementary and Secondary Education's Office of Educator Quality. This office is the organization in charge of funding and support for Missouri's Leadership Academy, as well as the Outdoor Leadership Experience. Attendees may include the director of the Missouri Leadership Development System, as well as Regional Professional Development Directors who facilitate Leadership Academy. The presentation will be impactful for this office in order to have feedback on participant's perceptions over the last 34 years as to the direct relationship the program had with their daily practice as leaders.

This presentation will occur as soon as the dissertation defense is complete, any corrections have been made, and the meeting can be arranged with the Office of Educator Quality's director, Paul Katnik. This presentation will allow for face to face questions and delivery of in-depth participant feedback. 


\section{MISSOURI'S OUTDOOR LEADERSHIP EXPERIENCE: THROUGH THE EYES OF PAST PARTICIPANTS}

Jenni Hayes, Ed.D.

Welcome everyone! For those of you who do not know me, my name is Jenni Hayes. I am an Elementary Principal at Lafayette County C-1 in Higginsville. I have been a school leader for 8 years. Additionally, I have been a facilitator for the Outdoor Leadership Experience for 5 years and a Regional facilitator for Leadership Academy for 1 year. I have also been serving on the Steering committee to help design the Leadership Academy programming for 2021-22. This presentation will detail the thoughts and perceptions of facilitators and participants over the last 34 years. Let's begin with the reason I began this study. 


\section{The STRESS of School Leadership can lead to ...}

School Administrators are under a unique level of stress. They face escalating expectations from parents and society, as well as the increasing needs of students.

Nearly $50 \%$ of school leaders leave by their third year in the profession (NAESP, 2016). This staggering fact, in conjunction with the fact that it takes 3-5 years to train a new principal, as well as acclimate them to the new position and build culture, highlights the need to keep school leaders in place. 


\section{Developing the leadership skills of principals will...}

One way to keep school leaders in their positions is to ensure they have proper training and support. Developing the leadership skills of principals should increase their ability to cope with the stress and complexity of the principalship (Cranston, 2008) and decrease principal turnover (Kafele, 2018).

Leadership skill development is vital to the effective support of school principals (Cranston, 2008; Nelsoney \& Welcome, 2017; Peterson, 2002). Riggio (2013) stated, "organizations believe that leadership development is important and worth the investment of resources and their time to work on their leadership development. There is a shared belief that leadership development works" (p. 12).

The instability of a school's climate and culture based on ongoing administrator turnover ripples down to teachers and then to students. Therefore, this leadership development is vital to the future of our students. 


\section{STATEMENT OF THE PROBLEM}

The continued pressure society places on schools, and specifically school administrators, is creating a high principal turnover. Miller (2013) and Rangel (2018) stated this creates a situation that is detrimental to the improvement of schools and impacts student success.

The discussion to decide the most effective methods for the development of principals created a need for more research on what is currently in place.

I know several principals who have left the profession due to the high stress and feeling incapable of successfully completing the demands of the job. This creates a problem that has lasting effects.

So the question can be asked: What are the most effective ways to train and support principals? Is it an outdoor leadership training? 


\section{WHAT DO WE KNOW ABOUT OUTDOOR LEADERSHIP TRAINING?}

\section{- Business leaders}

- Masters Level Students

- Youth

- NOLS

Whether the method is high adventure or low ropes courses, the outcome of leadership development is consistent (Hinge, 2016; Kanengeiter \& Rajagopal-Durbin, 2012, Myers \& Doyle, 2020). Business leaders who complete outdoor leadership development programs have higher retention than those who do not (Brymer et al., 2011; Williams, Graham, \& Baker, 2003).

Graduate students in the field of engineering, business, executive management, and recreation learn leadership skills transferable to their future careers in these programs (Judge, 2005; Kass \& Grandzol, 2011; Owen, 2015; Saulnier, Bagiati, \& Brisson, 2014). The transference learning from the masters-level students results in well prepared graduates who have leadership skills sought out by employers.

Youth programs focus on teaching the outcomes of character, leadership, and service. These programs result in students who are more confident and have the ability to interact and work effectively with others (Outward Bound, 2019b). Youth programs are found in many states including Missouri, Virginia, Delaware, and several east coast states. The programs focus on utilizing short, yet intense, outdoor learning experiences for youth leadership development of environmentally aware citizens (Covitt, 2002 Experiential Education Exchange, 2019; O'Neil et al., 2020; Pigza, 2015; Roberts \& Suren, 2010).

Outdoor adventure leaders must be effective leaders to safely lead a group through an excursion (Speelman \& Wagstaff, 2015) and leadership development is a pivotal piece of their programs (Ewert \& Overholt, 2010). Outdoor adventure programs embed leadership into high adventure skills training to increase effectiveness (Ballard et al., 2006; Ewert \& Overholt, 2010; Hayashi \& Ewert, 2006; Speelman \& Wagstaff, 2015).

Braymer, Gray, and Cotton (2011) cite the benefits of outdoor leadership training are hard to define; however, outdoor learning experiences have become a popular and effective medium for generic leadership skill development. A lack of understanding or research exists regarding OLE's impact on leadership development in, and the potential retention of, Missouri's administrators. The gap in the literature shows a scarcity of studies within the education profession specific to utilizing outdoor leadership training programs to develop leadership. 


\section{PURPOSE OF THE STUDY}

- The purpose of this qualitative study is to understand how the skills learned at the outdoor leadership experience are perceived to impact school leader effectiveness.

- Principal effectiveness is cited as a leading factor in the retention of quality teachers (Vekeman, Devos, Valcke, \& Rosseel, 2018), as well as the effectiveness of a school (DuFour \& Marzano, 2011).

- The growth of a principal's effectiveness increases their likelihood to remain satisfied in their job and retain their role.

The purpose of this study is to understand the effectiveness of the Outdoor Leadership Experience for leaders in their daily practice. 


\section{DESIGN OF THE STUDY}

- Site Selection

- Camp Rising Sun

- Lake of the Ozarks

- 1987-2013

-YMCA Trout Lodge, Camp Lakewood

- Potosi

-2014-present

The site of the Outdoor Leadership Experience has only been in two locations over the last 34 years. It was held at Camp Rising Sun at the Lake of the Ozarks from 1987-2013. Then in 2014 it was moved to the YMCA Trout Lodge at Camp Lakewood in Potosi and has remained there ever since. 


\section{DESIGN OF THE STUDY}

- Participant Selection

- Process:

- Past participant data from DESE's Office of Educator Quality

- Diverse demographic group in district size, school population, and gender.

- Participants:

- 22 Participants

- 11 Facilitators

I attempted to find a wide variety of past participants to interview. I acquired data from the administrative assistant here in the Office of Educator Quality prior to her retirement. However, the data base was only from 2006 to the most recent group. Additional names were given to me, however many of those early participants did not respond or were difficult to find.

I reached out to possible participants though my Professional Learning Network and was able to gain interviews and focus groups with a diverse group.

Participants consisted of the following: 13 Men, 9 Women, 14 Rural, 4 Suburban, 4 Urban. The average number of years of leadership experience at the time of attendance was 3.43 years.

Facilitator focus groups consisted of the following: 9 Men, 2 Women, 5 Rural, 2

Suburban, 4 Urban. The average number of years of facilitation experience was 9.55 years. Three focus groups were held in two groups of four and one group of three. 


\section{DESIGN OF THE STUDY}

- Data Collection and Analysis

- Interviews of Participants held via Zoom

- Focus Groups of Facilitators held via Zoom

- Interviews and focus groups were recorded and transcribed.

- Information was kept confidential and pseudonyms were used.

- Transcriptions were coded and themes emerged.

Due to the COVID pandemic, interviews and focus groups all had to be held via zoom. Interviews and focus groups lasted between 30-60 minutes and were recorded. I then transcribed the interviews and focus groups in order to discover themes from my coding. 


\section{Design of the Strudy}

- Limitations \& Assumptions

- Limitations: The database of past participants was comprehensive for the years 2006- present. For the years 1987-2005 the database was limited to personal connections with the data provider and researcher.

- Assumptions: The researcher is deeply connected to the program as a facilitator.

As you can see, the limitations were the limited data pool for participants and could have been expanded if COVID weren't so impactful.

The assumptions of the researcher were due to a significant connection to the program being studied. This was combated through a concerted effort to find participants I did not have significant contact with in their OLE journey. Due to the smaller number of possibilities within the facilitators contact list, it was impossible to not have a connection with many of the facilitators. However, I did attempt to leave my voice out of the focus group discussions, even if a personal connection was discussed. 


\section{FINDINGS}

- Increased Self-Awareness

- Vulnerability

- Physical

- Emotional

- Connections with Other Leaders

- Network

- Shared Leadership

- Transformation of Thought

The findings revealed several themes based on the participants' perceptions. These themes were enlightening as to what the participants found to be most impactful on them as leaders. Let's look at each theme in depth. 


\section{INCREASED SELF-AWARENESS}

Participants spoke of an increase in their self-awareness as leaders. They specifically spoke of an awareness of how their actions impacted those around them. Jason said, "I learned more intrinsically about myself from those three days than, arguably, any other time during my educational career. It wasn't until probably two to three weeks after the experience that everything I learned really sank in. I had to process. And then the caveat of that is once you know who you are, recognize your weaknesses and how to work with others."

Peter summarized the experience as "one of the more meaningful opportunities in leadership to really discover more about yourself and about others." Casey claimed, "you will come back with a whole new appreciation of who you are, who others are, and working together to accomplish a goal."

Chad related, "at the end of the experience to just see and talk to the participants: this is a powerful thing. It's beneficial. Obviously, not everybody walks away and says, 'Man that was great.' But the majority do. And I think they would all say, 'Yeah, I had some growth through this experience."' 


\section{VULNERABILITY $>$ Physical Vulnerability $>$ Emotional Vulnerability}

The majority of participants shared the importance of allowing themselves to be vulnerable throughout the experience in a variety of ways. Being vulnerable physically by being in an environment outside of their comfort zone, as well as being emotionally vulnerable through reflection was noted as pivotal. The notion of being open to being uncomfortable was repeatedly expressed as necessary for growth. Brady summarized it succinctly stating, "None of us had ever been tasked with anything like that before. We were thrust into a group of people that you don't really know that well to do this big thing and so everything is a brand new experience and it's the novelty of us all experiencing this together."

This physical vulnerability came through the hike, rappelling, and rock climbing. Jeanie and Marcia both transferred this learning to their role as leaders. Peter noted that everyone talks about the hike. "It actually pulls you out of a place that you feel pretty confident and now you have to navigate some uncharted waters."

The notion of the unique environment is described by Skip as a "great equalizer in that it's not our normal workspace. You find people who enjoy the outdoors, whether it's a couple of folks hiking or going into the woods for a hunting weekend. But then you have a group of 12-15, and it creates a very different dynamic for those of us who are comfortable in the outdoors."

Many participants stated they were able to truly embrace uncomfortable situations because of the trust that had been built within the framework of OLE. They felt safe to share and take risks in their discussions or input within team decisions because of this emotional safety. This emotional vulnerability stretches each participant to grow. This trust led Greg to realize and understand "that you don't have to do everything yourself. You have to trust in others, you have to build a team around you that has similar goals and similar vision as yours." Joey said the vulnerability of his team and all of the "stuff we went through really helped bond us and really grew a trust in just three days that many of us didn't have with our administrative team that we've worked with for a year or more." 


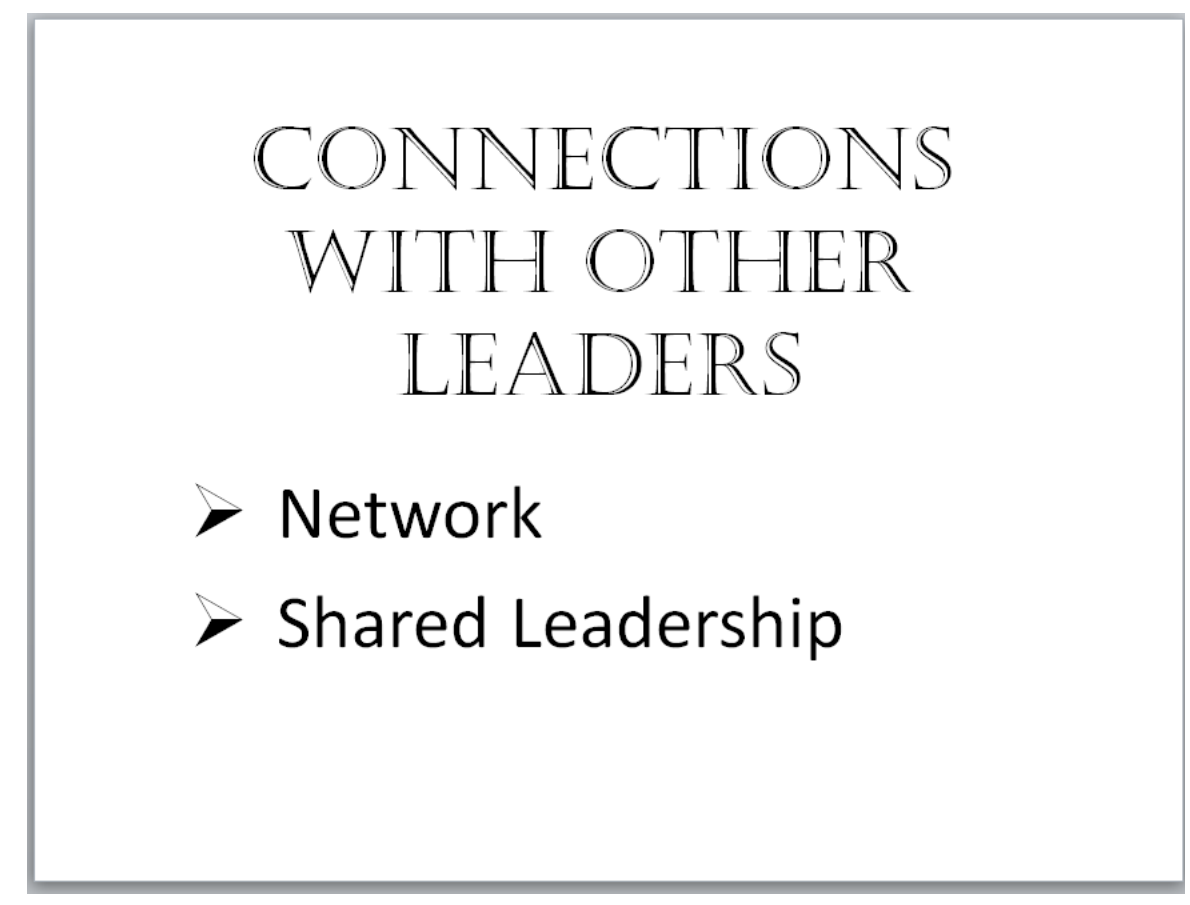

The connections that are forged when people go through what Hinge (2016) calls a crucible moment can be deep and lasting. Ron agreed, stating the team that went through the entire experience together became "extremely close and bonded deeper than you would ever think that you could get to know somebody in the course of three days." Tricia, Lydia, Marcia, Greg, Ron and Joey all noted their connections were so deep that they could reach out to anyone on their OLE team still today and ask for assistance with a problem or give support at any moment. Janice affirmed "in that short amount of time. I am still tight friends with some people from across the state that I only spent a weekend with. I'm talking about deep relationships. How did that happen? How do I have this much respect for that person out of such a short time? Our feelings were naked, our conversations were naked. We spoke personally, and sometimes we work with people for years and never do that." Tim also asserted, "I don't think we can ever overstate the importance of the networking that takes place, laughing and crying, spending those days at OLE, it creates a network that just isn't broken. When people see each other that they've been through this with, their eyes light up with a different sparkle than in their contact with others over their years of experience as a leader. Peter noted OLE is designed to "build trust with other people within the profession. A lot of people actually aren't great at networking, they network through proximity. And OLE is a space that allows you, because of the design, to connect with somebody out of St. Louis, and it allows you to connect with somebody in Northwest Missouri that has a school district of 200. It helps build perspective, a lot of different relationships."

For the purposes of this study, shared leadership is defined as collaboration to problem solve and build a team in order to move in a positive direction. Shared leadership was displayed at OLE through teamwork. Max, Lydia, Joey, Ron, and Blake all noted that teamwork was an important function of OLE. Cindy learned "building consensus, knowing that I can't really move forward unless I have everybody on the same page," was important for success. Marcia agreed, "because if you wanted to get done you had to rely on each other." John believed this shared leadership was intentionally wrought. "I think they probably intentionally paired you with people who were quite [the] opposite than you. It just seemed like we were a good mix of different personalities, different strengths." 


\section{TRANSFORMATION OF THOUGHT}

A transformation of thought came from a variety of sources.

Lydia: "Have confidence in yourself that you can do something that looks pretty big. Climbing that rock wall and thinking I couldn't do it and then I did it. I decided if I can climb a rock wall, then I can be a leader."

Lacey gained confidence in her place in leadership. "Tables turned for me at that point [of reflection]. I became a different person among leaders. It was the first time I stepped up amongst my peers and thought I might be good enough to do something. And it just gave me a surge, allowing myself to be what I want it to be. That was a moment that's made a big impact in the latter part of my career."

Prior to attending OLE, Joey felt like he had to have all the answers. When he "went to OLE, I found out about the idea of failing forward. I really embraced that."

Acknowledging that he will make mistakes, but "we're going to learn from it and we're going to get back on track. As a leader, you don't have to carry the weight on your own, but you have to build the capacity of those around you so they can help carry the weight."

Cindy "It helps you take the blinders off and realize what you do here at OLE can also be applied back in your school." 


\section{RECOMMENDATIONS}

1. Maintain the Significance of the Hike

2. Advanced Outdoor Leadership

3. Forced Pause

4. Train Facilitators

5. Share the History 


\section{MAINTAIN THE SIGNIFICANCE OF THE HIKE}

Recollections of the hike from participants and facilitators who attended stated the length of the hike was key. To be out in the woods after dark was an impactful experience and interviewees stated the need to keep this portion consistent. The majority of interviewees stated the hike was pivotal to their growth and application of skills. Cindy cautioned, "Don't take out the hike and orienteering. It brings you back to being a learner."

Having the right location is important to consider when designing an impactful hike for teams of adults. The recommendation for the hike is to choose a site that is safe, yet allows for extended time in the woods to ensure that the orienteering portion does not get shortened or watered down based on location or bureaucratic constraints.

Casey noted, "I just worry about that for the future and for it to continue to be viable and as impactful as it was." 


\section{ADVANCED OUTDOOR LEADERSHIP EXPERIENCE}

Participants in the study repeatedly stated a desire to go back to OLE, some saying they would go every year. Having the opportunity to experience the OLE, with an added layer of depth based on previous experience, will allow for advanced leadership development. As leaders become more experienced, the depth of learning that could occur is vastly expanded.

It was noted by many that OLE was the best professional development they had ever experienced. Daniel claimed the "impact of that over typical professional development is lightyears ahead."

Although the logistics and cost involved must be a consideration, participation numbers for a weekend of advanced OLE is predicted to be high. 


\section{ENSURE A FOR CED PAUSE}

It is important for busy leaders to pause. Sometimes we have to force that for leaders. The elements of OLE that were noted as impactful by participants were: creating a journal, having an entire hour of solo reflection time, and processing aloud during team activities.

The reflection is the piece that brings all of the experiences together and creates a meaningful impact. Judah noted that the processing time "around a common purpose makes it all above and beyond anything else I've experienced, because it's not in isolation. You can learn a skill in isolation, but it's not going to be visceral, it's not going to stick and you're not going to have the application breadth that you're going to have with a common purpose of educators like you have at OLE."

Jamie expanded on the theme of reflection. She discussed how facilitators give the participants "time for reflection, we reflect with them. We do a lot of reflection and I think that's one of the things people comment on all the time. They say they are not good about reflecting because we don't take the time. And I think it forces them to take the time and realize how powerful it is."

Additionally, staying the entire length of the experience is important. Ensuring that participants and facilitators are supported by their districts and can commit to staying from Wednesday afternoon through noon on Saturday is necessary. This will allow them to truly focus on their development. Tim stressed how important this is for participants. "It's really frustrating when people are leaving earlier and earlier every year. I think they're missing out on some of the experiences that you can have. We'd rather wait until next year, or a time that you could be there the entire time. We need them to slow down for three days and ignore everything that's going on around them. And that's easy for us to say, but there are not a lot of school districts that will say that same thing." A commitment to a forced pause will ensure that the experience is all that it could be. 


\section{TRAIN FACILITATORS}

Facilitation of adult learning requires skill. Jonah noted "working with adults, there's something to that besides having passion, you've got to have a level of expertise."

Having consistent training and expectations for facilitators will ensure consistency of the experience for participants. Casey suggested the organizers of OLE "are just relying on that they go as participant, they come back as an intern, and that's the training they get. I think we need training in order to ensure the viability of the experience into the future."

Extended training for facilitators will also ensure consistency of the shared history and program expectations. 


\section{SHARE THE HISTORY}

Although the program has been in place for 34 years, an acknowledgement of the history is necessary to inspire future leaders to carry on with minimal changes to the design. The history of the origins of OLE is in danger of being forgotten. The intentionality of design and the passion of the designers to develop administrators in Missouri cannot be lost.

Many noted that they recognized the intentionality of the design and the facilitators expanded on the why behind most of the activities, but did not have a deep understanding of the history. Updates are necessary for every program to be sustainable long term. However, the updates must be made without changing the true nature of the program.

Skip noted, "There's a history of OLE that is not contingent upon a place. I think being cognizant of how to structure it in such a way to capture who we are as an entity is important. There are those who have given us so much in the past, and for those who will come after us. And even then... who's coming next? I don't know, but I want to be there to make sure that somebody else has those same tools that were freely given to me." Every focus group of facilitators brought up Caesar Sodi, Doug Miller, and Paul Katnik, and the impact they had on OLE. Yet none of the participants discussed a connection to the history.

It is recommended to design the campfire to be intentional and impactful while giving depth to the history. One suggestion was to have the campfire more than one night or with each team in a smaller setting so that the connection is deeper.

Helping everyone understand how the history of OLE, as well as the connection to nature, will create a bond with all participants through the years.

Interviewees who mentioned the campfire either thought it was inspirational and reflective or it was hokey and turned them off. Those who thought it was hokey were turned off by the singing and the feeling of it being forced. Those who found it inspirational truly reflected on the experience and had an open mind to growth. The hope is that in creating more opportunities for the campfire(s) to be meaningful and more personal, participants will embrace the history and call to leadership that is intended. 


\section{Furure Research}

Which components of the hike were most impactful?

For future research consideration, I would be interested to discover which components of the hike were so significant for participants. It was universally noted as impactful for a variety of reasons. Was it the uncomfortable environment, the team building skills taught by the facilitators, or the reflection through processing aloud and journaling? 


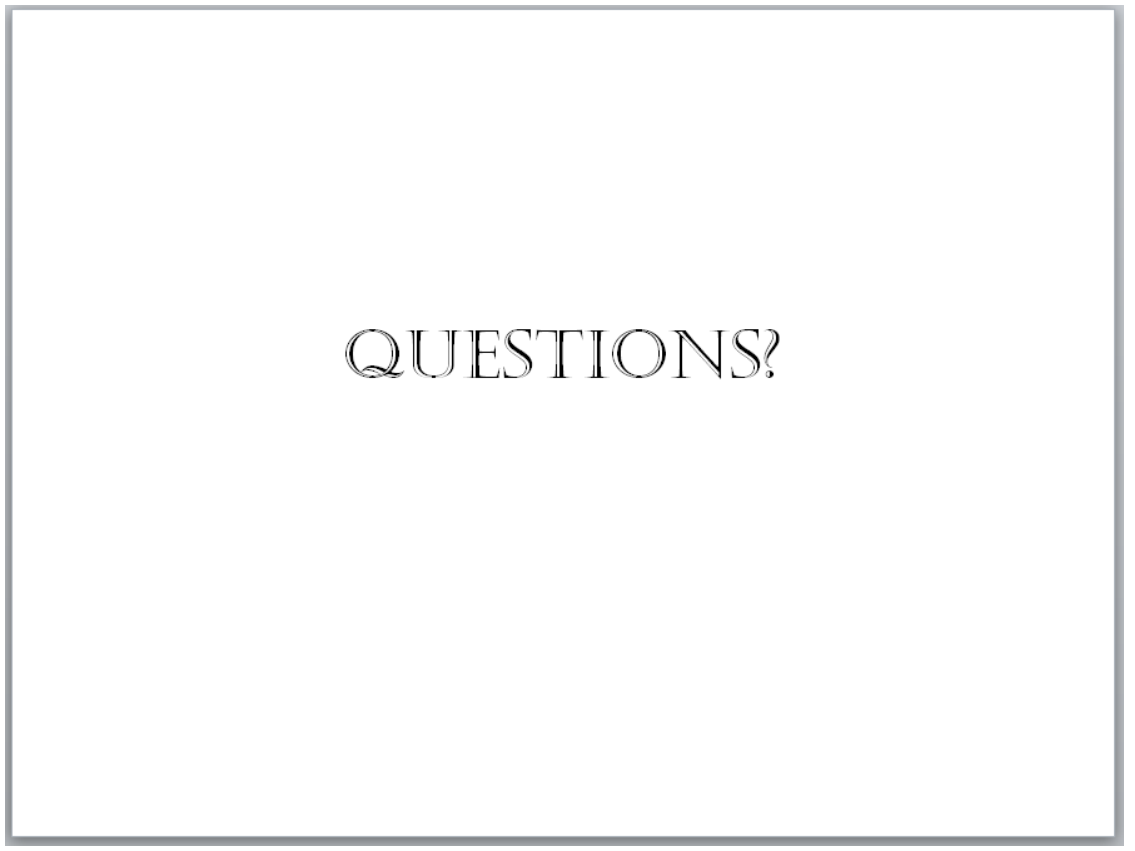

As you can see this is a topic had many facets and I believe we explored many of them. Thank you so much for your time and your interest in my research. Do you have any questions for me today? 


\section{REFERENCES}

Ballard, A., Shellman, A., \& Hayashi A. (2006). Collective meanings of an outdoor leadership program experience as lived by participants. Research in Outdoor Education, 8, 1-21.

Brymer, E., Gray, T., \& Cotton, W. (2011). Outdoor experiential training as a medium for today's leaders. Journal of Spirituality, Leadership, and Management, 5(1), 58-66.

Covitt B. (2002). Motivating environmentally responsible behavior through service-learning. Advances in Service-Leaming Research, 2, 177-197

Cranston, N. (2008). The use of cases in the leadership development of principals: A recent initiative in one large education system in Australia. Journal of Educational Administration, 46(5), pp.581-597. Retrieved from: https://oi.org/10.1108/09578230810895500

DuFour, R. \& Marzano, R. J. (2011). Leaders of learning: How district, school, and classroom teachers improve student achievement. Bloomington, IN: Solution Tree Press.

Ewert, A. \& Overholt, J. (2010). Fostering leadership through a three-week experience: Does outdoor education make a difference? Research in Outdoor Education 10, 38-47.

Experiential Education Exchange. (2019). Who we are. Retrieved from: https://www.eeestl.org

\section{REFERENCES}

Hinge, S. (2016). Can crucible led experiential learning effectively develop business leadership capabilities? New Zealand Joronal of Applied Business Research, 14 (1), 37-54

Hayashi, A. \& Ewert, A. (2006). Outdoor leaders' emotional intelligence and transformational leadership. Journal of Experiential Education, 28(3), 222-242.

Judge, W. (2005). Adventures in creating an outdoor leadership challenge course for an EMBA program. Journal of Management Education, 29 (2), 284 - 300. Retrieved from: https://doi. org $/ 10.1177 / 1052562904265251$

Kafele, B. K. (2018). Avoiding school leadership burnout. Educational Research, 23-26. Retrieved from: www.ascd.org

Kanengieter, J. \& Rajagopal-Durbin, A. (2012). Wilderness leadership—On the job. Harvard Business Review. Retrieved from: https:/hbr.org/2012/04/wilderness-leadership-on-the-job

Kass, D. \& Grandzol, C. (2011). Learning to lead at 5,267 feet. An empirical study of outdoor management training and MBA students' leadership development. Journal of Leadership Education, 10(1), 41-62.

Miller, A. (2013). Principal turnover and student achievement. Economics of EducationReview, 36, 60-72.

Myers, C. G. \& Doyle, M. (2020). Get adventurous with your leadership training. Harvard Business Review. Retrieved from https:/hbr. org/2020/02/get-adventurous-with-your-leadership-training 


\section{REFERENCES}

National Association of Elementary School Principals. (2016). Fixing the leaky principal pipeline. Communicator, 39(12). Retrieved from: https:/www.naesp.org/communicator-august-2016/fixing-leaky-principal-pipeline

Nelsoney, T. \& Welcome, A. (2016). Kids deserve it! San Diego, CA: Dave Burgess Consulting, Inc.

Outward Bound. (2019b). Outcomes. Retrieved from: https://www.outwardbound. org/about-outwardbound/philosophy/outcomes

Owen, J. E. (2015). Integrative and interdisciplinary approaches to leadership development. New Directions for Student Leadership, 145, 49-58. DOI: 10.1002/yd.20123

Peterson, K. (2002). The professional development of principals: Innovations and opportunities. Educational Administration Quarterly, 38 (2), 213-232. Retrieved from: https://doi.org/10.1177/0013161X02382006

Pigza, J. M. (2015). Navigating leadership complexity through critical, creative, and practical thinking. New Directions for Student Learning, 145, 35-48

Rangel, V. S. (2018). A review of literature on principal turnover. Review of Educational Research, 88(1), 87-124. do $10.3102 / 0034654317743197$

Riggio, R. E. (2013). Advancing the discipline of leadership studies. Journal of Leadership Education, 12(3), 10-14

\section{REFERENCES}

Roberts, N. S. \& Suren, A. T. (2010). Through the eyes of youth: A qualitative evaluation of outdoor leadership programs. Journal of Park and Recreation Administration, 28(4), 59-80.

Saulnier, C. R., Bagiati, A., \& Brisson J.G. (2014). Design based wilderness education: A cross-cultural experience in engineering education. IEEE Frontiers in Education. Retrieved from:

20403/2014FIE df? AWSAccesKevId=AKIAIWOWYYG Z2Y53UL 3A \&Expires $=1555566859$ \& Signature $=G \% 2 B 3$ ZjqDDV8V52tsEUbvollvQbdE\%3D\&response-content disposition=inline $\% 3 \mathrm{~B} \% 20$ filename $\%$ 3DDesign_Based_Wilderness_Education_A_Cros.pdf

Speelman, E. A. \& Wagstaff, M. (2015). Adventure leadership and experiential education. New Directions for Student Leadership, 7,89-98. doi: $10.1002 / \mathrm{yd}$

Vekeman E., Devos, G, Valcke, M, \& Rosseel Y (2018) Principals' configuration of a bundle of human resource practices: Does it make a difference for the relationship between teachers' fit, job satisfaction and intention to move to another school? Educational Management Administration \& Leadership, 46(5), 820-840. doi: 10.1177/1741143217711189

Williams, S. D., Graham, T. S., \& Baker, B. (2003). Evaluating outdoor experiential training for leadership and teambuilding. The Journal of Monagement Development, 22(2), 45-59. 
SECTION FIVE:

CONTRIBUTION TO SCHOLARSHIP 


\section{Missouri School Leaders' Perceptions of an Outdoor Leadership Experience}

Training school administrators to be more effective leaders through Missouri's Outdoor Leadership Experience is a unique concept that has been in place since 1987. Many other fields have used outdoor experiences for leadership training. This article discusses participants' perceptions of their experience and how it has impacted their leadership moving forward.

\section{Introduction}

Schools are facing escalating expectations from both parents and society, which causes many school principals to feel increasing levels of stress. Administrators are required to navigate a societal shift that is bringing both students and staff to their door with needs not seen in the school setting in the past (Elmore, 2018; Gajda \& Militello, 2008). The increased stress caused by the change in expectations results in principals not remaining in their schools or roles for a sustained amount of time. "The average principal now spends only two to three years in each school. Nearly 50 percent of new principals leave by their third year in the profession" (National Association of Elementary School Principals, 2016, para. 1). According to the National Teacher and Principal Survey (NTPS), for the 2015-16 school year, 75 percent of school principals were at their current school less than five years, and 49 percent less than three years (National Center for Educational Statistics, 2019). Short employment periods are problematic because it takes 3-5 years for a school leader to develop school culture, which over time translates to more significant student achievement (Elmore, 2018; National Association of Elementary School Principals, 2016; Pounder \& Crow, 2005; Pounder, Gavin, \& Shephard, 2003). If schools are losing leaders before any real changes in culture or student achievement can be made, schools are unable to create a productive environment needed for the new generation of learners (Elmore, 2018). Research shows that student test scores often drop 
in the year after a leadership change (National Association of Elementary School Principals, 2016). Principals must stay in their position long enough to create a lasting impact on the students, teachers, and educational system.

Leaders cite a variety of reasons for moving schools or leaving the profession. Gadja and Mitello (2008) found practicing principals planned to vacate their current positions due to job stress, low salary in relationship to the responsibilities of the position, and job complexity and time demands. These results are comparable to national results found by the Educational Research Service (Gadja \& Militello, 2008). Although not all principals who left positions left the field completely, the mobility rate of principals is decreasing their impact on the schools they serve.

Developing the leadership skills of principals should increase their ability to cope with the stress and complexity of the principalship (Cranston, 2008) and decrease principal turnover (Kafele, 2018). Leadership skill development is vital to the effective support of school principals (Cranston, 2008; Nelsoney \& Welcome, 2017; Peterson, 2002). Riggio (2013) stated, "organizations believe that leadership development is important and worth the investment of resources and their time to work on their leadership development. There is a shared belief that leadership development works" (p. 12). Therefore, this leadership development is vital to the future of our students. The instability of a school's climate and culture based on ongoing administrator turnover ripples down to teachers and then to students.

Missouri's Department of Elementary and Secondary Education (DESE) has recognized the need for leadership development. The Missouri Leadership Academy (MOLA) is a program that has been in place for 36 years and was initially designed to 
develop leadership skills and provide support for Missouri school administrators and aspiring administrators (D. Miller, personal communication, June 11, 2019). The Outdoor Leadership Experience (OLE) has been a part of MOLA since 1987. OLE is one of the four statewide meetings and is an integral part of the program (Missouri Department of Elementary and Secondary Education, 2019a). Based on his extensive research and training, MOLA designer Dr. Doug Miller purposefully placed the OLE in the program to develop skills that cannot be learned in any other environment (D. Miller, personal communication, June 11, 2019). Miller studied the necessary components of outdoor education with Hank Schafermeyer at the acclaimed Underway Adventures program located at Southern Illinois University Outdoor Lab (D. Miller, personal communication, June 11, 2019).

Basing his design for the OLE on the successful principles of Southern Illinois University's practicing program led Dr. Miller to create a sustainable plan for OLE which has been in place for 34 years. Researchers have found outdoor leadership training can teach a high level of transferable skills through high adventure activities and reflection (Ewert \& Overholt, 2010; Speelman \& Wagstaff, 2015). The training of educational leaders utilizing outdoor leadership skills through the OLE is an innovative program in Missouri that has not yet been duplicated in other states (Kensler \& Uline, 2019).

\section{Statement of the Problem}

The continued pressure society places on schools, and specifically school administrators, are creating a high principal turnover. Miller (2013) and Rangel (2018) stated this creates a situation that is detrimental to the improvement of schools and impacts student success. The discussion to decide the most effective methods for the 
development of principals created a need for more research on what is currently in place.

\section{Problem of Practice}

Ineffective training for leaders can lead to principal turnover (Kafele, 2018;

National Association of Elementary School Principals, 2016; Pounder \& Crow, 2005).

Principal turnover is problematic because of the pivotal role that principals play and are expected to play in leading the time-consuming task of school improvement (Rangel, 2018). The ability to retain effective principals is directly related to supporting them in their leadership development (Goldring, Taie, \& Owens, 2014). While the need to retain highly qualified administrators is recognized, the problem is the most effective method for leadership training has not been established. This study examined one leadership development model to evaluate the perceptions of effectiveness of the program for training school leaders, which potentially leads to reducing principal turnover.

\section{Existing Gap in the literature}

As previously stated, Missouri has placed several components into a leadership development program to train school administrators to increase principal retention rate (Masters \& Katnik, 2019). One aspect in year three of this training program is the Outdoor Leadership Experience (OLE). Very little research has been found to support outdoor education programs to develop school leaders. However, an abundance of research exists on outdoor education programs at many professional levels.

Employing outdoor adventure to develop business leaders is a practice that has been in place for many years (Brymer, Gray, \& Cotton, 2011). Whether the method is high adventure or low ropes courses, the outcome of leadership development is consistent 
(Hinge, 2016; Kanengeiter \& Rajagopal-Durbin, 2012, Myers \& Doyle, 2020). Business leaders who complete outdoor leadership development programs have higher retention than those who do not (Brymer et al., 2011; Williams, Graham, \& Baker, 2003).

Outdoor education programs have also been utilized by masters-level students in a variety of majors. Graduate students in the field of engineering, business, executive management, and recreation learn leadership skills transferable to their future careers in these programs (Judge, 2005; Kass \& Grandzol, 2011; Owen, 2015; Saulnier, Bagiati, \& Brisson, 2014). Often these programs are a semester in length, with a culminating outdoor experience as part of an overall class (Judge, 2005; Kass \& Grandzol, 2011). The transference learning from the masters-level students results in well prepared graduates who have leadership skills sought out by employers.

Youth programs, such as Outward Bound and the Chesapeake Bay Foundation's educational harbor programs, focus on teaching the outcomes of character, leadership, and service. These programs result in students who are more confident and have the ability to interact and work effectively with others (Outward Bound, 2019b). Additional youth programs are found in many other states including Missouri, Virginia, Delaware, and several east coast states (Covitt, 2002; Experiential Education Exchange, 2019; 2020; Pigza, 2015; Roberts \& Suren, 2010). The programs focus on utilizing short, yet intense, outdoor learning experiences for youth leadership development of environmentally aware citizens (Covitt, 2002 Experiential Education Exchange, 2019; Pigza, 2015; Roberts \& Suren, 2010).

The training of outdoor adventure leaders includes outdoor education programs. However, those classes also include specific instruction on how to lead (Ballard, 
Shellman, \& Hyashi, 2006; Ewert \& Overholt, 2010; Hayashi \& Ewert, 2006; Speelman \& Wagstaff, 2015). Outdoor adventure leaders must be effective leaders to safely lead a group through an excursion (Speelman \& Wagstaff, 2015), and leadership development is a pivotal piece of their programs (Ewert \& Overholt, 2010). Outdoor adventure programs embed leadership into high adventure skills training to increase effectiveness (Ballard et al., 2006; Ewert \& Overholt, 2010; Hayashi \& Ewert, 2006; Speelman \& Wagstaff, 2015)

Braymer, Gray, and Cotton (2011) cite the benefits of outdoor leadership training are hard to define; however, outdoor learning experiences have become a popular and effective medium for generic leadership skill development. A lack of understanding or research exists regarding OLE's impact on leadership development in, and the potential retention of, Missouri's administrators. The gap in the literature shows a scarcity of studies within the education profession specific to utilizing outdoor leadership training programs to develop leadership.

\section{Purpose of the Study}

The purpose of this qualitative study was to understand how the skills learned at the outdoor leadership experience are perceived to impact school leader effectiveness. Principal effectiveness is cited as a leading factor in the retention of quality teachers (Vekeman, Devos, Valcke, \& Rosseel, 2018), as well as the effectiveness of a school (DuFour \& Marzano, 2011). The value of outdoor leadership training is described by Ewert and Overholt (2010) as "involve[ing] active and direct experiences with many of the components associated with leadership such as decision-making, assessment, motivation, and goal-setting” (p. 40). Sharing learning experiences that establish a common base for reflection and discussion creates opportunities for participants to act on 
new insights and practice transformative learning (Taylor, 2008). The transformation of skills and ideas can then be applied to increase the effectiveness in their roles as leaders, as well as continue to create meaning of the experience and embed emergent stories into their daily lives (Ballard et al., 2006).

The researcher studied the impact of outdoor adventure education on the leadership skills of school leaders. The study focused on this through the context of the Missouri Leadership Academy (MOLA), specifically the Outdoor Leadership Experience (OLE) (Missouri Department of Elementary and Secondary Education, 2019a). The researcher studied the skills utilized at OLE that have also been found useful with varying levels of students and business leaders. The researcher examined the impact of a leader's transfer of these skills to their practices.

\section{Theoretical Framework}

This study was examined through the lens of transformative learning theory. As the seminal researcher in this area, Mezirow's 1978 transformative learning theory explained how adults make sense of their experiences and how influences affect this development (Mezirow, 1997). The process involves transforming frames of reference through critical reflection of assumptions, validating contested beliefs through discourse, taking action on one's reflective insight, and critically assessing it (Mezirow, 1997). Two frameworks for transformative learning exist. The first emphasizes personal transformation and change, with critical reflection and critique of assumptions as points of emphasis; and the second emphasizes social change as well as personal change, and the link connecting these two changes (Ettling, 2012). For this study, the focus was placed on the first framework. 
Transformative learning theory asserts that learning can occur gradually or from a sudden, powerful experience, and changes the way people see themselves and their world personally, socially, and professionally (Baumgartner, 2001; DeCapua, Marshall, \& Frydland, 2018). Whether the learning takes place over time or from an intense experience, reflection and dialogue are the pieces of the experience critical to transformation (Merriam, 2004). Reflection takes time, structure, and intention to create a transformation of learning (Merriam \& Bierema, 2014; Mezirow, 2009; Taylor, 2009).

Transformative learning theory continues to be a growing area of study within adult learning and has significant implications for the practice of teaching adults (Baumgartner, 2001; Hoggan, 2016; Merriam \& Bierema, 2014; Mezirow, 2009; Taylor, 2009). The growth is so significant that it seems to have replaced andragogy as the dominant educational philosophy of adult education, offering teaching practices grounded in empirical research and supported by sound theoretical assumptions (Taylor, 2008). As such, Hoggan (2016) defined transformative learning as "processes that result in significant and irreversible changes in the way a person experiences, conceptualizes and interacts with the world" (p. 71).

Cranton and Taylor (2012) asserted that learning could only be called transformative if a fundamental change occurred at a deep level. Designing a program to foster transformative learning which reaches a deep level requires a safe and trusting relationship to be built, engaging the learner in discovery while overcoming fears or preconceived ideas, and acknowledgment of the learner as a whole person (Taylor \& Snyder, 2012). The Outdoor Leadership Experience (OLE) was designed to create a 
transformation of perspective and skill through reflection, discussion, and facilitated activities (Missouri Department of Elementary and Secondary Education, 2019a).

\section{Design of the Study}

A qualitative study was designed to gather information about participants' perceptions. The research methods chosen were consistent with the qualitative case study design of Creswell (2016), as well as Merriam and Tisdell (2016). The components included in the design of this study are participant sampling, site description and selection, methods, and coding procedures.

The methods chosen for this qualitative study for data collection and triangulation included historical data from the Missouri Department of Elementary and Secondary Education, interviews of participants, and focus groups of facilitators. Interviews were conducted until saturation was reached (Seidman, 2013), with a total of 22 participant interviews. Interviews were the primary source of data for this study and were approximately 30-60 minutes, with a conversational style to explore the participants' views. The interviews were based on a set of flexible questions to allow for a more natural flow of conversation.

Focus groups were formed to explore the experiences of participants who became facilitators for the OLE. The focus groups followed a similar questioning pattern to the interviews, again with flexibility, to ensure a natural and honest discourse of the participants' experiences. Focus groups allowed the researcher a unique insight into common perceptions of facilitators, as well as detailed information and personal narratives (Kruger \& Casey, 2009). There were 11 total focus group participants divided over 3 focus groups. 


\section{Setting}

The Outdoor Leadership Experience (OLE) is a four-day experience focused on developing leadership skills in school administrators by placing leaders in an environment outside their normal routine. Facilitators guide them through outdoor adventure, team building activities, and reflection designed to develop leadership skills that can be implemented when they return to their roles. The OLE took place at Camp Rising Sun at Missouri's Lake of the Ozarks from its inception in 1987 until it was moved in 2014 to the YMCA Trout Lodge in the Mark Twain National Forest near Potosi, MO. The OLE has been in place for 34 years, and at this time the impact of leadership skills learned has not previously been studied.

\section{Participants}

Because the Outdoor Leadership Experience (OLE) has been part of Missouri Leadership Academy (MOLA) for 34 years, there was a large pool from which to seek participants. Participants from each of the three decades of operation were contacted. Past participants and facilitators were sent an email describing the study and inviting them to participate in interviews and focus groups to be held at their convenience. Due to COVID 19, interviews and focus groups were held electronically. Potential participants were contacted via email, from a list procured through DESE's Office for Educator Quality that coordinates the Missouri Leadership Development System (MLDS), MOLA, and the OLE.

Participants were, or had been, practicing administrators with varying levels of experience, whether they were facilitators or past participants of the OLE. Some administrators from the early years of OLE were no longer active principals, but their 
participation provided valuable information about the early years of the program and their perceptions of the effect of OLE on their leadership throughout their career. Participants were sought from rural, urban, and suburban schools throughout the state. The researcher was seeking as much diversity in experience, gender, ethnicity, and location as possible. Participants who attended the OLE only as an attendee were interviewed individually. Individual interview participants consisted of 13 men and nine women. They came from 14 rural, four suburban, and four urban school districts. Their average amount of administrative experience at the time of their attendance was 3.43 years. Facilitators who have led groups through the OLE were interviewed in three focus groups of three or four participants. Facilitator focus group participants consisted of nine men and two women. They came from five rural, two suburban, and four urban school districts. Their average amount of experience facilitating the OLE was 9.55 years. There were a total of 33 study participants who shared their perceptions.

\section{Research Questions}

The research questions guiding this study are:

1. What are the perceptions of the participants of Missouri Leadership Academy who attended the Outdoor Leadership Experience?

2. How do participants implement the leadership toolkit skills developed through the Outdoor Leadership Experience in their daily role as Missouri school leaders?

3. How does transformative learning theory relate to the perceptions of the participants' experience?

4. How does the Outdoor Learning Experience impact the participants' commitment to remain a school leader in Missouri? 


\section{Findings}

After analysis of the interview and focus group transcripts, the research questions were answered in full and significant insight was gained. Each participant shared with the researcher their perceptions of the Outdoor Leadership Experience (OLE) and the impacts the experience had on them as leaders. Within these conversations, rich descriptions of their thoughts provided the researcher with a comprehensive and multifaceted perspective of their experiences.

\section{Research Question One: Perceptions}

The first research question asked about the perceptions of the participants. As each individual and facilitator shared their perceptions of the Outdoor Leadership Experience (OLE), the vast majority stated the experience shifted their perceptions of themselves as leaders. Additionally, they spoke of vulnerability, which in turn promoted growth and self-awareness. They also spoke of the diverse groupings as well as being out of their usual environment and how those factors impacted them as leaders.

Peter summarized the experience as "one of the more meaningful opportunities in leadership to really discover more about yourself and about others." Casey claimed, "You will come back with a whole new appreciation of who you are, who others are, and working together to accomplish a goal.” Jason did not initially enjoy the experience. However, as he shared his experience with colleagues and reflected on all the experience contained, he came to a new realization. "I learned more intrinsically about myself from those three days than, arguably, any other time during my educational career. It wasn't until probably two to three weeks after the experience that everything I learned really 
sank in. I had to process. And then the caveat of that is once you know who you are, you recognize your weaknesses and how to work with others."

Of the 33 study participants, only two had differing perceptions. They stated a lack of connection or transformation through their experience. However, both of these participants voiced an aligned vision of the goal of OLE and stated several positive perceptions from the experience. Max shared, "I enjoyed it for the most part. I'm a pretty private, quiet person, I like to observe more than participate in a lot of things. I got frustrated with my group not following what I thought we should do. So I can't say from that experience that I went back and changed how I behaved or how I act or anything like that. There were some positive things about it, but it's just not who I am as far as like being open and sharing and that type of thing. But I did enjoy it and I do like the outdoor stuff."

\section{Research Question Two: Skill Implementation}

The second research question asked how participants implement the leadership toolkit skills developed at the Outdoor Leadership Experience (OLE) in their daily role as Missouri school leaders. The leadership toolkit skills are strategies of decision-making, based upon the work of Tom Leahy, taught to leaders at the outdoor leadership experience to enhance their leadership abilities. Participants listed numerous instances of skills they developed and implemented through the OLE. Participants stated an increased capacity in teamwork, reflection, self-awareness, confidence, listening, and shared leadership. Learning to fail forward, build consensus, and develop skills in others were specifically listed as impactful. The majority of participants also noted that the skills they developed not only made them better leaders, but improved their teams. 
Ross noted "to be able to have those tools and articulate that here's how we're going to do things and why we're doing it this way" was impactful. Daniel said he was aware of some tools prior to attending, "but until you really internalize those and practice those in a situation like OLE, it's not solidified." Tyler noted that "there's always these things that are intentionally challenge by choice. There's low challenge by choice and there's high level challenge by choice, but you learn from them." Prior to attending OLE, Joey felt like he had to have all the answers. When he "went to OLE I found out about the idea of failing forward. I really embraced that.” Acknowledging that he will make mistakes, but "we're going to learn from it and we're going to get back on track. As a leader, you don't have to carry the weight on your own, but you have to build the capacity of those around you so they can help carry the weight."

Jamie believes OLE is designed for this purpose. "I think part of OLE is that we set them up to fail in certain ways because they need to experience that. I think we have to experience that to be forced to remember what it feels like because it's so important for our students to fail forward. That's what life's all about, we're going to fail. But what do you do when you fail? I think that's one of the top things that has to be instilled in everyone."

\section{Research Question Three: Transformative Learning}

Research Question Three asked about the relationship of Transformative Learning Theory to the participants' perceptions of the OLE. Nearly every participant claimed a transformation in some way. Some stated a life-changing transformation, while others merely had a transformation of certain skills or thought processes. Transformative Learning Theory asserts that an event must cause a shift in thinking that is significant in 
order to be transformational (Merriam \& Bierema, 2014; Mezirow, 2009; Taylor, 2009). The majority of interviewed participants and facilitators cited a change in thinking after attendance at OLE, confirming the relevance of Transformative Learning Theory. Judah noted that transformation is at the root of experiential education. "It's an experience that's both visceral and academic that carries with you. I think it's an igniter, not only of ideas but a passion. You can process that experiential education piece there, but then extrapolate that to your home setting." Tim claimed that "as far as the outdoor transfer from non-school activities to school activities, OLE is unmatched anywhere.” Although Jonah has been retired and away from OLE for many years, he could recall how transformational the experience was. "It pushes us out of our comfort zones, but yet it's such a safe environment. It is such a life giving experience that buoys you up for forever. I still carry that and I haven't seen anybody for a long time. It changes your heart, really. It opens up your mind to what real leadership and what relationships are all about in an informal way, but then it carries over."

\section{Research Question Four: Commitment to School Leadership}

The fourth research question asks how the OLE impacted the leaders' plans to stay in school leadership in Missouri. Every single participant stated a desire to stay in Missouri school leadership or revealed that they retired after a long career in educational leadership. Many participants had advanced in their leadership role since their attendance at the OLE. For those who had retired from school leadership, many had moved on to a state level leadership position with Missouri's Department of Elementary and Secondary Education or a Regional Professional Development Center. Many participants cited the impact OLE had on their leadership roles as significant in their growth as leaders and 
their passion to stay in education. Joey responded that "it's ever evolving. The one thing that I think I have decided after OLE is not to pigeonhole myself into one place. Something to do with education for sure; even if it was just to be the principal here the rest of my career, I'd be more than happy." Lacey passionately claimed, "I will stay in school leadership because I'm not done yet with what I came to do."

\section{Recommendations}

Interviewing both participants and facilitators about their perceptions of the Outdoor Leadership Experience (OLE) led the researcher to several recommendations for the future of the OLE. Due to the fact that the OLE has been in place for 34 years, a conclusion can be made that the overall design is effective. This conclusion was confirmed by the study participants. Overwhelmingly, the participants stated their belief that each piece of the experience was impactful regardless of the year or site of participation. However, the facilitators and participants who were interviewed had some memories and unique perceptions. The study led the researcher to create recommendations for the future designers of the OLE.

\section{Maintain the Significance of the Hike}

The comparison of the OLE in the more rustic site at Camp Rising Sun versus the updated site at Camp Lakewood was based more on the hike experience than the camping accommodations. Recollections of the hike from participants and facilitators who attended stated the length of the hike was key. To be out in the woods after dark was an impactful experience and interviewees stated the need to keep this portion consistent. The majority of interviewees stated the hike was pivotal to their growth and application of 
skills. Cindy cautioned, "Don't take out the hike and orienteering. It brings you back to being a learner."

For those who had attended OLE more than once, or were facilitators, there is a comparison point between the two sites. Having the right location is important to consider when designing an impactful hike for teams of adults. The recommendation for the hike is to choose a site that is safe, yet allows for extended time in the woods to ensure that the orienteering portion does not get shortened or watered down based on location or bureaucratic constraints. Casey noted, "I just worry about that for the future and for it to continue to be viable and as impactful as it was."

\section{Advanced Outdoor Leadership Experience}

Interviewees repeatedly noted that they desired another OLE experience. Several mentioned wishing they could go every year and take that time for quality professional development. Having the opportunity to experience the OLE, with an added layer of depth based on previous experience, will allow for advanced leadership development. Furthermore, as leaders gain experience, the depth of learning that could occur is vastly expanded. It was noted by many that OLE was the best professional development they had ever experienced. Daniel claimed the "impact of that over typical professional development is lightyears ahead.” An overwhelming majority of interviewees stated a desire to complete the experience again. Although the logistics and cost involved must be a consideration, participation numbers for a weekend of advanced OLE is predicted to be high.

\section{Ensure a Forced Pause}


Another recommendation is to keep or expand the reflective nature of OLE which requires busy leaders to take a forced pause. Creating a journal, having an entire hour of solo reflection time, and processing aloud during team activities are key points that were noted as impactful by participants. These elements contribute to the forced pause created within the experience. The reflection is the piece that brings all of the experiences together and creates a meaningful impact. Marcia said the reflection during the "alone time in the woods because we got time to write in our journals. I thought, 'Oh my gosh, that was so important because here we were busy, busy, busy and I just needed a little bit of time to collect my thoughts and gather myself."' Judah noted that the processing time "around a common purpose makes it all above and beyond anything else I've experienced, because it's not in isolation. You can learn a skill in isolation, but it's not going to be visceral, it's not going to stick and you're not going to have the application breadth that you're going to have with a common purpose of educators like you have at OLE." Jamie expanded on the theme of reflection. She discussed how facilitators give the participants "time for reflection, we reflect with them. We do a lot of reflection and I think that's one of the things people comment on all the time. They say they are not good about reflecting because we don't take the time. And I think it forces them to take the time and realize how powerful it is."

Additionally, interviewees observed that staying the entire length of the experience is important. Ensuring that participants and facilitators are supported by their districts and can commit to staying from Wednesday afternoon through noon on Saturday is necessary. Additionally, participants need to make the commitment to stay the entire time which will allow them to truly focus on their development. Tim stressed how 
important this is for participants. "It's really frustrating when people are leaving earlier and earlier every year. I think they're missing out on some of the experiences that you can have. We'd rather wait until next year, or a time that you could be there the entire time. Because it seems like the world is not slowing down any. And we need them to slow down for three days and ignore everything that's going on around them. And that's easy for us to say, but there's not a lot of school districts that will say that same thing." A commitment to a forced pause will ensure that the experience is all that it could be.

\section{Train Facilitators}

It was noted that OLE facilitators at one point in history had a required training weekend. The current model of interning for one year with current facilitators has varied levels of effectiveness. Shadowing a pair of current facilitators can give an intern a model to emulate, but not necessarily specific training of facilitator expectations. Facilitation of adult learning requires skill. Jonah noted "working with adults, there's something to that besides having passion, you've got to have a level of expertise." Having consistent training and expectations for facilitators will ensure consistency of the experience for participants. Casey suggested the organizers of OLE "are just relying on that they go as participant, they come back as an intern, and that's the training they get. I think we need training in order to ensure the viability of the experience into the future.” Extended

training for facilitators will ensure consistency of the shared history and program expectations.

\section{Share the History}

The history of the origins of OLE is in danger of being forgotten. The intentionality of design and the passion of the designers to develop administrators in 
Missouri cannot be lost. Many noted that they recognized the intentionality of the design and the facilitators expanded on the why behind most of the activities, but did not have a deep understanding of the history. Although the program has been in place for 34 years, an acknowledgement of the history is necessary to inspire future leaders to carry on with minimal changes to the design. Updates are necessary for every program to be sustainable long term. However, the updates must be made without changing the true nature of the program. Skip noted, "There's a history of OLE that is not contingent upon a place. I think being cognizant of how to structure it in such a way to capture who we are as an entity is important. There are those who have given us so much in the past, and for those who will come after us. And even then... who's coming next? I don't know, but I want to be there to make sure that somebody else has those same tools that were freely given to me to be a better human being."

Generally the history of OLE is shared at the campfire experience. Therefore, designing the campfire to be intentional and impactful will create the opportunity to give depth to the history. One suggestion is to have a campfire more than one night or with each team in a smaller setting so that the connection is deeper. Helping everyone understand how the history of OLE, as well as the connection to nature, creates a bond with all participants through the years.

Interviewees who mentioned the campfire either thought it was inspirational and reflective or it was hokey and turned them off. Those who thought it was hokey were turned off by the singing and the feeling of it being forced. Those who found it inspirational truly reflected on the experience and had an open mind to growth. The hope 
is that in creating more opportunities for the campfire(s) to be meaningful and more personal, participants will embrace the history and call to leadership that is intended.

\section{Conclusion}

There is general agreement in research that leadership development now needs learning opportunities from multiple disciplines and aspects; it is not enough to learn or practice leadership in isolation from context (Owen, 2015). To train our educational leaders in a variety of disciplines, evaluation of the impact of leadership development programs must occur. The longevity of the Outdoor Leadership Academy (OLE) implies value in the program. The reflective nature of the current leadership of OLE, as well as the organizational structure, lends itself to be open to study and feedback. This study about the OLE allowed participants to share their perceptions of their experience and reflect on how their leadership has been impacted by their experience. Through the data analysis, the researcher was able to make recommendations to the designers of the OLE. Knowing the impact this experience has on Missouri school leaders, the state must make every effort to continue the OLE and adhere to the purpose of the original designers. 


\section{References}

Ballard, A., Shellman, A., \& Hayashi A. (2006). Collective meanings of an outdoor leadership program experience as lived by participants. Research in Outdoor Education, 8, 1-21.

Baumgartner, L. M. (2001). An update on transformational learning. New Directions for Adult and Continuing Education, 89, 15-24.

Brymer, E., Gray, T., \& Cotton, W. (2011). Outdoor experiential training as a medium for today's leaders. Journal of Spirituality, Leadership, and Management, 5(1), 58-66.

Covitt, B. (2002). Motivating environmentally responsible behavior through servicelearning. Advances in Service-Learning Research, 2, 177-197.

Cranton, P. \& Taylor, E. W. (2012). Transformative learning theory: Seeking a more unified theory. In P. Cranton, E. Taylor, \& Associates (Eds.), The handbook for transformative learning (pp. 3-20). San Francisco, CA: Josey-Bass.

Cranston, N. (2008). The use of cases in the leadership development of principals: A recent initiative in one large education system in Australia. Journal of Educational Administration, 46 (5), pp.581-597. Retrieved from: https://doi.org/10.1108/09578230810895500

Creswell, J. W. (2014). Research design: Qualitative, quantitative, and mixed methods approaches (4th ed.). Thousand Oaks, CA: Sage.

DeCapua, A., Marshall, H. W., \& Frydland, N. (2018). The transformational 
learning journey of a novice ESL teacher of low-literate adults. Journal of Transformative Education, 16(1), 17-38.

DuFour, R. \& Marzano, R. J. (2011). Leaders of learning: How district, school, and classroom teachers improve student achievement. Bloomington, IN: Solution Tree Press.

Elmore, T. (2018). Marching off the map (2nd Ed.). Atlanta, GA: Poet Gardener Publishing.

Ettling, D. (2012). Educator as change agent: Ethics of transformative learning. In P. Cranton, E. Taylor, \& Associates (Eds.), The handbook for transformative learning (pp. 536-551). San Francisco, CA: Josey-Bass.

Ewert, A. \& Overholt, J. (2010). Fostering leadership through a three-week experience: Does outdoor education make a difference? Research in Outdoor Education 10, 38-47.

Ewert, A. \& Sibthorp, J. (2014). Outdoor adventure education: Foundations, theory, and research. Champaign, IL: Human Kinetics.

Experiential Education Exchange. (2019). Who we are. Retrieved from: https://www.eeestl.org/

Gadja, R. \& Militello, M. (2008). Recruiting and retaining school principals: What can we learn from practicing administrators? ASAA Journal of Scholarship and Practice, 5(2), 14-20.

Goldring, R., Taie, S., \& Owens, C. (2014). Principal attrition and mobility: Results from the 2012-2013 Principal Follow-Up Survey: First look (NCES No. 2014-064). Washington, DC: National Center for Education 
Statistics.

Hayashi, A. \& Ewert, A. (2006). Outdoor leaders' emotional intelligence and transformational leadership. Journal of Experiential Education, 28(3), $222-242$.

Hinge, S. (2016). Can crucible led experiential learning effectively develop business leadership capabilities? New Zealand Journal of Applied Business Research, 14 (1), 37-54.

Hoggan, C. D. (2016). Transformative learning as a metatheory: Definition, criteria, and typology. Adult Education Quarterly, 66(1), 57-75. doi: $10.1177 / 0741713615611216$

Judge, W. (2005). Adventures in creating an outdoor leadership challenge course for an EMBA program. Journal of Management Education, 29 (2), 284 - 300. Retrieved from: https://doi.org/10.1177/1052562904265251

Kafele, B. K. (2018). Avoiding school leadership burnout. Educational Research, 23-26. Retrieved from: www.ascd.org

Kanengieter, J. \& Rajagopal-Durbin, A. (2012). Wilderness leadership - On the job. Harvard Business Review. Retrieved from: https://hbr.org/2012/04/wilderness-leadership-on-the-job

Kass, D. \& Grandzol, C. (2011). Learning to lead at 5,267 feet: An empirical study of outdoor management training and MBA students' leadership development. Journal of Leadership Education, 10(1), 41-62.

Kensler, L. A. \& Uline, C. (2019). Educational restoration: A foundational model inspired by ecological restoration. International Journal of Educational 
Management, 33(6), 1198-1218.

Masters, J. \& Katnik, P. (2019). Missouri Leadership Development System. Retrieved from: https://www.dese.mo.gov/sites/default/files/fas-MLDS-UpdateMasters-Katnik-6-10-19.pdf

Merriam, S. B. (2004). The role of cognitive development in Mezirow's transformational learning theory. Adult Education Quarterly, 55(1), 60-68.

Merriam, S. B \& Bierema, L. L. (2014). Adult learning: Linking theory and practice. San Francisco, CA: Josey-Bass. .

Merriam, S. B. \& Tisdell, E. J. (2016)Qualitative research: A guide to design and implementation (4th ed.). San Francisco, CA: Jossey Bass.

Mezirow, J. (1997). Transformative learning: Theory to practice. New Directions for Adult and Continuing Education, 74, 5-12.

Mezirow, J. (2009). Transformative learning theory. In J. Mezirow, E.W. Taylor, \& Associates (Eds.), Transformative learning in practice: Insights from a community, workplace, and higher education. San Francisco, CA: JoseyBass.

Miller, A. (2013). Principal turnover and student achievement. Economics of Education Review, 36, 60-72.

Missouri Department of Elementary and Secondary Education. (2019a). Leadership Academy. Retrieved from: https://dese.mo.gov/educatorquality/educator-development/leadership-academy

Myers, C. G. \& Doyle, M. (2020). Get adventurous with your leadership training. Harvard Business Review. Retrieved from: https://hbr.org/2020/02/get- 
adventurous-with-your-leadership-training

National Association of Elementary School Principals. (2016). Fixing the leaky principal pipeline. Communicator, 39(12). Retrieved from:

https://www.naesp.org/communicator-august-2016/fixing-leaky-principal-pipeline

National Center for Education Statistics. (2019). National Teacher Principal

Survey 2015-16. Retrieved from: https://nces.ed.gov/surveys/ntps/tables_list.asp

Nelsoney, T. \& Welcome, A. (2016). Kids deserve it! San Diego, CA: Dave Burgess Consulting, Inc.

Owen, J. E. (2015). Integrative and interdisciplinary approaches to leadership development. New Directions for Student Leadership, 145, 49-58. DOI: 10.1002/yd.20123

Peterson, K. (2002). The professional development of principals: Innovations and opportunities. Educational Administration Quarterly, 38 (2), 213-232. Retrieved from: https://doi.org/10.1177/0013161X02382006

Pigza, J. M. (2015). Navigating leadership complexity through critical, creative, and practical thinking. New Directions for Student Learning, 145, 35-48.

Pounder, D. G. \& Crow, G. (2005). Sustaining the pipeline of school administrators. Educational Leadership, pp. 56-60.

Pounder, D. G., Galvin, P, \& Shepherd, P. (2003). An analysis of the United States educations administrator shortage. Australian Journal of Education 47(2). 133-145.

Rangel, V. S. (2018). A review of literature on principal turnover. Review of Educational Research, 88(1), 87-124. doi: 10.3102/0034654317743197 
Riggio, R. E. (2013). Advancing the discipline of leadership studies. Journal of Leadership Education, 12(3), 10-14.

Roberts, N. S. \& Suren, A. T. (2010). Through the eyes of youth: A qualitative evaluation of outdoor leadership programs. Journal of Park and

Saulnier, C. R., Bagiati, A., \& Brisson, J.G. (2014). Design based wilderness education: A cross-cultural experience in engineering education. IEEE Frontiers in Education. Retrieved from:

https://s3.amazonaws.com/academia.edu.documents/36520403/2014FIE.pdf?AW SAccesKeyId=AKIAIWOWYYGZ2Y53UL3A\&Expires=1555566859\&Signatur $\mathrm{e}=\mathrm{G} \% 2 \mathrm{~B} 3 Z \mathrm{jqDDV} 8 V 52 \mathrm{tsEUbvollvQbdE} \% 3 \mathrm{D} \&$ response-contentdisposition=inline $\% 3 \mathrm{~B} \% 20$ filename $\%$ 3DDesign_Based_Wilderness_Education_A_Cros.pdf

Seidman, I. (2013). Interviewing as qualitative research: A guide for researchers in education \& the social sciences (4th ed.). New York, NY: Teachers College Press.

Speelman, E. A. \& Wagstaff, M. (2015). Adventure leadership and experiential education. New Directions for Student Leadership, 7, 89-98. doi: 10.1002/yd

Taylor, E. W. (2008). Transformative learning theory. New Directions for Adult and Continuing Education, 119, 5-15.

Taylor, E. W. (2009). Fostering transformative learning. In Transformative learning in practice: Insights from community, workplace, and higher education (pp. 18-31). San Francisco, CA: Josey-Bass.

Taylor, E. W. \& Snyder, M. J. (2012). A critical review of transformative learning 
research theory, 2006-2010. In P. Cranton, E. Taylor, \& Associates (Eds.), The handbook for transformative learning (pp. 37-55). San Francisco, CA: Josey-Bass.

Vekeman, E., Devos, G., Valcke, M., \& Rosseel, Y. (2018). Principals' configuration of a bundle of human resource practices: Does it make a difference for the relationship between teachers' fit, job satisfaction and intention to move to another school? Educational Management Administration \& Leadership, 46(5), 820-840. doi:

$10.1177 / 1741143217711189$

Williams, S. D., Graham, T. S., \& Baker, B. (2003). Evaluating outdoor experiential training for leadership and teambuilding. The Journal of Management Development, 22(2), 45-59. 


\section{SECTION SIX:}

SCHOLARLY PRACTITIONER REFLECTION 


\section{Scholarly Practitioner Reflection}

A scholarly practitioner reflects in order to develop and grow. Reflection takes time, structure, and intention in order to create a transformation of learning (Merriam \& Bierema, 2014; Mezirow, 1997; Taylor, 2009). Reflecting on my evolution as a leader through the University of Missouri's Doctor of Education program has allowed me to recognize how I have been transformed as I seek to improve my effectiveness as an educational leader.

\section{Leadership in Practice}

Leadership has many facets with slight variances depending on the situation in which the leader operates. "Leadership is a highly sought-after and highly valued commodity" (Northouse, 2016, p. 1). Successful leaders are examined in hopes of replicating their success. While much has been learned about leadership, researchers are still studying leaders to gain empirical support about their assertions concerning the definitive styles, characteristics, or personality traits that cause leaders to prevail (George, Sims, McLean \& Mayer, 2007/2011; Northouse, 2016). Studying what makes leaders exceptional and reflecting on my practice has inspired growth in my leadership abilities.

Evaluating my strengths allows me to continuously sharpen my skills and compensate for weaknesses depending on the situation in which I find myself. Upon completion of the Clifton Strengths Quest, I discovered my top five strengths, in order from first to fifth, to be Positivity, Communication, Winning Others Over (Woo), Adaptability, and Activator (Clifton, Anderson, \& Schreiner, 2006). Additionally, from the 16 Personalities Test, I found that I am an Assertive Campaigner: Extroverted, Intuitive, Feeling, Prospecting, Assertive (ENFP-A) (NERIS Analytics Limited, 2019). I 
have utilized the knowledge of these strengths to interact with others throughout my doctoral journey.

\section{Change as an Educational Leader}

Functioning as a positive and extroverted leader allows me to always look for the best in each person and situation, as well as bring excitement to learning. Although some can see this skill as a weakness that causes me to look past reality, I utilize it in combination with my other strengths to stay positive and focused when tackling a seemingly overwhelming amount of work or an untenable situation. Being adaptable, intuitive, and a communicator, bring flexibility to ideas and information to peers. Wanting to work actively and get tasks done, although not systematic, allows for movement in any situation. Although this does not always endear me to my more strategic peers, my other strengths allow me to communicate the benefits and possible positive outcomes of a plan.

As a leader of an elementary building, I have learned that adults have different needs for learning than students. Bringing forth knowledge, empowerment, and change with adults who have years of experience and emotion is a challenging path to navigate (Merriam \& Bierema, 2014). Being the leader of a staff of 58 teachers and support staff creates a unique environment which is impacted by my approach to adult learning. My

definition of a leader is: someone others turn to in times of difficult decision, for support as well as advice. The process of the doctoral program has solidified my definition of leadership and given research-based support to my thoughts and actions.

Analyzing my leadership of adult learning required me to become honest with myself and vulnerable with staff. My strengths and values impact every decision I make, 
not only in quick decision-making but also in professional development and guidance of our school mission. However, acknowledging my personal beliefs, I have to remember: It's not about me; it's about the organization.

Through the conversations in our school, our teachers have created a collaborative learning culture. Merriam and Bierema (2014) described the need for adult learners to be fully engaged through a variety of activities, for leaders to value their contributions, and an environment that allows for adults to learn from each other and gain personal experience. Creating a school culture with adult learners where they feel safe to have conflicting opinions, knowing they are striving for the best outcome for students, is an accomplishment I am proud of. Kofman and Senge (1993) note, "It is not what the vision is, but what the vision does that matters" (p. 16). The transformations I enable and the actions I take allow the vision I see for our school and stakeholders to be realized. This knowledge has allowed me to be confident in a variety of settings within the field of leadership.

\section{Change as a Scholar}

A colleague in my professional learning network is fond of saying, "Nothing grows in your comfort zone." I truly believe that in order to transform, people must ask hard questions that cause them to be a bit uncomfortable in their quest for growth. Throughout the dissertation process of a qualitative study, I found that I embraced the idea of transformation and growth. Interviewing other leaders about their experiences caused deep professional and personal reflection.

As a leader seeking to create change, having self-awareness of my own values and agenda is necessary for transformational interactions. Ettling (2012) reminds leaders to 
self-evaluate for strengths and weaknesses, be mindful to create a trusting environment, and engage in critical reflection. These principles guided me as I delved into the research process. Being passionate about my topic and embedded in the program I was studying necessitated constant self-evaluation about my biases within my research process. Operating with a desire to create an ethical study with honest and transferrable results caused a scholarly focus and allowed me to rely on the foundation of our doctoral coursework. Writing the dissertation document inspired me to continue scholarly work in other ways and employ research to my decisions and processes.

\section{Conclusion}

Seeking knowledge and attempting to progress as a person and leader has been a journey I have embraced. It is exciting to feel as if I am transforming as a leader, as well as helping others to transform. I am inspired by the learning, work, reflection, and research I have completed through this process. The hope I have for future implementation, reflection, and growth guides my direction as a scholarly practitioner and future researcher. The concept of 'standing on the shoulders of giants' and building on the work of previous scholars spurs me to embed myself in scholarly work and continuous growth in leadership. 


\section{References}

Anderson, N. (2019). Institute for outdoor learning: The impact of outdoor learning. Retrieved from: https://www.outdoorlearning.org/Portals/0/IOL \%20Documents/About\%20Us/IOL\%20-20About $\% 20$ the $\% 20$ Institute\%202019.pdf?ver=2019-04-09-163132-623

Ballard, A., Shellman, A., \& Hayashi A. (2006). Collective meanings of an outdoor leadership program experience as lived by participants. Research in Outdoor Education, 8, 1-21.

Baumgartner, L. M. (2001). An update on transformational learning. New Directions for Adult and Continuing Education, 89, 15-24.

Baruch, J. (2019). Self-actualization assessment tools for leaders and managers. Wilderness. Retrieved from: https://www.coloradocorporateteambuilding.com.

Bell, B., Gass, M., Nafziger, C., \& Starbuck, J. (2014). The state of knowledge of outdoor orientation programs: Current practices, research, and theory. Journal of Experiential Education, 37(1), 31-45.

Bennis, W.G. \& Thomas, R. J. (2011). Crucibles of leadership. In HBR's 10 must reads on leadership (pp. 97-113). Boston, MA: Harvard Business Review. (Reprinted from September 2002)

Bolman, L.G. \& Deal, T. E. (2013). Reframing organizations: Artistry, choice and leadership (5th ed.). San Francisco, CA: Josey-Bass.

Brandt, K. W. (2016). Outdoor Leadership Development Training (Master's Thesis). California State University, San Bernadino. 
Brymer, E., Gray, T., \& Cotton, W. (2011). Outdoor experiential training as a medium for today's leaders. Journal of Spirituality, Leadership, and Management, 5(1), 58-66.

Clifton, D. O., Anderson, E., \& Schreiner, L. A. (2006). StrengthsQuest: Discover and develop your strengths in academics, career, and beyond. New York, NY: Gallop Press.

Covitt, B. (2002). Motivating environmentally responsible behavior through servicelearning. Advances in Service-Learning Research, 2, 177-197.

Cranton, P. \& Taylor, E. W. (2012). Transformative learning theory: Seeking a more unified theory. In P. Cranton, E. Taylor, \& Associates (Eds.), The handbook for transformative learning (pp. 3-20). San Francisco, CA: Josey-Bass.

Cranston, N. (2008). The use of cases in the leadership development of principals: A recent initiative in one large education system in Australia. Journal of Educational Administration, 46 (5), pp.581-597. Retrieved from: https://doi.org/10.1108/09578230810895500

Creswell, J. W. (2014). Research design: Qualitative, quantitative, and mixed methods approaches (4th ed.). Thousand Oaks, CA: Sage.

DeCapua, A., Marshall, H. W., \& Frydland, N. (2018). The transformational learning journey of a novice ESL teacher of low-literate adults. Journal of Transformative Education, 16(1), 17-38.

Drago-Severson, E. \& Blum-DeStefano, J. (2015). Make time to recharge.

Learning Forward, 36(4), 38-42. Retrieved from: www.learningforward.org 
DuFour, R. \& Marzano, R. J. (2011). Leaders of learning: How district, school, and classroom teachers improve student achievement. Bloomington, IN: Solution Tree Press.

Dyment J. E. \& O'Connell, T. S. (2010). The quality of reflection in student journals: A review of enabling and limiting factors. Innovations in Higher Education, 35, 233-244. doi: 10.1007/s10755-010-9143-y

Elmore, T. (2018). Marching off the map (2nd Ed.). Atlanta, GA: Poet Gardener Publishing.

Ettling, D. (2012). Educator as change agent: Ethics of transformative learning. In P. Cranton, E. Taylor, \& Associates (Eds.), The handbookfor transformative learning (pp. 536-551). San Francisco, CA: Josey-Bass.

Ewert, A. \& Overholt, J. (2010). Fostering leadership through a three-week experience: Does outdoor education make a difference? Research in Outdoor Education 10, 38-47.

Ewert, A. \& Sibthorp, J. (2014). Outdoor adventure education: Foundations, theory, and research. Champaign, IL: Human Kinetics.

Experiential Education Exchange. (2019). Who we are. Retrieved from: https://www.eeestl.org/

Gadja, R. \& Militello, M. (2008). Recruiting and retaining school principals: What can we learn from practicing administrators? ASAA Journal of Scholarship and Practice, 5(2), 14-20.

Gans, (2011). Expedition leadership in the wild. Harvard Business Review. Retrieved from: https://hbr.org/2011/04/expedition-leadership-in-the-w 
George, B., Sims, P., McLean, A. N., \& Mayer, D. (2011). Discovering your authentic leadership. In HBR's 10 must reads on leadership (pp.163-177). Boston, MA: Harvard Business Review. (Reprinted from February 2007)

Goldring, R., Taie, S., \& Owens, C. (2014). Principal attrition and mobility: Results from the 2012-2013 Principal Follow-Up Survey: First look (NCES No. 2014-064). Washington, DC: National Center for Education Statistics.

Hattie, J., Marsh, H. W., Neill, J. T., Richards, G. E. (1997). Adventure education and outward bound: Out-of-class experiences that make a lasting difference. Review of Educational Research, 67(1), 43-87. doi: $10.3102 / 00346543067001043$

Hayashi, A. \& Ewert, A. (2006). Outdoor leaders' emotional intelligence and transformational leadership. Journal of Experiential Education, 28(3), 222-242.

Hinge, S. (2016). Can crucible led experiential learning effectively develop business leadership capabilities? New Zealand Journal of Applied Business Research, 14 (1), 37-54.

Hoggan, C. D. (2016). Transformative learning as a metatheory: Definition, criteria, and typology. Adult Education Quarterly, 66(1), 57-75. doi: $10.1177 / 0741713615611216$

Judge, W. (2005). Adventures in creating an outdoor leadership challenge course for an EMBA program. Journal of Management Education, 29 (2), 284 - 300. Retrieved from: https://doi.org/10.1177/1052562904265251 
Kafele, B. K. (2018). Avoiding school leadership burnout. Educational Research, 23-26. Retrieved from: www.ascd.org

Kanengieter, J. \& Rajagopal-Durbin, A. (2012). Wilderness leadership — On the job. Harvard Business Review. Retrieved from: https://hbr.org/2012/04/wilderness-leadership-on-the-job

Kass, D. \& Grandzol, C. (2011). Learning to lead at 5,267 feet: An empirical study of outdoor management training and MBA students' leadership development. Journal of Leadership Education, 10(1), 41-62.

Kavalsky, A. (2018). Veteran carries NOLS lessons to Afghanistan. The Leader. Retrieved from: https://issuu.com/nols.edu/docs/nols-alumni-the-leadersummer-2018

Kensler, L. A. \& Uline, C. (2019). Educational restoration: A foundational model inspired by ecological restoration. International Journal of Educational Management, 33(6), 1198-1218.

Koffman, F. \& Senge, P. M. (1993). Communities of commitment: The heart of learning organizations. Organizational Dynamics, 22(2), 5-23.

Lencioni, P. (2002). The five dysfunctions of a team: A leadership fable. San Francisco, CA: Josey-Bass.

Levi, D. (2017). Group dynamics for teams (5th ed). Thousand Oaks, CA: SAGE Publications.

Magolda, M. B. B. (2009). Authoring your life: Developing your internal voice to navigate life's challenges. Sterling, VA: Stylus Publishing, LLC.

Masters, J. \& Katnik, P. (2019). Missouri Leadership Development System. 
Retrieved from: https://www.dese.mo.gov/sites/default/files/fas-MLDS-UpdateMasters-Katnik-6-10-19.pdf

McKenzie, M. (2002). Research on the Outward Bound process: Implications for practice. Pathways: The Ontario Journal of Outdoor Education, 14(2) 4-8.

Merriam, S. B. (2004). The role of cognitive development in Mezirow's transformational learning theory. Adult Education Quarterly, 55(1), 60-68.

Merriam, S. B \& Bierema, L. L. (2014). Adult learning: Linking theory and practice. San Francisco, CA: Josey-Bass.

Merriam, S. B. \& Kim, S. (2012). Studying transformative learning: What methodology? In P. Cranton, E. Taylor, \& Associates (Eds.), The handbook for transformative learning (pp. 56-72). San Francisco, CA: Josey-Bass.

Mezirow, J. (1997). Transformative learning: Theory to practice. New Directions for Adult and Continuing Education, 74, 5-12.

Mezirow, J. (2009). Transformative learning theory. In J. Mezirow, E.W. Taylor, \& Associates (Eds.), Transformative learning in practice: Insights from a community, workplace, and higher education. San Francisco, CA: JoseyBass.

Mezirow, J. (2012). Learning to think like an adult: Core concepts of transformation theory. In P. Cranton, E. Taylor, \& Associates (Eds.), The handbook for transformative learning (pp. 73-95). San Francisco, CA: JoseyBass.

Miller, A. (2013). Principal turnover and student achievement. Economics of 
Education Review, 36, 60-72.

Missouri Department of Elementary and Secondary Education. (2019a).

Leadership Academy. Retrieved from: https://dese.mo.gov/educatorquality/educator-development/leadership-academy

Missouri Department of Elementary and Secondary Education. (2019b). Missouri

Leadership Development System. Retrieved from:

https://dese.mo.gov/educator-quality/educator-development/missourileadership-development-system

Missouri Department of Elementary and Secondary Education. (2019c).

Department Offices. Retrieved from: https://dese.mo.gov/department-offices

Missouri Department of Elementary and Secondary Education (2019d). Missouri

Leadership Development System. Retrieved from: https://dese.mo.gov/educatorquality/educator-development/missouri-leadership-development-system

Myers, C. G. \& Doyle, M. (2020). Get adventurous with your leadership training. Harvard Business Review. Retrieved from: https://hbr.org/2020/02/getadventurous-with-your-leadership-training

National Association of Elementary School Principals. (2016). Fixing the leaky principal pipeline. Communicator, 39(12). Retrieved from: https://www.naesp.org/communicator-august-2016/fixing-leaky-principal-pipeline National Center for Education Statistics. (2019). National Teacher Principal Survey 2015-16. Retrieved from: https://nces.ed.gov/surveys/ntps/tables_list.asp Nelsoney, T. \& Welcome, A. (2016). Kids deserve it! San Diego, CA: Dave Burgess Consulting, Inc. 
NERIS Analytics Limited. (2019). 16Personalities: Jenni Hayes - The Campaigner.

Retrieved July 2, 2019, from

https:///www.16personalities.com/profiles/b39a1cb167514

NOLS. (2019a). Annual report 2018. Retrieved from:

https://www.nols.edu/en/annual-report/

NOLS. (2019b). Our History. Retrieved from:

https://www.nols.edu/en/about/history/

Northouse, P. G. (2016). Leadership: Theory and practice (7th ed.). Thousand Oaks, CA:

Sage

Outward Bound. (2019a). Outward Bound today. Retrieved from:

https://www.outwardbound.org/about-outward-bound/

Outward Bound. (2019b). Outcomes. Retrieved from:

https://www.outwardbound.org/about-outward-bound/philosophy/outcomes/

Outward Bound. (2019c). History. Retrieved from:

https://www.outwardbound.org/about-outward-bound/outward-boundtoday/history/

Owen, J. E. (2015). Integrative and interdisciplinary approaches to leadership development. New Directions for Student Leadership, 145, 49-58. DOI: $10.1002 / y d .20123$

Passarelli, A., Hall, E., \& Anderson, M. (2010). A strengths-based approach to outdoor and adventure education: Possibilities for personal growth. Journal of Experiential Education, 33(2), 120-135. doi: 10.5193/JEE33.2.120

Peterson, K. (2002). The professional development of principals: Innovations and 
opportunities. Educational Administration Quarterly, 38 (2), 213-232. Retrieved from: https://doi.org/10.1177/0013161X02382006

Pigza, J. M. (2015). Navigating leadership complexity through critical, creative, and practical thinking. New Directions for Student Learning, 145, 35-48.

Pounder, D. G. \& Crow, G. (2005). Sustaining the pipeline of school administrators. Educational Leadership, pp. 56-60.

Pounder, D. G., Galvin, P, \& Shepherd, P. (2003). An analysis of the United States educations administrator shortage. Australian Journal of Education 47(2). 133-145.

Rangel, V. S. (2018). A review of literature on principal turnover. Review of Educational Research, 88(1), 87-124. doi: 10.3102/0034654317743197

Riggio, R. E. (2013). Advancing the discipline of leadership studies. Journal of Leadership Education, 12(3), 10-14.

Roberts, N. S. \& Suren, A. T. (2010). Through the eyes of youth: A qualitative evaluation of outdoor leadership programs. Journal of Park and Recreation Administration, 28(4), 59-80.

Rochelle, S. (2018). Research connects wilderness experience with stronger problem-solving skills. NOLS. Retrieved from: http://blog.nols.edu/ 2018/08/28/research-shows-better-problem-solvinglearned-in-wilderness.

Rooke, D. \& Torbert, W. R. (2011). Seven transformations of leadership. In Harvard Business Review: On Leadership (pp. 137-161). Boston, MA: Harvard Business School Publishing Cooperation. (Reprinted from April 2005) 
Saulnier, C. R., Bagiati, A., \& Brisson, J.G. (2014). Design based wilderness education: A cross-cultural experience in engineering education. IEEE Frontiers in Education. Retrieved from:

https://s3.amazonaws.com/academia.edu.documents/36520403/2014FIE.pdf?AW SAccesKeyId=AKIAIWOWYYGZ2Y53UL3A\&Expires=1555566859\&Signatur e=G\%2B3ZjqDDV8V52tsEUbvollvQbdE\%3D\&response-contentdisposition=inline $\% 3 \mathrm{~B} \% 20$ filename $\%$ 3DDesign_Based_Wilderness_Education_A_Cros.pdf

School Leaders Network. (2014). CHURN: The high cost of principal turnover. Hinsdale, MA: School Leaders Network.

Seaman, J. \& Rheingold, A. (2013). Circle talks as situated experiential learning: Context, identity, and knowledgeability in "learning from reflection". Journal of Experiential Education, 36(2), 155-174.

Seidman, I. (2013). Interviewing as qualitative research: A guide for researchers in education \& the social sciences (4th ed.). New York, NY: Teachers College Press.

Shooter, W., Paisley, K., \& Sibthorp, J. (2010). Trust development in outdoor leadership. Journal of Experiential Education, 33(3), 189-207.

Speelman, E. A. \& Wagstaff, M. (2015). Adventure leadership and experiential education. New Directions for Student Leadership, 7, 89-98. doi: 10.1002/yd

Southern Illinois University. (2019). Touch of Nature. Retrieved from: https://ton.siu.edu/index.php

Taylor, E. W. (2008). Transformative learning theory. New Directions for Adult 
and Continuing Education, 119, 5-15.

Taylor, E. W. (2009). Fostering transformative learning. In Transformative learning in practice: Insights from community, workplace, and higher education (pp. 18-31). San Francisco, CA: Josey-Bass.

Taylor, E. W. \& Snyder, M. J. (2012). A critical review of transformative learning research theory, 2006-2010. In P. Cranton, E. Taylor, \& Associates (Eds.), The handbook for transformative learning (pp. 37-55). San Francisco, CA: Josey-Bass.

Tennant, M. C. (1991). The psychology of adult teaching and learning. In J. M. Peters, P. Jarvis and Associate (Eds.) In Adult education: Evolution and achievements in a developing field of study. San Francisco, CA: Josey-Bass.

Timken, G. L. \& McNamee, J. (2012). New perspectives for teaching physical education: Preservice teachers' reflections on outdoor and adventure education. Journal of Teaching in Physical Education, 31, 21-38.

Tisdell, E. J. (2012). Themes and variations of transformational learning: Interdisciplinary perspectives on forms that transform. In P. Cranton, E. Taylor, \& Associates (Eds.), The handbook for transformative learning (pp. 21-36). San Francisco, CA: Josey-Bass.

Vekeman, E., Devos, G., Valcke, M., \& Rosseel, Y. (2018). Principals' configuration of a bundle of human resource practices: Does it make a difference for the relationship between teachers' fit, job satisfaction and intention to move to another school? Educational Management Administration \& Leadership, 46(5), 820-840. doi: 10.1177/1741143217711189 
Whitaker, T. (2012). What great principals do differently (2nd ed.). New York, NY: Routledge.

Williams, S. D., Graham, T. S., \& Baker, B. (2003). Evaluating outdoor experiential training for leadership and teambuilding. The Journal of Management Development, 22(2), 45-59.

Wolfe, B. D. \& Kay, G. (2011). Perceived impact of an outdoor orientation program for first-year university students. Journal of Experiential Education, 34(1), 19-34. doi:10.5193/JEE34.1.19 


\section{Appendix A}

Interview Questions

Purpose statement: The purpose of this study is to understand how the skills learned at OLE are perceived to impact school leader effectiveness.

\begin{tabular}{|c|c|}
\hline Interview Question & $\begin{array}{l}\text { Research } \\
\text { Questions }\end{array}$ \\
\hline 1. Could you tell me a little about yourself? & \\
\hline 2. How long have you been a school leader? & RQ4 \\
\hline 3. When did you attend OLE? & \\
\hline 4. How many years of experience as a school leader did you have & \\
\hline when you attended? & \\
\hline 5. What was your Kolbe? & RQ1 \\
\hline 6. Please share your thoughts with me in regard to the OLE? & RQ1 \\
\hline 7. Have you ever attended an experience that was comparable to OLE? & RQ1 \\
\hline If so, how did your perceptions correlate? & \\
\hline 8. What were your most impactful experiences at the OLE? & RQ1 \\
\hline 9. How would you characterize the elements of OLE? (I.E. & RQ1 \\
\hline Physicality, Trust, Teamwork) & \\
\hline 10. What was your familiarity with the toolkit strategies you learned at & RQ2 \\
\hline OLE? & \\
\hline 11. What was your comfort level with the activities engaged in during & RQ1 \\
\hline the OLE? & \\
\hline
\end{tabular}


12. Think of a difficult situation you have had to resolve as a leader. How would you have handled it prior to attending OLE? How would you handle it after attending OLE?

13. How has your attendance at the OLE impacted your daily leadership RQ2 activities as a school leader?

14. In what ways do you feel the OLE impacted your professional network outside of your local school district?

15. What would you tell someone who was thinking about attending the OLE?

(If Needed) What would you tell them to physically prepare for? What would you tell them to mentally prepare for?

16. What would you tell the leaders of OLE as far as the design? What would you keep, take away, or add?

17. What is your plan for your future as a school leader?

18. Is there anything else you feel I should know about your experience at the OLE?

\section{Interview Responses}

Question 6: Please share your thoughts with me in regard to the OLE?

Blake: I enjoyed it. Of course I had a farm background. So a lot of the stuff I know how to do I actually had two backgrounds. I had when I first started teaching I taught for four years. and then basically went to work as a soil conservation office, and then went back into teaching. I was working on my master's degree. And that gave me experience with 
the topography maps and doing that type of stuff. So some of that stuff I was really comfortable with. But again, I really enjoyed it and then they grouped us with a bunch of people with a lot of different backgrounds. You know I was coming from an Ag background and I had to deal with people from a totally urban background. Of course a lot of that is to teach you to work together and, and to utilize each other's skills and that type of thing. And the facilitators I thought did a real good job and I got to know other people too.

Brady: I didn't really want it to end so mainly it was about better connections with other people. We built some friendships and a lot of emoticons spun off and then haven't heard from them, but it was good at the time to be able to share ideas and to know what was happening in different places of the state.

Cindy: I enjoyed it, I felt like I learned a lot about myself. I did not have the experience of, Oh, this is a group that I have bonded with and will be with forever. I mean, everybody talks about that. That wasn't how my group operated.

Daniel: The intermingling, and the coming together of educators in that different environment. Just the connection and I remember really enjoying that. Feeling refreshed, that no one really understands. I mean, you have the people you work with and they're great support but it was just neat to see people from all over the state coming together who were interested in leadership, interested in education. You're interested in growing and taking next steps and whatever their leadership journey is. And just the feeling of that was really good. It felt energizing. It made me want to do more. There's just something about the humanity of the experience, and it was really cool. 
Greg: Overall, a very good experience. I made a lot of professional contacts, through that, that, that I still have today. The both the personal aspect as well as the professional learning that took place with that was beneficial, probably would have been more beneficial if I would have been in a different time in my career. I probably didn't take it as seriously as I should have to be honest with you. I think if I would have waited a little longer, maybe I would have been grounded a little bit more in the profession. More focused on what my long term goals or outcomes were.

Janice: I thought it was a wonderful experience because it brings leaders from across the state in different roles, such as we're not all assistant superintendents we're not all principals. We come from all roles together; we actually live, eat, and play together. And so I think it brings a rich conversation to leadership, because we're looking through different lenses of what are our current issues and what's most important to each one of us. For me, coming to the OLE reduced the stress of posturing. I found it to be refreshing that we could all meet as human beings on the same level.

Jason: I thought it was an absolutely wonderful experience. I learned more intrinsically about myself from those three days than, arguably, any other time during my educational career. It wasn't until probably two to three weeks after the experience that it really sank in everything that I learned. I had to process. Like when we sang the songs at the campfire and stuff I know everybody loved that I could have gone home right then. I was like, this is ridiculous. I don't want to sing a song with you. There were aspects that I did not care for. It wasn't that there was anything wrong with them. They just weren't for me. A lot of the team building stuff was wonderful. And also, what frustrated me a lot. I had 
to learn that my personality type is not the easiest to work with. I see that goal and I want to go and I don't necessarily care about details and a lot of people need to know that stuff. Jeanie: What I found interesting was who sort of rose to that almost immediate leadership role, and in the whole idea of trust, so that person stood out. And they might not have been an extrovert, they could have been just one of those very backlight people. But it was interesting to see who rose and who was accepted. And who was listened to. So it was really interesting to see who was given that trust.

Joey: First, it was an amazing networking event, to be a part of. Even to this day, over a year later, the rabbit group I was a part of we stay in contact with each other probably once a quarter. The little book that we got with the protocols in it has been very helpful in how to facilitate adult learning. And then building out a team. The other thing that we talked about is just being able to depend on each other or looking at things in detail, really understanding the whole process before you dive in. So there were a lot of things we got from those protocols that I was able to come back and implement right away.

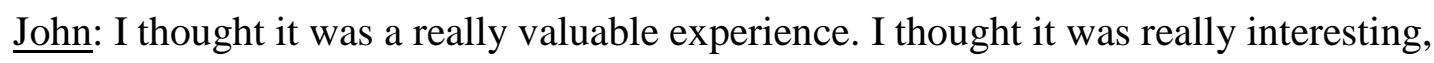
because we were paired with people who we didn't really know that well. And I think they probably intentionally paired you with people who were quite opposite than you. It just seemed like we were a good mix of different personalities, different strengths. Honestly, I thought it was a good team building type of experience. I think I learned a lot about myself, just the way that I work and the way that I think is way different than other people. So that helped me to be able to just reflect on how I lead or how I attack problems, compared to others. It was eye opening. 
Lacey: There are some stories about us. Okay. It was the year that it was like the perfect storm of heat and moisture. So the bugs weren't dead, they were alive and well.

Luke: The thing that I remember most was probably like the challenges that we would have to do and trying to figure them out. But I also obviously remember walking through the dark and all that orienteering, which was fun. I enjoyed that. And then the group members. It's odd because there's people in my group that like I still talk to and communicate with today. There's definitely some of those bonds obviously are longer than others, but it's nice to be able to keep in touch with some people. And some of those people are in different situations than I am. But overall we can lean on each other, especially in a year like this: How do you run virtual and how do you support teachers in that role as well? So it's nice to expand your network.

Lydia: I think one of the things that keeps coming back to me is how it really tested my empathy. I was in a group with a lot of people from urban districts. And they would just look up at the stars and go, 'Isn't this beautiful?' And I'm like 'yeah, yeah, yeah, let's go!' So, yeah, empathetic with people and differences and what really drives people and maybe appreciation for differences of others. The rock wall. I still go back to that. Climbing that rock wall and thinking I couldn't do it and then I did it. Then I wanted to go up the bigger one. Just having a little bit of confidence in myself and I decided if I can climb a rock wall, then I can be a leader.

Marcia: It was challenging, but I'm an outdoor person. I felt like it was probably one of the most rewarding things I'd done with a group, because if you wanted to get done you had to rely on each other. We had people that wanted to take charge and we had people that wanted to be led. And so it was a really unique experience because it would ebb and 
flow throughout the hours that went by. It's like running a marathon. I felt like afterwards, I accomplished something bigger than myself. Max: I enjoyed it, and for the most part. I'm a pretty private, quiet person, I like to observe more than participate in a lot of things. I got frustrated with my group not following what I thought we should do.

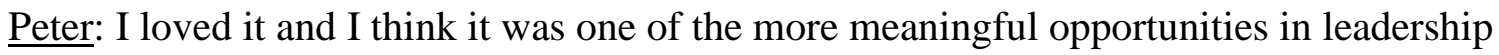
to really discover more about yourself and about others. You're also networking, which I love. We did an activity at the end of it that I loved, just so much, and we're essentially everybody just speaks into the individuals life of what they saw on that person and just super powerful lots of tears and so I think the whole week he did a great job of designing us for success. And the hike. Everyone talks about the kike. It's really about experiences and everyone comes from a different place and how they choose to handle it. I think you also recognize people who desire significant control and then people who are more willing to give up control and allow others to lead. It says a lot about who people are as leaders and I think it builds on the social intelligence of individuals. I think it is a microcosm of what we try to do on a continual basis as school leaders. They're able to grow in a lot of ways that they've never grown before in their life. So I think if you're in a position to be vulnerable, it can be one of the most impactful moments, or leadership experiences in your life.

Phoebe: I think the best part of it for me was that it was a chance to get away and do something I don't normally get to do. I had to make decisions but it wasn't the same. I got to focus on myself and just think about things and reflect. I think that was the biggest thing. I got to slow down and reflect on my practice and my leadership, and just think 
about how I could do better. I would do OLE every year. If I was given the opportunity. I was doing a lot of leadership within teaching when I went the first time. But when we were sitting around the fire in 2011. They had us all come up and we had to share some thoughts and it was when I was sharing those thoughts that it clicked for me. That I do want to make a bigger impact. I do want to go into administration and so that became my goal after the first time.

Ron: Yeah, so I got into leadership academy because my head principal had gone through it. He's like, this is something you need to do this is you know if school admin is where you think you are going to be, then this is something you need to attend. Going into OLE, all I had heard was the horror stories of the hike in the woods. So I didn't really know what to expect, but was looking forward to it, and definitely went in with open arms and was excited about it. There were 12 of us when we first got there that first day. And when we left there were only six of us left. The six of us were extremely close and bonded deeper than you would ever think that you could get to know somebody in the course of three days or so.

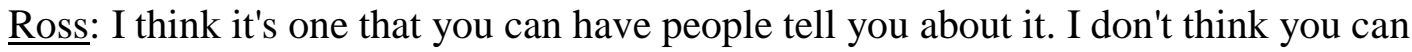
grasp it until you do it. I don't think you're gonna understand the impact because it is impactful for a number of reasons. Whether it's the different activities you engage in, or whether it's the different leadership styles that you interact with, I don't know. It's neat to see everybody's personality come out in different ways. How often do you get a couple of days of uninterrupted professional development or uninterrupted time with peers and colleagues where you can really focus on leadership and learning from other people? So, yeah, it's definitely impactful. And then, then you're left with all the chigger bites. 


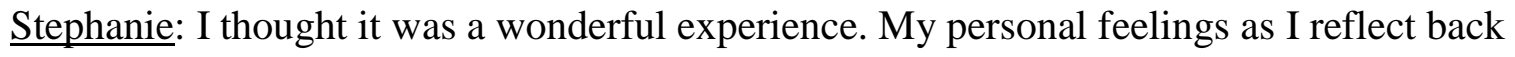
on that I went way too soon in my career as a principal because I was just so unsure of everything that I was doing. I was just taking it all in. I didn't feel like I had a lot to offer the team. I was just more of sitting back and observing and then starting to second guess myself. I very much enjoyed the networking of when we were sitting around the campfire and people were being very open and honest.

Trent: Some people said you will have this huge cathartic experience that will change your life. I tell people I had a fun time and I enjoyed it. I talked with people and walked around the woods and had some fun and just goofed off it. It wasn't some sort life changing altering moment. I liked the orientation part of it. I just didn't see the value of doing the corny campfire. If we were doing some funny songs for camaraderie, I like that stuff. Some of the cornier stuff, like the deep philosophical cathartic moment that people claimed just seemed forced. I don't think it loses its value, because it's not a cathartic experience.

Tricia: I think it was a great opportunity to network to learn from people who were already in the profession. The skills that it taught you. I think it helped build character, helped shape your leadership style because I think once you understand what your style is and getting to know what the people around you, what their style is, you learn how to compromise and how to really take the best of everybody. And work together. So I think the team building that it promoted was awesome. It was a great experience. I mean I would have done it every year, if I could. One of the best things I've ever done as far as leadership goes. 
Question 7: Have you ever attended an experience that was comparable to OLE? If so, how did your perceptions correlate?

Blake: I've never gone to say anything quite like that and I think that's what made it special.

Brady: Yes, in high school we had student council leadership camp in Fulton. The leadership lessons and team building correlate.

Cindy: I haven't.

Daniel: No. Maybe church camp as a kid, had a similar vibe.

Greg: No, not the full package deal.

Janice: We did a lot of team building activities in my old district. We went axe throwing, picnics, traveled together, lots of outside the classroom activities.

Jason: Probably not from a leadership standpoint, not as far as pressure professional development. However, as a young man, my dad and my uncle, and myself, we used to do history reenactments.

Jeanie: NO. I think it's probably the most powerful learning experience that I had. And I was glad I had the outdoor learning experience Outdoor Leadership experience, simply because it helps you see things from different perspectives. And I think that just helps you as you come across situations or, or issues that you have to deal with. You really think about that whole idea of perspective.

Joey: Basic Training in the Airforce. Paying attention to the detail, understanding the full picture of something before just diving in. And then really that just like tearing down those layers, and then building them back up better. Basically, overcoming obstacles and then being able to see something through to the end. 


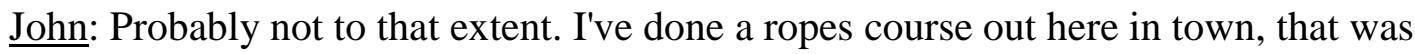
similar, but it really wasn't as extensive.

Lacey: Church camps growing up. They sent you out and made you form a group, it did not have the intellectual component of finding your compatibilities. It was Christian based.

Luke: As far as the actual activities, probably not. As far as trying to bring a team together from different backgrounds and trying to figure out your strengths and negotiate like everybody being a leader. Everybody negotiating when to back off and not be a leader like I am at the school. I would say my doctorate was probably the closest experience I've had to that.

Lydia: No. Never.

Marcia: Not to that extent. I had done some team building but nothing like OLE. Max: Not that I can think of.

Peter: No.

Phoebe: Nope, I wish.

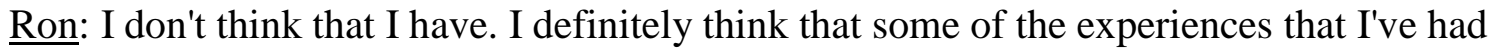
afterwards are a reflection of what it was like to go through OLE, just because of having attended.

$\underline{\text { Ross: }}$ You know in college in a fraternity, we had a hell week. The end result and end goal is different or two different experiences but I think the similarity is that you are spending a big chunk of time, with a small group of people, and you are working together to find a common goal. You're working together, and playing off of each other's strengths and weaknesses. You're learning a lot about yourself. 
Stephanie: I have not. No.

Trent: As far as going out woods thing? No.

Tricia: I can't say that anything other than working with my doctorate, I guess, but honestly No, I don't think there's anything I've ever been through that compared to what the experiences were you got from OLE.

Question 8: What were your most impactful experiences at the OLE?

Blake: Probably was working with people from different backgrounds.Coming from a small rural area, dealing with people from the big urban areas. And some of the things they dealt with and some of the ways they had to try to handle problems which we never dreamed of having those kinds of problems. Then I guess the other part is the collaboration and trying to work with everyone just once again. When you have someone that has a very different background, that thinks quite a different way than what you think. Being able to work together, respect other people's opinion and if it's far different than your opinion and be willing to look at it, and evaluate it for its worth. And, and if it would work in your system or not and, and just be willing to try those things. But a lot of collaboration. I think that taught me as a school administrator Respect: Respect my teachers, respect their opinions, respect my principals opinions, counselors, support staff, you know, everyone. So, yeah, I guess that's probably the main thing. I think that a lot of people were uncomfortable in the whole environment.

Brady: She built her, her identity, being so strong that she didn't need any help. She didn't want anybody to help her. She was that person who's going to be the rock for everybody else, and never asked for help. And that was who she was and she just couldn't be that person she, she had to rely on someone else she had to give up that. Being so humble, she 
had to accept help, because it was required to get as the team for us all too, she was the one she had never been that one, she'd never been the weak link in the cog of leadership and getting something accomplished. She didn't want to be looked at as the person who could not meet the task. And yet there she was and she just had a hard time with that real realization that is going to take more than just herself to be successful. And it's okay to ask for help and to need help to get across, whatever line you're trying to get across. You might have to have some people at your side, and they might have been carrying your stuff. And it's okay to do that. So anyway, that was. You can tell that was, that was huge for me. There was something that happened where there was nobody who was going to forge ahead without the group, and no one was going to give up without the group. We knew we were all in this together from the get go. And then are you willing to give up your lead to someone else who you think might have the better idea. It's just phenomenal. Cindy: The trek, There were so many learning pieces there: you had to learn how to use the compass and how to use the maps, you had to learn how to be a leader, but you also had to learn how to be a follower. You had to learn how to communicate. We're sitting there and there's like, controversy on which way we should go, or you know, what we should do? And he looks at me and he says, so what do you think? What would you do when you're faced with a decision and you don't know what to do? And I just looked at him, I said, I think I'd sleep on it. He was like, well, we're not going to sleep on it tonight. I said, No, we'll make a decision. I said, but if it's really big to where it's that pressing and I said I'd probably give myself some time, but I think that realizing when you get pushed to that corner where you have to make a decision, and you're not sure what the right decision is. That was a reality check, I guess of what's to come. 
Daniel: Oh, I remember the orienteering team and we had to learn how to read a compass and we were all going to go together as a team. Rappelling I definitely remember because I'm terrified of heights. But I do remember it was challenge by choice. You know it wasn't like you had to do it. But I wanted to, I didn't want to not do it.

Greg: It helped me to evaluate myself personally in regards to my take as a leader. How I present myself as a leader, what my role in a leadership team is. Not always having to take the lead, but being able to step back and take perspective from other directions. That was very beneficial from those team building activities. And then the second one is to be able to see the different dynamics from leaders from across the state. What they bring to the table and how their vision and perspective can impact a common goal and achieve success for the team.

Janice: The friendships that I made at OLE. It's insane. But in that short amount of time. I am still tight friends with some people from across the state that I only spent a weekend with. It's amazing to me. And it had to be the way the experience was framed and the way the activities were planned to remove the layers. So you can see each other as more human.

Jason: It was not the reflection and the journaling aspect. But the personal reflection two to three weeks later, some of the incidents at the time that I struggled so much with, and then in hindsight, and I guess what really made the breakthrough was when I came back and people asked me about how it was. And I remember when we started, I guess in my mind, it was a it was a competition. It was a race, we're going to get all 12 flags and be the first one out of the woods. And I don't want to say it was me versus my group. But I in hindsight, I thought I can do this without you guys....And I think we sat on top of that 
hill for 20 minutes. And well, what do we do here? What do we do? I'm not telling you! I threw a temper tantrum, very immature. It was horrible. I didn't get my way and people weren't listening to me, so I revolted. So I had some wonderful leaders in my group, absolutely wonderful, that finally pulled me aside and said the purpose of this expedition is for you to grow as a leader. Not to make people follow you. And so what they advised me to do was to work in lead from behind the group. That was difficult for me. And they kept dragging me back to the goal and away from the goal is not to get the flags and be the first out of the woods. The goal is to grow as a leader, and you tramping around the woods and telling everybody else to follow you is not a leader. That's just a guy tramping around in the woods. In the beginning, there was clearly a divide between me and my group. And that went away by the end of the hike. And we became super close.

It was dark and we were lost. Our guide said, trust your instincts and go anyway. And as far as looking back, you know that three weeks later, that tip of advice from the lady with the GPS was so true. Things always seem farther in the dark when you don't exactly know where you're going, you don't exactly know where you're at. But she said, don't let them get scared. Just keep going.

All those things made me a better leader. At the time, I was just too immature to realize that I was. I was just too immature to realize that it took me three weeks and telling my wife how infuriating the experience was to realize how amazing it actually was for me. I love my group individually, every single one of them was an absolutely amazing person. As a group, I don't know that I want to take them into the woods again. I'm trying to win a race and they're trying to survive, like literally. 
Jeanie: Providing space or opportunity for folks who might not be one of those powerful people to really show you where they're coming from, and the value that they have in that thought process. And I'm thinking that it was so powerful. In that moment of being put in a situation (rappelling), you really did have to trust someone other than yourself. And the value of that. And so you know, there are lots of things in our jobs that we may not like doing. But from that, we have the confidence to do difficult things.

Joey: A lot of that stuff we went through really helped bond us, and really just grew a trust in just three days that many of us didn't even have with our administrative team that we've worked with for a year or more. It was an amazing experience. I'd highly recommend it to people to go in and just really find out more about yourself that you didn't know was in you.

John: I think the most probably the most impactful would be the times where we had time to sit and talk and reflect as a team about how we attacked something or how we did this, and to hear other people's perspective. That really changed my thinking because we don't often hear people process out loud. Hearing other people's perspectives and know that there's a rhyme and reason for the way that people think and process.

Lacey: I tend to struggle maybe with self confidence. When you're making decisions that impact a lot of people, where there is not one answer and a lot of right answers, but maybe a best answer at times, I can start to second guess myself. And so I'm quick to give it to someone else, if they step up and if they're louder than me, or they're quicker, I tend to be quiet. And just, I'm a good follower, or if I need to be, I'm a team player. I learned leaders are not good followers, and they're not good at admitting when they don't know how to do something. So that was eye opening to me because I was wondering 
'how do you not see that you clearly don't know how to do that? Especially when you're in the woods, in a real life situation. I started to voice it. And finally, that it just tables turned for me at that point. I became a different person among leaders. It was the first time I stepped up amongst my peers and thought I might be good enough to do something. And it just gave me a surge, though that was a tiny moment, allowing myself to be what I want it to be. That was a moment that's made a big impact in the latter part of my career.

Luke: Probably just reframing how I think about situations. Stopping and thinking about my initial reaction. But from a different perspective, some people may take it this way or it may be viewed this way. So in problem solving, especially just think of taking the time to step back and then look at it from multiple lenses.

Lydia: Having empathy. Getting to know people from other parts of the state, not just little rural All different types of school districts and where they are. And what's important to them, as opposed to what's important for us.

Marcia: When one person got tired. We had to rely on others. So I feel like that's really important and leadership you know there's going to be times where you have to allow the other people around you to help you make the decisions to get from point A to point B and that's okay. And then just that collegiality. Let's make an informed decision but stay together.

Max: I regret bowing out at the midway point of that late night hike. But nothing in particular stands out.

Peter: It was the culminating event that he had us do. We spoke into each individual and the impact that had on each individual's life. To give them the courage, to give them the 
affirmation that is needed to say I'm a leader. If you're a leader who doesn't question your own leadership, then you're probably an arrogant leader. It creates such a rightful place for people to be vulnerable, for people to be coached to grow.

Phoebe: Both times it has been the hike. And then the time to reflect. Building trust with people I don't quite know takes me a long time. Just that balance of depending on others and letting them depend on me, I don't know. So, the hike was probably the most valuable, and then the reflection and the journaling was huge for me, too. Ron: I definitely think it had to be the hike in the woods. I think that that was definitely the point of the trip where we bonded. So I set out at the beginning like, 'Alright we're gonna get through this as fast as we can.' And then by the end of it you realize that's not what it's about it all. So it was good.

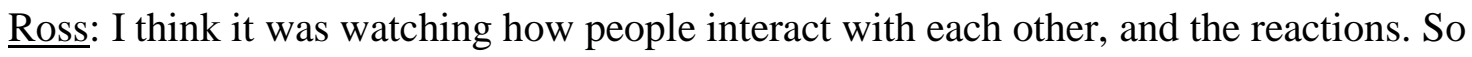
what I took away from that is: it's important for me to think about what I say and how I do things and how it's going to impact others, whether it's going to make them want to do what I want them to do, or is what I'm about to say and how I'm going to say it going to make them do the exact opposite. And more from the hike, there were instances where sometimes you just gotta make a decision and do it. If it doesn't work, we'll turn around and go back the opposite direction. And that's not necessarily my predominant leadership style or my personality.

Stephanie: When we were doing the hike, just seeing how people were getting tense and irritable with one another. Really over my years I reflected because I had gone through some experiences with bickering. I could connect those two experiences with those that were not very good listeners and went off of professionalism and got more personal. 
Those two experiences connected for me and I realized that in the big picture I don't like heated debates. As we went on our little journey everybody brought something different to the table. Even our leadership team here at school, we've been having those conversations about how everybody has a different personality and brings something different and positive to the team and that's what makes a good cohesive team.

Trent: I enjoyed helping other people during the hike. There was another administrator, someone that somewhat relied on me to get through. And then that's another thing is the inefficiency process if you don't mind, your best people aren't doing what they're good at waste a lot of time doing that.

Tricia: Honestly, I think they all work. I mean every single thing that you did seemed to add just another level to what you were already learning. The leadership around the campfire, the things that we talked about, and again the networking and the friendships. I honestly can't say that any one piece alone was more powerful than the other I think just combined it was the whole experience was just impactful.

Question 9: How would you characterize the elements of OLE? Think big, overarching themes.

Blake: Collaboration and the teamwork, what you're going to have to do to try to accomplish it. Not get too frustrated, you know some of the people come back in the middle of the night, don't get back to the camp until the middle of night, or the wee hours of the morning, you know, a lot of them would be frustrated and that's education in general.

Brady: You're building trust but you're also building teamwork. None of us had ever been tasked with anything like that before. We were thrust into a group of people that you 
don't really know that well to do this big thing and so everything is a brand new experience and so it's the novelty of all experiencing this together. We had so many fun bonding experiences, I think bonding would be a good theme. And team, and learning how to problem solve.

Cindy: Pushing beyond boundaries. And, seeing things from a different perspective. And I do believe that OLE helps you take the blinders off and realize what you do here at OLE can also be applied back in your school. It also showed that you could conquer and do things that you probably didn't expect yourself to do.

Daniel: I would say the theme was inspiration. And it has to do also with your development of your perspective, your attitudes, your beliefs.

Greg: Trust. Realizing and understanding that you don't have to do everything yourself. You have to trust in others, you have to build a team around you that has similar goals and similar vision as yours.

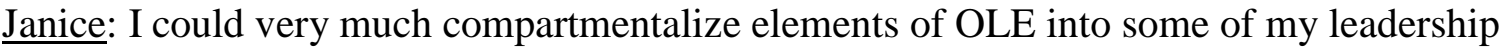
books for my doctoral program. The political side, you could see a relationship side. I could see all of those elements. One of the beautiful characteristics for me of OLE is that obvious planned leadership motive that we have in public schools, was dissuaded by us all coming together to talk about our experience.

Jason: One, the big thing is learn who you are. That was a big one for me. It really allows you to learn about yourself. And then the caveat of that is once you know who you are, recognize your weaknesses and how to work with others. And I remember, Phantom rules I took away with and I say to my staff, there's always another way. We just don't always see it at the time. 
Jeanie: The whole team concept isn't about me or I, that if we're in a team, then and we've got a certain goal to accomplish, then, you know, making sure that our team members are heard. And that whole collegiality piece because of the setting, it was an opportunity to really develop that that team concept of a we're stronger together. And I'm actually going to take some real serious, powerful learning back with me in whatever role I'm in.

Joey: Trusting the people that you work with, and understanding that you can't do it all on your own. And I think as leaders sometimes we think we have to carry the load by ourselves. And it's hard to rely on our team around us and delegate certain things. So I think that was the big thing that I took away from it was that you have to be able to rely on your team. As a leader, you don't have to carry the weight on your own, but you have to build the capacity of those around you so they can help carry the weight.

John: You had to develop relationships, like that (snaps fingers). And so building trust came quickly. And I would say team team building would be another one. It was all about doing things as a group, making decisions as a group.

Lacey: It reminds me of church camp where you're among everyone that thinks the way you think. For the first time, you are among people that believe in something you believe so there's internal fire that gets to rage externally. It burns so much brighter because everybody around you is on fire for the same thing, and it is acceptable. There is an element of OLE that is similar. We school leaders get to be together and not worry. So it's okay to take the hat off for a minute and just talk about my strengths or weaknesses and they're actually acceptable both ways. And then when we went back and we're trying to burn our lights all by ourselves. There was a connection that we had made and this support network, because when you get in your own district you tend to not ask for help 
very often. But you will ask a stranger, that you have made this connection with for more help.

Luke: Definitely trust because there were situations where you had to work with your team and you had to lean on each other to accomplish what you're trying to accomplish. So I would say trust is one. Teamwork definitely because you'd have to work together. And a part that I enjoy because it's like solving puzzles and then relating that back to okay in the real world of dealing with a critical issue. How would I use this frame of thinking?

Lydia: Having confidence in yourself, that you can do something that maybe looks pretty big. Trust and teamwork definitely. We all have our jobs and we had to trust each other to get us to the woods. Knowing that everybody has their own position and their strengths and what they can provide to the team.

Marcia: Vulnerability like that last night, when you are around the campfire, when people almost give their testimony. And I thought that was huge. That's like how we are in leadership. Just have been having to be vulnerable and that night. I bonded with people in a matter of a few days and, that was huge. So the vulnerability, teamwork, trust, reliance, to name a few. Oh, the rock claiming too. That was pretty big too. I felt like that part was similar to the job when we have hurdles. I didn't want to be the one to let people down too so I went outside of my comfort zone to do some things.

Max: I guess the overall theme is about teamwork. I guess that's what the theme is meant to be anyway.

Peter: One is safety, both mental, physical right, and even in the space of physical safety at OLE. There's enough support for those who don't feel safe to say we need it, but let's 
keep moving on. So, but the mental safety that's there. The second thing is vulnerability. OLE allows for a lot of reflection time which I think is critical to self-awareness and ultimately can lead people to better put them in a position to be vulnerable. The last one is collaboration. And so if you think about what is created on an ongoing basis. We're doing this event together and for us to succeed, we have a conversation about it. On a continual basis, on the hike, throughout the process we collaborate. I think about the intentionality of each element. When you have a safe environment, when it's vulnerable, and when you have collaboration--if you think about safety, vulnerability--it all hinges upon trust, and trust hinges upon relationship and so continually at OLE, it's about building relationships. So I think trust. Absolutely. And like I said collaboration, vulnerability, and safety.

Phoebe: Trust. I would say it is building trust with other people, quickly, and then depending on others. And then also, figuring out how your leadership style blends with other leaders' leadership style.

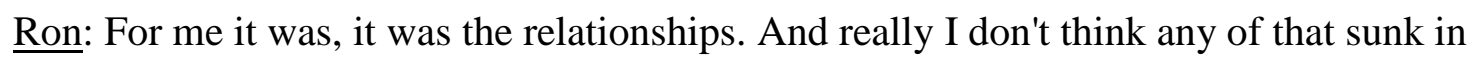
until the very end of camp. When we were going around and sharing what we'd written down in our notebooks, about other people. It was definitely impactful the things that they had done for me but then to sit back and reflect on things that I had done, not realizing what impact it had until they shared those things. The people are definitely what sticks with you and even if we only run into each other once a year at MAESP or whatever like it's still just like you picked up right where you left off.

Ross: Knowing your own strengths and weaknesses is important. I think that's one of the overarching themes that you have to know yourself to really maximize your leadership 
potential. The other thing I took away is that you have to make sure that you're taking time for yourself and focusing on your own development.

Stephanie: I think the theme is to get to know who you are and what traits you bring to the team. Understanding that you are a part of the team and that you have a valuable piece to the team. And you have to be cohesive and collaborative, and recognize the strengths and sometimes the weaknesses and opportunities for improvements in yourself and in other people as well.

Trent: Like I said, I don't think as far as the translation of some of those skills into actual things I could use in my district, other than maybe being a little bit more aware how much those personalities need to be in the right spot. And not thrust people into certain positions that they're not capable of doing.

Tricia: It really helps you to connect with your own leadership style and understand the leader that you are. Not being this other person but knowing I have a lot of gifts and things that I offer from my perspective and from my gifts or talents. And so I think it helps you connect with yourself and your leadership style and helps you to not really compare yourself to others anymore.

Question 10: What was your familiarity with the toolkit strategies you learned at OLE? Blake: I would say some familiarity but not a lot.

Brady: I feel like I learned most of them there.

Cindy: A little bit from PLC, more concepts without the official names.

Daniel: No, I don't really remember any of it.

Janice: I think I knew some of them by idea but not by name. I did some of them without knowing the formal concept. 
Jason: As far as any of the terms, I'd never heard the terms. They'd never been explained. Jeanie: None.

Joey: I knew about consensus. But that was the only one. But the one I took back and use regularly is Ready Circle. When we get ready to leave a district principal's meeting we say, 'let's sit back and just debrief what happened here today. What can we take away from this? What are we looking forward to next time? What are we going to bring back?' Really take the time to process, not the decision, but the process it took to make the decision.

John: Yeah, I would say a few. We work with the RPDC.

Lacey: A little through my experiences in special education.

Luke: Consensus I think from PLC, I was familiar with that. Lydia: None, not really.

Marcia: No, I didn't know about a lot of those but I used some of them afterwards. Peter: No, no, not necessarily in those terms I think maybe as a leader like through classes and stuff you have that but I think what makes it so much more real is that you're using them at the end of an activity. It becomes way more transferable. It's really good instruction to allow us to experience it both physically, but also mentally by processing through it.

Phoebe: Yes, especially consensus and ready circle. When I went through teachers Academy I went through with , and he isn't a pro at all of that. So, those became just part of my language. 
Ron: No, not really. Consensus obviously it's just something that we all do. But no I did not have much familiarity with the toolkit, but I've used many of those strategies since, for sure.

Ross: Well, when you talk about consensus and things like that, you know, I think, you know there's a degree of knowledge. I really didn't have a whole lot of familiarity with the others. But it's neat to be able to have those tools and articulate that here's how we're going to do things and why we're doing it this way.

Stephanie: I would say no.

Trent: I know consensus from PLC training.

Tricia: I didn't know them. It was all new to me. It was only my second year. Everything was still new.

Question 11: What was your comfort level with the activities engaged in during the OLE?

Blake: Probably not. I mean the only thing that I would say is, I was always a little uncomfortable with some of the closeness on some of the things that you had to do. I mean, that made me uncomfortable and some of the "games" that you play. I got a pretty big, wide area that I consider my space and I want people to stay out of it. And you had to give that up.

Brady: I loved them all. There wasn't a time when I was uncomfortable with the activities...I am the type of person who is going to lean in to any activity and be all in. Cindy: We did the rappelling. And I was not very comfortable with that because I was scared. I'm scared because I've never done it and scared because I'm bigger. But I did it. And I was like that was fun, you know? 
Daniel: I was never uncomfortable. But empathy and recognizing others were struggling. Recognizing that as a leader like you are there for your team, not to just go; it's not about you being the fastest of the best or the strongest or the smartest. It's more about working with the team to be stronger together. So that really was a message that stood out to me. When you're a young leader, you're picking up on those things and it's helping to shape your leadership philosophy. Some things that maybe you know. But until you really internalize those and practice those, and I do think that did have a contribution in some of those things. Just having empathy as a leader, and being there for your people, the people that you're working with. That's very important to me.

Greg: I was very comfortable. I think the whole reason behind leadership is to make you feel a little bit uncomfortable. To put you in some uncomfortable situations, because as a leader (of course we would like for everything to run smoothly all the time), we're forced to juggle, we're forced to wear many hats and we're forced to make decisions on the fly. I think part of being leaders is staying in a state of uncomfortability, but being able to manage that. To make sound decisions and to gain input.

Janice: I loved them. The only thing that bothered me a little bit was. There's a very aggressive outward leader who immediately took over when we went to the woods Jason: Perfect example, all the social stuff, my comfort level was very low. All the outdoor activities, I was so happy. Like in the very beginning, the meet and greet, where you say what you've done, and you walk around, you talk to random people. that was out of my comfort level. I'm the new guy, I'm gonna stand here and be quiet, wait for somebody else to come up and talk to me. 
Jeanie: I've had to be perfectly honest with people, I just want you to know that this is a stretch for me. But, hey, you know what, this is not my favorite thing to do. I see the value, I see value here. And the wonderful thing was that you had challenge by choice. There were choices in the approach that you took, went by water and went by land, and those kinds of things.

Joey: At the rock climbing and rappelling wall, other people weren't comfortable with it at the beginning. Then basically as we rallied around them and cheered them on, they were able to overcome that fear and conquer that. So for me personally I don't think I was uncomfortable with any of it. But I saw people who were uncomfortable with certain parts of the experience at first. They wanted to be on the hike or the rock climbing situation, and they were able to overcome their fears and see some success. Also, when we had the Lego tower that we had to rebuild and it was how we're gonna send somebody back there three times, to be able to get the information. And just a thought that somebody was a spy, or was trying to derail the situation, created tension within the group. So I think, out of all of them. I think that situation was the most uncomfortable for us as a group, because it pit us against each other. And it started to form alliances with other people that we hadn't seen up until that point, right

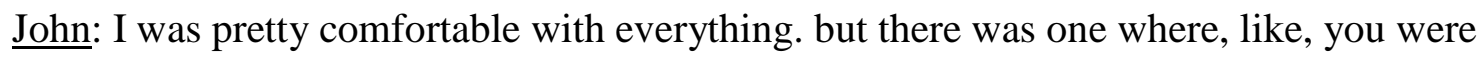
just like, I can't remember what the task was. But I think we all had to get onto these boards and have the whole team cross over something. I can't remember, but I just remember that we were not socially distanced, all these strangers were up close and personal. So that was probably the least comfortable because you have these strangers up 
in your business. But I mean, it wasn't terrible. It was just, it was different. I'm just not used to getting up close and personal with people that I don't know well.

Lacey: I love everything about being outside in nature. But some of the team building activities made me uncomfortable because a lot of those activities required you to touch people. And I don't touch people that I don't know, except females.

Luke: Probably most uncomfortable with dealing with the people. I'm not comfortable meeting new people and so it took me a while to warm up and like feel comfortable, put myself out there in front of other people. And just even like discussing or trusting other people. So I'd say that would be the weakness for me. And probably like rock climbing I thought I would have done better...I didn't. So that was frustrating.

Lydia: When we did some of those group activities at the very beginning I was quiet. And the rock climbing was not comfortable at all.

Marcia: I felt like as the weekend passes started to get more comfortable. I was not as comfortable to begin with. I got fearful of some things but overall, I felt pretty comfortable.

Max: That whole you know circling grabbing the rope thing was, that was too much for me. Well, a lot of the physical stuff I was uncomfortable with because I am an oversized overweight guy, and that made me uncomfortable. So, embarrassing. The whole sharing and getting into your feelings thing is not my cup of tea.

Peter: No, not uncomfortable for me. I love rock climbing and outdoors stuff. But there's emotion along the way and so you have to have a little more grace and I am a time guy, a speed guy. 
Phoebe: I was very comfortable. Those are things I like to do anyway. I was reflecting back to like the most the time that I was uncomfortable the most was probably during one of our team builders. I do not want to be the person in front. I was trying to make it work and I was getting there. But it's hard for me when others are all watching me, depending on my success, so that was just a little uncomfortable for me but it was good for me. I feel like during OLE they're constantly putting people into uncomfortable positions on purpose so that you can see how you'll work through it.

Ron: Just being able to put it all together and work as a team was definitely an interesting dynamic but there was some comfortableness with the different activities. And social situations are pretty comfortable for me.

$\underline{\text { Ross: }}$ So I think some of that goes along with my personality, I'm not necessarily the most extroverted person. You get outside your comfort zone a little bit when you're with people for a couple days that you don't normally spend that much time with or you haven't met before. I really enjoyed the whole weekend and all the activities. So, You know when you talk about comfort level. There was never a time where I was uncomfortable, or I didn't want to be there. I was never uncomfortable, but it was outside my comfort zone.

Stephanie: Honestly, probably during that time because it was my second year as a building principal and I was paired up with people that had a lot more experience than I did. I felt a little inferior to that. However, it was still valuable to me. At one point, we had circled up and we were sharing and one poor gal she started crying. I don't remember what it was about. But just being real and open and honest. That was a little uncomfortable. I felt bad for her. But there were lots of fun experiences and a few 
uncomfortable moments but I think that's part of what it is. I mean that's part of being vulnerable and being uncomfortable and you grow from those experiences.

Trent: No, I was not uncomfortable really. I mean, I know there were some others that were really struggling through.

Tricia: I tend to be kind of shy, you know I'm not the type that likes this stuff. I like to be in the background. I don't want to be out in front, so to speak. I like to be that silent leader, that encourages and motivates and all that. So the comfort level for me at first...it was really hard when they had us get up and talk about things and share stories and stuff. That part was probably the hardest for me.

Question 12: How has your attendance at the OLE impacted your daily leadership activities as a school leader?

Blake: Again just the differences. A lot of times you have to hire people that are thinking the way you think. But you get those different personalities, we went through those different personalities and gave me an understanding that, you know, that person there that fine arts person just doesn't think the same way I think and doesn't see the world the same way I see the world.

Brady: I think that I probably implemented a lot early on it but I still am guided by some of the philosophy that I learned there. It depends on your role. If I were asked to do more of a school role besides my department chair or a district role or a different position and probably roll some of those things out. I still kept the books.

Cindy: It would probably be around the building consensus. Knowing that I can't really move forward unless I have everybody on the same page. 
Daniel: I recognize how powerful that was for connecting and for reflecting, because I think that the impact of that over typical professional development is lightyears ahead, which really shapes a lot of my philosophy of education. You know if we can make the lesson more of an experience in the classroom, kids are going to get into it. I feel I need to create these experiences for my staff, my people, my team, so that we can connect and grow together.

Greg: It changed my leadership style. I started to do more team building activities. Once I attended the Outdoor Leadership Academy, I felt like it was important to draw people together.

Janice: I would say a combination of OLE and my doctorate at Mizzou; those two experiences together have very much impacted the way I interact with others. In my particular job as a building leader over teacher preparation and professional development and guiding teachers and selecting curriculum, all of those things. I'm very much a shared leadership person. I think OLE is very much that way, very collaborative, everyone's voice was heard.

Jason: Definitely has helped me. It has rearranged my perspective of leadership. I thought a leader stood at the front of the line and blazed a trail for others to follow. OLE taught me that no, that is not necessarily what a leader does. You empower others, to blaze their own trail, I think is what a true leader does now. And, you know, let's not get hung up on what we can't do. Let's focus on and being goal oriented, let's focus on what we can do. And find that other way that right now, we can't see, let's turn that last piece over, you know, flip it upside down, and now all of a sudden, it works, you know? 
Jeanie: The biggest thing that it taught me was, it's okay to be outside your comfort zone. You have a team around you.

Joey: I think a big victory for me is building the capacity of my team. And being able to find a team that you can actually trust. The team that I brought on board. It helped me from day one to really instill in them that purpose of shared leadership. I don't have to micromanage: if you make a decision, then we're gonna stick with your decision.

John: I think that I know more about myself as a leader. Before, I think I would make a decision and assume that everybody would get on board and figure it out. Because that's what I do. So now, I think I've had to be more reflective about those people who are the fact finders, who need to know $\mathrm{XY}$ and $\mathrm{Z}$ before we do it, I've had to be more thorough about creating plans and communicating that with others and making sure people get their questions answered.

Lacey: For me it was just validation and again some reference points that I could then continue every day. I think everybody needs to learn how to bond and build as a team. Luke: And so this year, more than ever, just like stepping back and thinking about like everybody comes from a different perspective, a different background and trying to figure out, well how do we make these teams work and continue to move our culture forward in the, in the way that we're at because our culture as a school is great, but adding that many new people. It's like, you can have a major shift real quick. If you don't acclimate them to the way things are done.

Lydia: I think the confidence level, a lot. And then I started looking on a daily basis, because I was new in a principal's position, looking at how to get along with others and looking at other's strengths, and the trust part of building a team. 
Marcia: It's helped me realize that, to get the job done I need everybody to follow through with a project. I need everybody using some of the tools we had for consensus. Realizing that sometimes you have to fill in leadership gaps or have people help you not do it alone. And the networking, I think that is huge for me too, because I always want to be better at communicating and keep listening.

Max: I would say, and this is nothing against OLE, but I don't know that it had a huge impact. Just because I tend to, I don't want to say that I'm set in my ways. But I have my personal style. I just feel like I still do what I've always done. So I can't say from that experience that I went back and changed how I behaved or how I act or anything like that.

Peter: I think it makes me think about what experiences I am creating for my people to come together and to think of how they how they're perceived by their team and how they can lead better as teammates. Looking through things from a different paradigm is a huge piece of what OLE also teaches. But the OLE experience allows for a very different side that is not just education. It actually pulls you out of a place that you feel pretty confident and now you have to navigate some uncharted waters. Honestly, I think we should do more of it. I think about the amount of superintendents (because that's my space now) that would really benefit from understanding who they are more as a person through an experience like this.

Phoebe: So I've learned I like to jump in and fix things right away. I'm a fixer. So, I have learned to take a step back, and I've also learned that some problems don't have to be fixed in the moment. Let me think about it, let me step back and look at it. Or let's meet about it, and then we'll come up with a solution together. 
Ron: Again, I think I just have to go back to the fact that it's all about relationships. You know there's a reason behind everything, I feel like, and so you know I always try to be very conscious about my interactions with people because you never know who they know or what impact it makes. That same conscientiousness about, you know, making sure that you're being kind to people and. And because you never know what's going to happen and or what impact you may have on them or they may have on you.

Ross: It's more an intangible. You know it's one of those experiences that reinforces that belief that I can make things happen. Which I never had a big problem with self doubt, but it is nice to get outside of that comfort zone and do things. Sometimes I think back to that climbing wall. Where I'm like, 'that's tall' and I don't really like heights. But then I see all these other people around me who are doing all these other things with no qualms, and are scared to death. So I thought I guess I'm just gonna scale this wall so everybody sees somebody that can do it. It's that reinforcement that if I want to do something I can make it happen. You know, maybe you have a little more swagger.

Stephanie: I think it probably just made me more comfortable with my leadership qualities that I bring to the table. Being there at OLE and recognizing everybody's different qualities and so forth was a comforting aspect.

Trent: Probably none. I mean, honestly, other than I have a story.

Tricia: I had a better understanding of my own leadership style. And so to try to, I think it made me more confident and knowing that the reason I was the leader I was because of my personality traits. I would say that it did change me. It made me more secure in who I was as a leader and more confident in who I was. 
Question 13: Think of a difficult situation you have had to resolve as a leader. How would you have handled it prior to attending OLE? How would you handle it after attending OLE?

Blake: You know, the only thing I wish I could say then maybe probably helped me (and again it was so long ago) was probably as a principal dealing with some of those kids that were coming from a completely different background. So it probably gave me a little more open mind that they were coming from quite a bit of a different background. And it just over all probably made me again like I said more willing to work with people and listen to people. Not just immediately say no, this is what we're gonna do, and be willing to change and go with what they say. Sometimes they would have better ways to do it than the way I was thinking, so.

Daniel: Recognizing how people were experiencing things differently. It may have helped me to develop patience as a leader and more understanding as a leader. More willingness to try to really understand someone else's perspective.

Greg: Probably the simplest one would be just overall daily routines, directives, that I've may have just put in place prior to OLE. Upon attending that. I think that I started to look at directives and procedures. Not so much from top down as from trying to get by, and then implement new procedures, and that would be one thing probably I would have done differently.

Janice: I have to give up the ownership and allow other people to have input as well. And I would say I probably wasn't that way before. Before I was very much, 'Give me an assignment. I'm a Fact Finder/Follow Through. I'll get it finished and it'll be done before you want it.' And now I will say that I'll delegate, so they can have the opportunity to 
grow. To empower others to grow and become leaders, and it all happened through OLE. I mean, I can remember very clearly the interactions of OLE and how everyone was very, very collaborative and allowed other people to lead.

Jason: I think one thing that it has taught me is, is I have time to make decisions. That things are not always a race, the first one to get all the flags and get out of the woods does not necessarily make you the winner. I can't give all the credit to OLE (experience and confidence). But I think OLE helps you understand the why behind it. Now, when a crisis comes in---and everybody's crisis is a crisis to them--that re evaluation of what is a good leader has really helped me calm down and relate to other people's problems. And to not to not just power through, but to slow down and give them that time to let them figure out the why; to guide them in dismissing the Phantom rules so that they can get through the situation. I can't give all that to OLE. But it was certainly illustrated during that experience, and I think probably sped up that process of my development.

Joey: Coming on as a new principal, and with a lot of unknowns. Last year prior to going to OLE, I feel like I had to be the one that always had the answers. I had to be the one carrying all the weight. I couldn't make a mistake. What are people gonna think about you if you made a mistake. Then when I went to OLE I found out about the idea of failing forward. I really embraced that. I told my staff 'we're gonna get some things wrong, but we're not gonna have the answer to everything in every question. What we are going to do is when we do make those mistakes, when we do have the wrong answer, we're going to admit that we made the wrong turn. We're going to learn from it and we're going to get back on track. We're not going to let that hold us back. We're not gonna let the last play dictate what the next play is gonna be. 


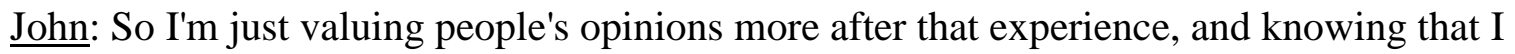
need to surround myself with people who don't just think like me.

Lacey: It just reminded me that it's okay to be frustrated, right? But how do they handle it? And how can I hear everyone but then find an ending point so we can move forward? Because that was a big struggle for me.

Luke: So my first step (before OLE) is to get rid of these textbooks and just throw them away and then we'll address it later when we meet face to face. Um, that wasn't the best approach. It didn't go over so well. Even though it was the right thing. So, this year with a new ELA resource just be more understanding and thinking about what do you need from me to support you in using this resource? Understanding that different people need different things, and some people may not even be saying what they need so I need to check in with them frequently as well and others may need something where I'm like, I don't get that. But also understanding that they're a different person and they may have different strengths and weaknesses.

Lydia: When we would get families from other places, that are not like ours or just being able to really accept their diversity, to be more accepting. Being more accepting of diversity and really trying to get to know the people from people from places other than mine.

Peter: You think you have to make every decision and you don't. And so you create a space for more collaboration and get around it, and then a much better decision comes from it. I think back to when I was a principal, some programs were dictating everything we did. So the tail was wagging the dog rather than the dog wagging the tail. It's that they one don't understand it or two didn't have ownership in it. And so we asked if we think 
looking at students' data is important, that was like the first initial question. And everyone said yes. Then the next question becomes, then how does that look for us, and we designed it ourselves and came to a place that was, I think, pretty successful.

Phoebe: The first time I think OLE helped build my confidence within my leadership skills. I wasn't a leader but I think it caused me to want to be one. After the second time, I think that I rely on my leadership team more than I would have before OLE because I know they're all very capable. And I think also I'm working harder to build leaders within our building.

Ron: Prior to OLE I looked at a school administrators job as one where you want to 'win'. I want my building to be the best, and I want all of our scores to be the best and our students to love that building the most. And I think there are times where in education we just want to micromanage because I think I know what's best. Before OLE I think I would have handled it more from an aggressive stance. I'm worried about the bottom line. I'm not worried about my feelings towards you or your feelings towards me. Let's just get the job done. I think now it's much more of a coaching aspect that I approach it with. I'm going to give you every opportunity to be successful and I'm going to give you the tools that I think you need to be successful. So I think just understanding that everybody has their strengths. The more that we embrace those, the better off we're going to be as a team.

Ross: Sometimes it's just like you just gotta put one foot in front of the other and we're going to do this and get through it, whether it's the 12 hour hike or it's having to do things that are unpleasant because you're having to reprimand somebody for something they did. 
But you know it's the right thing, so we're gonna do it and get through it and get over it and move on.

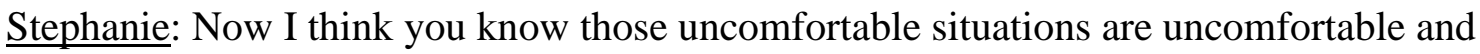
you just grow from them. Again my whole reflection on OLE is recognizing the differences in people and the way that people are going to handle situations. And then being okay with that and being vulnerable and being humble and so forth. So, my answer would probably be different if I just had attended OLE like two years ago.

Trent: I think it reinforced making sure you are putting people in the right places. And just because I might personally like someone doesn't mean I would give them a job. I've got a lot of friends that I wouldn't hire. I could separate my feelings from who they were in relationship to me, versus the task that they were doing so.

Question 14: In what ways do you feel the OLE impacted your professional network outside of your local school district?

Brady: At first it was pretty cool, because we kept in touch with each other. Our little group hung together, probably for two or three years afterwards. And I think within that group there might have been some job changes and some job opportunities. You know like, hey, we've got a job over here for you and they would go, you know I think there were some professional connections that were used. The only reason we had that little tight community for even that little window of time in our life was because of the OLE. Cindy: I didn't make those bonds with my team. But I did make bonds. There were other people that I knew of going into that that took part in that that I've kept relationships with. And it actually helped me see where I wanted to go as a leader. 
Daniel: I don't really think that I kept those ties long term. But I do remember at the time really enjoying the connection with people from all around the state and getting to know them and hearing their stories and just the feeling that connection as educators.

Greg: I've got colleagues now that I've met there that I still correspond with and have throughout the years. We keep in touch whether it be personal or professional, just to see how things are going. People got the same problems all across the state.

Janice: It was huge. So there are people that I met at Outdoor Leadership experience and we were both in different jobs at the time. Now we've all matriculated to major leadership positions, and when I see them I just want to run over and grab them. Because from that weekend, from that one experience, I'm talking about deep relationships. How did that happen? How do I have this much respect for that person out of such a short time? Our feelings were naked, our conversations were naked. We spoke personally, and sometimes we work with people for years and never do that.

Jason: Not as much as it could have, but that's by my own fault. So I allowed those networks to dissolve by my own accord. It's not something I'm proud of, but had I put in any effort, I think I could still have very strong networks that I had built in that area. I just didn't, I allowed them to dissolve. And I take full responsibility for that. The opportunity was there.

Jeanie: Sometimes we can just be in a silo. And so I just feel like that it was so crazy, incredible, because I don't know what a principal in St. Louis or Kansas City is going through. But there were so many times that it wasn't much different. It probably saved lives, to be able to have that network to be able to call somebody because I didn't have anyone. 
Joey: Our Rabbit group is amazing. To this day I feel like I can text or call any one of them. And they'll pick up the phone and we can bounce ideas off each other..

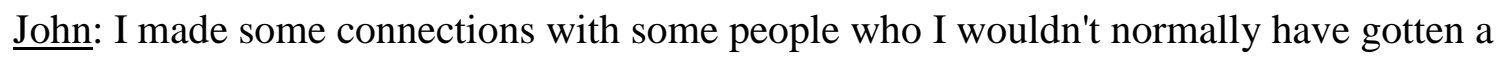
chance to interact with. I still see them at a conference or I'll email them about certain things. I think it's just helped me be able to look past our local neighbors here and actually look at what people are doing across the state. So it's just been a good experience to just talk to people who see things way differently than we do.

Lacey: Well, because of OLE, and just building some confidence, they saw me differently than I saw myself. They have continued to reach out for things. It's given me the opportunity to teach what I'm so passionate about to so many different people. I've been at school districts all over the state. And then just through my own network I got to do some nationwide speaking but I would have never had that unless I'd gone to OLE. Luke: Yeah. I think it's definitely expanded it. Being able to continue those connections on Twitter, definitely helped, and those are probably the ones where it's a little bit closer. Lydia: We kept up with each other with emails, and especially when because we were all new. We're like, 'Hey, I had this experience. What did you guys do so that we were able to tap into each other's expertise or just to really vent sometimes. I mean we all kept in touch with each other quite a bit for several years

Marcia: I mean I feel like there are still people I met that weekend that I have close friendships with. If I have a question or we call each other we talk about how things are going. We bounce off ideas so I feel like it's strengthened my network outside of my normal circle of people. 
Max: I don't have any contacts from that outdoor experience that I'm still in contact with today. I do value and appreciate the idea of professional networking and stuff like that, but I can't say that I have any lasting contact from that experience.

Peter: To build trust with other people within the profession. I think a lot of people actually aren't really great at networking, they network through proximity. And OLE is a space that allows you, because of the design, it allows you to connect with somebody out of St. Louis. It allows you to connect with somebody in Northwest Missouri that has a school district of 200. So I love that aspect of it, because again it helps build perspective, a lot of different relationships.

Phoebe: I think that it helped me a lot just getting to know other admins. Our admin team is really close but sometimes just getting outside of that circle and knowing you're not alone. And seeing what other districts are doing in ideas or struggles. Just being able to communicate with them. I do wish that our group stayed in contact a little more.

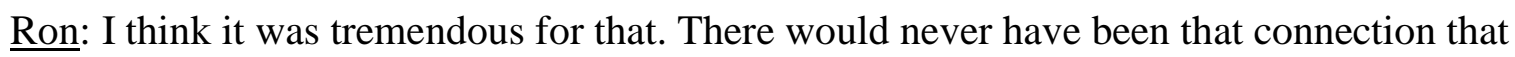
there was because of OLE. And I know that they're only just a phone call away and that we can touch base and pick up right where we left off.

Ross: We get a little bit insulated from other school districts and you know how other places do things for better or worse. My professional network wasn't very large. Now it has grown quite a bit. And I learned a lot from the different people in those those different organizations and I've got people that I can reach out to to get perspective. Stephanie: Well you know for a long time I would bump into the people that I went camping with down at our conference. And that was great because you know we'd visit 
and so forth so that started expanding my networking. I don't understand how people cannot network.

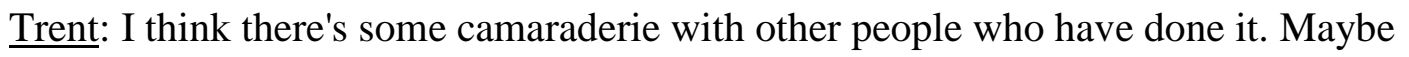
having a shared bond with some people.

Tricia: That was huge. I had so many people that I met there that we're still friends today and I can still pick up a phone or email them and you know they'll do whatever they can to help. So the networking part you can't you can't get it anywhere else. Because not everybody going through the OLE were necessarily building principals, some of them were teachers and coaches and I think there were some superintendents and people from RPDC. You really broadened your network of people that you could call on and so that was awesome.

Question 15: What would you tell someone who was thinking about attending the OLE? (If Needed) What would you tell them to physically prepare for? What would you tell them to mentally prepare for?

Blake: Go into it with an open mind and understanding that you might be uncomfortable but you need to go ahead and do those things. And then again, there's some touchy feely parts of it. It'll be alright. You'll survive.

Brady: I wouldn't hesitate to say do it. That it is a fantastic experience. Prepare to be open and introspective to really reflect on who they are as a leader and how they respond. Cindy: I tell them to go, always,. The main thing is you're going to learn so much about yourself, that you're not as limited as you probably think you are. And that you can learn from a lot of other people. It just gets you out of your mind space, and really gets you to see things from a different perspective. 
Daniel: I would definitely encourage it. Right at the top of my list of things that you should do if you have the opportunity.

Greg: Go into it with an open mind. You know understand that it's an experience for growth for professional growth and. And that's what we're all supposed to be in it for. And if you do so that you'll gain a lot out of it if you go into it with, with a closed mind and this attitude, you probably won't get as much out of it.

Janice: $100 \%$ they should do it. I can't say enough about being raw to the respecter of no persons and embracing the ability of all people and their talents. I think it's one of the best experiences ever, especially for young leaders. They should all do something like that.

Jason: It's not an option. GO! Mentally, be prepared to be out of your comfort zone, one way or the other. And it might be totally different than what you expect. Be prepared to be out of your comfort zone, embrace that you're not good at something.

Jeanie: Do it! And prepare for a great learning experience. You will not be disappointed. Joey: Don't go into it with any preconceived ideas. Your experience is going to come from what you bring to the experience. We all experienced it differently, even though we were in the same place. Our experience is different based on what we brought to the experience and how vulnerable we are willing to be with this experience. And don't expect any cell phone reception.

John: I would tell them to go for it, because I think it was one of the most valuable PD experiences that I've had as a leader. I would tell people to go into it with an open mind. Just learn a little about yourself and come back and reflect on it. Make yourself better because of it. 
Lacey: I definitely think if they are unaware that they will be walking they need to get aware very quickly. The other thing would just be to relax and have a good time. Somehow set yourself up for knowing that you might not have contact with your building for three days. You can have contact more than that, but you know I checked my phone every chance I could because I was so worried about how it was going, since there just aren't enough people anyway right, and I took away some of my own joys I could have had there. And I would have done that part differently.

Luke: To go for it. It's definitely a worthwhile experience. And I'd also say you probably get out of it what you put into it. I think that's one of those things where the more you throw yourself into it, the better off it's going to be down the road for you. And to lose your inhibitions, let your guard down.

Marcia: I think it's a life changing experience because you're outside your comfort zone and you realize you can do things that you never thought you could do. You are a significant member of a team. It's okay to be vulnerable and it's okay to put yourself in compromising situations and lean on others to get jobs done. It's just something I will never forget. It has made me a better person. The friendships I've made from it, I can never replace those people.

Max: To embrace it and take advantage of it the best you can. I would say mentally be open and willing to new ideas and sharing because I think that's really a lot of it.

Peter: Be brave enough to be vulnerable, brave enough to question your own beliefs and to seek to understand other people's perspectives. Take risks. Go beyond yourself, if you're in fear. And even though some of the things may feel silly at first, every piece of it is intentional. And so, trust the process. 


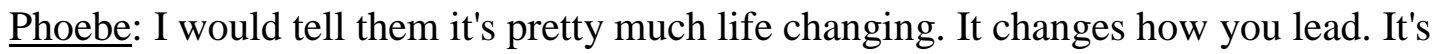
also just that mental break to get away and do something with other leaders and get to reflect with them. And then the relationships that you build with others is huge. And just the self reflection time. I think it's your responsibility to go as a leader, because you need to always be learning and it's just a wonderful experience.

Ron: You're going to go to OLE and you're going to meet new people and you're going to have a wonderful experience for the time that you're there. But it's what impact lasts beyond that's going to be the most beneficial.

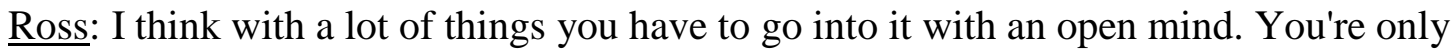
going to learn as much as you want to, like with anything. I think the only thing you can do to mentally prepare yourself is to understand that you will be out of your comfort zone at times and that's okay. And to go in with an open mind and know that you're going to meet different people and have different experiences, but ultimately your toolbox is going to get fuller because of that.

Stephanie: I would highly encourage anyone to go. Just for that networking and being around other people. But then you start, you go to an experience like this and you really get to know people and people are vulnerable in that situation. And it provides you with not only that knowledge and that comfort level of 'these are just regular people who go home to their families. There's nothing more special about them than us, they're regular people.' So, I would highly encourage anybody to go.

Trent: I think if you're not ready to do the walk in the woods it can be grueling. Make sure you have proper footwear. I think also to just be open to other people and that you 
may not have the answer. You may not have the right way, listen but do not be afraid to interject your opinions without being a jerk.

Tricia: It will be one of the most probably the best experiences you'll have. I think anyone who's been a principal for at least two or three years. I think they need to do it, because the benefits are amazing and I'd go through it again.

Question 16: What would you tell the leaders of OLE as far as the design? What would you keep, take away, or add?

Brady: It was such a great experience. I would just caution them not to change it from negative comments.

Cindy: Don't take out the hike and orienteering. It brings you back to being a learner. So you realize maybe how frustrating it could be or what it's like to not understand. I think that's an aspect that needs to stay in there. I don't know how they decide the groups. I don't know what that's based on. It would have been nice if I'd had more people from my area. So that I could have had at least those bonds to carry afterward.

Daniel: It's like there's a lot of intentionality around what's happened to you. And you just know when you're part of something that somebody really thought through. It wasn't a brand new thing because it's been around for so long and grown over the years to make it work so well. It was great.

Janice: I think it'd be cool if there was a way to identify, through their characteristics and their traits, the leadership team themselves would choose the wolf pack leader, rather than the people (team) choose the wolf pack leader. And I think it'd be great if they chose somebody that was less aggressive. I find some of the least verbal people are some of the most intelligent people, they just have refined self control to moderate their behavior. 
Jason: To me, I think the hike is vital. That was the best and the worst part for me. But I love that, in hindsight, in reflection. For me, it made it different than just a regular professional development. It forced implementation in a longer setting so that it could come to the boil and go over and I had to deal with it. That boiling point is crucial. I did get tired of writing in my journal. But I know the reflection is huge. And how do you hold people accountable and get them to reflect if you don't have the journal thing? But no, I wouldn't change much, I would be very cautious.

Lacey: I don't know that there's anything I would get rid of. I didn't have anything that I thought was a waste of my time because I feel like you get out of what you put into it. I think there could be fire every night. And that may happen now that it's more localized and whatnot. I think there's more bonding outside your group in that moment that you didn't get otherwise, because you know once you start it's just your group if there was way to combine more groups together, even in some of those activities where you had to rely on a group strength with another group strength I think could be powerful, I know it would take very intentional thought because you're still time bound, but I think you could do it and I think that that would expand that network that you're trying to create for people.

Luke: I remember feeling like I don't really know who these people are. As a group, if there is a way to like meet those people prior to being grouped with them prior to the outdoor leadership experience.

Lydia: Don't change anything!

Marcia: I would just keep it as it is. I really think the team building along the way is crucial. Also, definitely would keep us that alone time in the woods because we got time 
to write in our journals. I thought, 'Oh my gosh, that was so important because here we were busy, busy, busy and I just needed a little bit of time to collect my thoughts and gather myself.'

Max: I don't have enough knowledge to be making that type of advice except I, I would be interested in doing it again. I would like to maybe do that with teachers and staff. I'm usually in a small school with 25 to 35 teachers and I would like to do something like that with them because I think it's really important to build that team thing within a district. Peter: I really wouldn't change a lot. I think the only thing I would add is extended coaching afterwards. And so what does it look like to create some goals and to create some accountability partners that are, that becomes ongoing. But the power is that you've changed individuals personally and professionally.

Phoebe: I would say one of the most powerful pieces is the campfire. So both times they did the fire and we sat around and people went up and spoke but I feel like the first time was much more intimate, and everyone went up and spoke. So even those like me who wouldn't have volunteered originally. I wish that (I know that's probably budget and all of those things) but just how do you continue it? Is there a way to continue it, at least virtually? Like a second year or something like that, just a mini OLE.

Ron: I don't know if there's anything that I would take away, definitely love the homemade books that we make and share with those people at the end. I love the hike to the woods, obviously, just because it's something that not a lot of people have experience with. And it's not like hiking in the woods by yourself, you know it's definitely an experience that will force you to bond. I think for the leaders, it's just conveying to the group that this is about your personal growth as much as it is your professional growth. 
It's about being open and embracing what's going on. And every activity may not be a strong activity for you. But it's just about perseverance and going through it and finding a way to lift somebody else up and develop that strength as a team. So, I don't think there's anything that you need to take away and I can't think of anything to add right now.

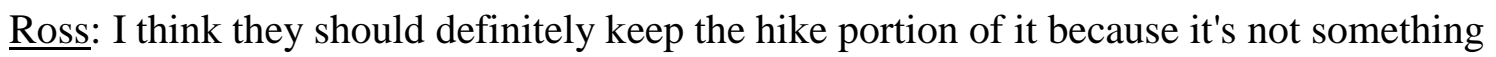
you're really going to do in too many scenarios. So when you talk about getting out of your comfort zone, that'll do it for most people. The only thing that I thought was a little bit hokey was sitting around the campfire that one night, but whatever, it's all part of the experience.

Stephanie: I think they need to add in the advanced Leadership Academy. And I would recommend they do that twice, maybe at the beginning and the end or something, Trent: I think it would be neat for everybody to have to go through the night time. Just to add another element to it that may, may make you think a little bit and coordinate a little bit differently. The forced testimonial at the campfire just took me out of the moment. Tricia: I'm sure it's probably changed since I was there in 2006. There's nothing I would take away. And I can't even think of anything else that I would add in because every single component of it was perfect. It was just such a great experience.

Question 17: What is your plan for your future as a school leader?

Brady: So if you'd asked me this question a little while ago, like shortly after the OLE, maybe I would say I'd go into administration. But right now, as close as I am to retirement, I am probably just going to stay a department chair and teacher. 
Cindy: Probably, if you would have asked me two years ago, I would say, to do this job for another few years, and then move into the superintendent position. And not to say that that still isn't a goal. But I am so thankful I'm not a superintendent right now.

Daniel: There was a time I thought central office leadership. I mean that's part of the reason I pursued the doctorate. But, you know, I've come to a place now where, you know, I just really want to keep growing and do my best here, right where I am. Greg: I've got my doctorate degree, I worked my way up there with the goal of Superintendency. If a position presents itself, I would probably pursue it.

Janice: So, having been a central office administrator for 15 years now, my next role will be influencing politics somehow, and funding and educational departments for the benefit of marginalized children.

Jason: Actually I just accepted a position. I will be a new superintendent.

Joey: It's ever evolving. The one thing that I think I have decided after OLE is not to pigeonhole myself into one place. Something to do with education for sure. Even if it was just to be the principal here the rest of my career, I'd be more than happy.

John: I would like to probably just stay in this role and do more with that. Do more to support teachers, aligning curriculum or using ed tech stuff to just be a better teacher. Hopefully, I can just be better at this.

Lacey: I will say in school leadership. Because I'm not done yet with what I came to do. Luke: I really don't have any, any like concrete plans. The plan was one day to be a superintendent, but I don't necessarily have that burning fire where, like, I've got to do it right now. I finally have gotten to a point being in the same school where I know families I know kids. And so just enjoying it, I think is my plan right now. 
Max: To become a superintendent. I think I've learned something from taking the classes at Mizzou that have made me better and refreshed me rather than you know being stale a little bit.

Peter: I will stay here another three to eight years and then retire. My desire is to develop executive coaching and there's several things I've been doing, because that's my heart. I love to coach people and help them unlock their own potential and so really.

Phoebe: So I don't know if it's just this year and all of the things we've been through, or if it's just time for me but I've thought a little bit about, I don't know. moving on to something different, maybe still be in education.

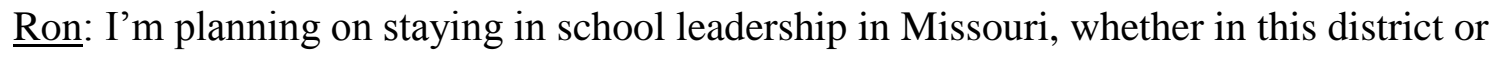
in another one. Eventually move to the Central Office.

Ross: I'm pretty happy where I'm at. I feel like I've had a unique path. And every time I've gone to a different level it's surprised me and it's been a good surprise. So, in a couple years I don't know maybe I will have some more solid aspirations. I don't know where it'll take me.

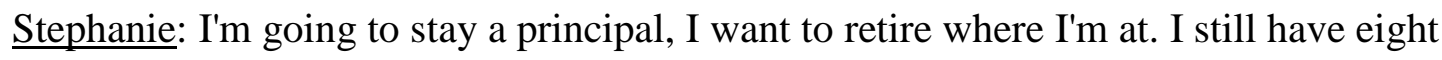
years, seven, this year, but I'm really happy where I'm at.

Trent: Yeah I plan on retiring from this district.

Tricia: I'm planning to stay until retirement in this role. And then I want to do something in education because I just, I'll get emotional, because I love it. I can't imagine not doing something revolving around education because it's a really important position, an important role. 
Question 18: Is there anything else you feel I should know about your experience at the OLE?

Blake: You know I always encouraged people to go through it. They'll create all kinds of... um, different people to collaborate with and it just opens your mind up a little bit. So, so yeah, I mean it definitely was a great experience.

Cindy: There was a lot of reflection, you know, and the journaling and different things like that. Which I didn't have a problem with. And then you know, you make the journal and you pass it around. So people can tell you what they see in you. I think that is a wonderful thing. But there needed to be more people to write in it. So you could have more feedback.

Greg: I think I was one of those close minded individuals when I went. I don't think I had a really good perspective on being a leader. When I went, I think I was more so winging it. I was doing the best I could, but not really probably doing a very good job of it. And so as the weekend went on, you know I laughed at people, I made fun of people. You know, I questioned myself. But I leaned on others because there were definitely areas of strengths that I didn't have. It was very positive for me professionally. Jason: You said that you heard that I didn't like the experience. Please understand that. That's not entirely true. I loved the experience. The experience itself was very difficult for me.

Jeanie: I'm glad that Missouri stepped out and decided to try this, because I think it's good for administrators and for leaders. It was life saving. 
Joey: I just want to just highlight the networking piece. How valuable for my career that has been. Not just the people in my rabbit group, but meeting people like the other facilitators and speakers. It has really opened up some other doors for me.

John: Just that it was probably one of the most impactful PD experiences that I've had. And it really would be something that would be cool to do every so often. I mean, it's seven years ago, and something like that every couple years just to regroup, to learn more about yourself, would be awesome.

Max: It was not the worst thing I've ever done and there were things that I did. I mean don't get me wrong there were some positive things about it, but it's just not who I am as far as like being open and sharing and that type of thing. But I did enjoy it and I do like the outdoor stuff.

Peter: Again I would just say it's one of the most impactful, intentionally designed experiences to help you as a leader become the best person you can be, so you can lead and become a much better leader.

Phoebe: I just couldn't say enough good things about it.

Ron: I could run into any of the people that I went through that whole experience with, and we could sit down and have a great meaningful conversation. Those relationships have definitely expanded past the few days that we spent together at OLE.

Ross: I think the bottom line is that if you go through it, you're going to come out a better leader at the end of it. And getting yourself out of that comfort zone is beneficial. Tricia: It was just such an incredible, incredible experience. 


\section{Appendix B}

\section{Focus Group Questions}

Purpose statement: The purpose of this study is to understand how the skills learned at Outdoor Leadership Experience (OLE) are perceived to impact school leader effectiveness.

\begin{tabular}{|c|c|}
\hline Focus Group Questions & Research \\
\hline 1. Could you tell me a little about yourself? & \\
\hline 2. How long have you been a school leader? & RQ4 \\
\hline 3. How many years have you been a facilitator for OLE? & RQ4 \\
\hline 4. Please share your thoughts with me in regard to the OLE? & RQ 1 \\
\hline $\begin{array}{l}\text { 5. Have you ever attended an experience that was comparable to OLE? } \\
\text { If so, how did your perceptions correlate? }\end{array}$ & RQ1 \\
\hline $\begin{array}{l}\text { 6. What were your most impactful experiences at the OLE either as a } \\
\text { participant or facilitator? }\end{array}$ & RQ1 \\
\hline $\begin{array}{l}\text { 7. How would you characterize the elements of OLE? Such as the big } \\
\text { overarching themes. }\end{array}$ & RQ2 \\
\hline 8. What is it that draws you back to facilitate each year? & RQ3 \\
\hline $\begin{array}{l}\text { 9. What would you tell the leaders of OLE as far as the design? What } \\
\text { would you keep, take away, or add? }\end{array}$ & RQ3 \\
\hline $\begin{array}{l}\text { 10. Is there anything else you feel I should know about your experience } \\
\text { at the OLE? }\end{array}$ & \\
\hline
\end{tabular}




\section{Focus Group Responses}

Question 4: Please share your thoughts with me in regard to the OLE?

Casey: Well, I'm generally I always found it to be an incredibly uplifting experience. I think people came away and learned a lot that they could take back and use in their schools in terms of collaboration and getting along with people and those things that are sometimes hard to teach in a classroom environment.

Tyler: It was my first year in administration when I went through OLE so it was blissful ignorance. I enjoyed participating, through all the activities, but I wasn't cognitively making the connections to real life. But it wasn't until the next year when I started facilitating and getting my feet wet more into administration, that all these connections started to be formed between what we learned and did in that Think Tank environment and how it transferred out.

But that same activity had a different impact on different people, but still good. It's the dynamic nature of that that is really intriguing. As a facilitator it deepened my appreciation for group dynamics and how to work with a variety of people. While I went in thinking I was going to help these other people, actually I've benefited immensely from facilitating. I needed that to learn more about my role, and I enjoyed the safe place to take that risk.

Austin: It's just a good refresher, but there's lots to take away from OLE, but I think one of the biggest things is the relationships. You form relationships but are you also reminded about how important relationships are in your day to day. I think I've learned way more as a facilitator than I did as a participant. It's been phenomenal. 


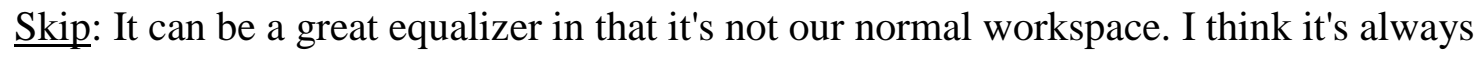
interesting because you find people who enjoy the outdoors, whether it's a couple of folks hiking or they go into the woods for a hunting weekend. But then you have a group of 12 , and it creates a very different dynamic for those of us who are comfortable in the outdoors. In conversations at campfire or on a long hike, you really find how much more commonality there is in the issues we have. Whether it's poverty and resources, or the needs we have around testing, all those things are so much more common. There are commonalities that you don't recognize if you're in an urban or suburban or rural district, until you find that we're all working to grow human beings, and we have common needs and common support for each other. So it's a great opportunity for that.

Judah: I think the experiential education piece of it allows for everybody to be in a setting that's not their foundation; people from all across the state, whether from small districts to large districts, from diverse to homogeneous districts. It allows for that 'what, so what, now what' processing. The experiential education piece you're doing but you don't really learn from orienteering or small group tasks. It's about how we interact to solve a problem. How do we collaborate, how do we listen, how do we share vision; those skills of facilitating and leading and being part of a group, not just dictating. And then you can process that experiential education piece there, but then extrapolate that to your home setting. Once we were at a campfire, and a woman got on the seat of wisdom. It was a struggle for her on the orienteering part. She said "my entire life I've never known what it was like to struggle." She said life came easy: “I'm from high socioeconomic class, I could sing, I was popular in school and I did well in school. I did well in college and went to work at school and now I'm an administrator. And all of a sudden now I know 
what it feels like to dig down, to actually try to accomplish something." She said it gave her a connection to kids, trying to help those who are struggling trying to find hope. And all of a sudden now I have a visceral feeling of what they are going through.

Harley: The vulnerability of coming into an atmosphere like OLE. I remember coming in, not really knowing exactly what it was going to consist of and being very worried because it was outside of my realm of comfortableness. Bringing that in, along with the team building that occurred, and just the people that I met. I did OLE in my third year of being an administrator and I felt being in a very small rural district I was on an island by myself. After going to OLE, it was just life changing for me. The team building that occurred, the people that I met, and the leadership skills that I learned. How to work better with a team. How to show that you could be vulnerable as a leader, and take that back to my district. Then the people that I met along the way through, not just being a participant but then facilitating. I've met a ton of people this way and the networking and collaborating. I no longer feel like I'm alone in this. I have a team of people that I can work with as well. I think that another aspect of it too is just that self care piece for us, as leaders, and how important that is. What OLE taught me was that professional development, being able to network and talk with other leaders, think outside the box; all of those skills are going to be such important skills to bring back to your own building and communities.

Jonah: To work at DESE with Paul Katnik, Doug Miller, Susan Hodges and see the inside of it and the theory, the thinking that went behind it. All the prep and then the impact that it had year after year after year is still fresh in my mind. I just can't say enough good things about what it did to develop the whole big picture perspective, the 
interpersonal development of how critical relationships are. Listening and being a servant leader is a buzzword that's been around for a while, but also the technical detail. We had quite a bit of training on really how to be a leader, that had a profound effect. And it was a meaningful thing that still continues.

It pushes us out of our comfort zones, but yet it's such a safe environment. You go there and everybody is uplifted, they're positive, they're supportive. If you screw up or push against others' ideas, it's without getting into the politics that we see today where everybody has to be adversarial and I have to hate you. It's just the opposite of that. That is such a life giving experience that buoys you up for forever. I mean I still carry that and I haven't seen anybody for a long time. It changes your heart, really. It opens up your mind to what real leadership and what relationships are all about in an informal way but then it carries over.

Jamie: I think it's an integral part of the year long Leadership Academy experience. I think it's the biggest hands-on part of it. We teach things throughout the year through Leadership Academy. And we do things throughout the year. But I think OLE is the hands on, get in the middle of it, learn how to work as a team, practice the toolbox skills. Really applying all of those things that they're going to take back and apply within their building.

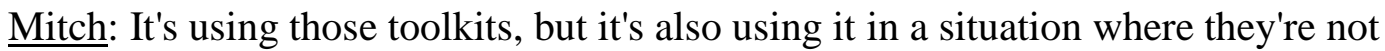
completely comfortable. Which is really what we're expecting our students to do on a daily basis. So we're giving them all these tools, but we're putting them in a situation that, probably $90-95 \%$ of them, were not used to in being outdoors. So I think that's the leverage point and making sure that we're getting them where they need to go. 
Tim: I don't think we can ever overstate the importance of the networking that takes place. You network when you join stations, but I think laughing and crying and spending those days at OLE, it creates a network that just isn't broken. When people see each other that they've been through this with, their eyes light up with a different sparkle than in their contact with others over their years of experience as a leader. I also think that it builds this commitment, that camaraderie that we need to be supportive of each other. So it goes to that networking piece.

Chad: It's still the number one professional development experience that I've engaged in. Certainly the other components of Leadership Academy were powerful and very beneficial, but OLE was the single most significant professional development still in my experience. Now as you facilitate it, you pay attention to the participants and how they respond. And it just really embraces the complete being of each individual. You never know what might surface. You don't know what's gonna happen next. The problem solving skills that they are exposed to in teams and to be exposed to different thinking and different ideas and different ways to approach things for a building leader, it's just powerful. And so the networking, all of those things, and at the end of the experience to just see and talk to the participants. You know this is a powerful thing. It's beneficial. Obviously, not everybody walks away and says, 'Man, that was great.' But the majority do. And, and I think they would all say, 'Yeah, I had some growth through this experience.'

Question 5: Have you ever attended an experience that was comparable to OLE? Casey: I would echo that day long, team building stuff but nothing extended like OLE. 
Tyler: We used to do a program called challenge leadership with groups of students. Some of the things that we did in OLE in terms of the in camp stuff mimic or mirror that. But I don't think there's any other development that allows you to take such an active role in your learning as OLE does.

Austin: We've had groups come in and have done team building exercises but no, there's nothing on that level or that scale.

Skip: About 35 plus years ago, there's a program in St. Louis called the Metropolitan Student Leadership Program, and it was designed in a similar fashion to OLE around bringing students from different regions right in St. Louis and Sibley. Again very much where you go to high school thing, so it was intended to bring folks together to do both outdoor experiences as well as urban experiences and there was a lot of purpose. As a teenager, as a high school student, I experienced some of those same pieces, and they stuck with me then, when I first did OLE all those pieces came back. It struck me, too, the other comparison would be, there's an American Youth Foundation. They have a camp in Minnewanka, Michigan, and a lot of the similar kinds of pieces that we communicate with OLE occurred. That's been around for 40 or 50 years. Judah: I did in college for emerging leaders that had low ropes initiatives and tried to walk through work on the focus pieces, but the thread it didn't have was the purpose. Educators are coming to OLE with a common purpose of how to meet the needs of kids, our community, our school community, our parents, our faculty and staff, our children. And what skills are required for that.

That processing time around a common purpose makes it all above and beyond anything else I've experienced, because it's not in isolation. You can learn a skill in isolation, but 
it's not going to be visceral, it's not going to stick and you're not going to have the application breadth that you're going to have with a common purpose of educators like you have at OLE. I would add on top of that, the processing with folks you've just met. They have various leadership experiences and districts and settings, it really helps tease that reflection out and I think it's unique about a OLE

Harley: I can't say I've taken part in any other any other type of PD or anything like that that's come close to OLE

Jonah: When I was in college, I went to two six weeks summer camps and marine platoon officer training. And I mean obviously it's a completely different thing. It was military and you were practicing for war, but it was command and leadership. You were out in teams and you had to lead and you had to be a team player and there were a lot of similar dynamics, even though the context was about 180 degrees away. But it still had carry over. However, there was no joy in those experiences, even though there was a tremendous amount of learning but OLE had so much joy to it.

Jamie: When I worked for the YMCA, we went on a retreat type thing. OLE is definitely on steroids compared to that experience, but it was a similar, watered down version of that. And I think the YMCA does a lot of adult retreat activities like that, and they encourage the same types of leadership skills that we do for other businesses.

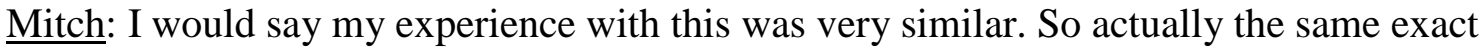
leaders that we have for OLE were running groups in St. Louis when I was a kid. I was not a kid who was exposed to the outdoors, and at 15 years old, a freshman in high school, the same group that helped has helped with OLE for years, and 
those guys, were the guys that dragged me out of the classroom. And I saw the value of it at that age, and it's just continued through high school, college and then now.

Tim: The only thing that really came to mind for me, since I've been in this position, we work closely with Mike Rutherford. He has a leadership retreat in North Carolina, and I was able to be a part of that. It's not at all the outdoors type experience, but it is the intensity of identifying different components of leadership and making the transfer to a school setting. So, as far as the outdoor transfer from non-school activities to school activities, OLE is unmatched anywhere.

Chad: I've not attended anything similar to that. I've tried to recreate it with my staff on a smaller scale, but nothing overnight or the orienteering piece.

Question 6: What were your most impactful experiences at the OLE either as a participant or facilitator?

Casey: I don't know. There's so many! The guide was looking at the map and we knew we were going to miss the flag. But we figured we were going to hit a road as a back stop maybe. Well, we finally hit a road, but where we thought we were hitting the road was wrong. We were hitting the road over here, we've done a whole 90 degree turn in making a little adjustment every time. So it was a great opportunity for discussion with the group and it was late. It was every bit of midnight and we had a guy in that group that I really thought was going to fall out. He had the worst blisters. But you know what, he hung with it and the group hung together, and he left Sunday morning with a really good experience.

Tyler: We literally met it at the fork in the road. We had to sit down in the middle of the road, and have a discussion about which way we are going to go and what we are going 
to do and like. That just sticks out as being the right time at the right place and you had that moment. If you would have rushed it just to get done, that wouldn't have happened. But it was frustrating until that point, and then 'it' happened! I'll always remember that as just a moment of being, of learning at deeper levels. That can't be replaced. So, it's a little nugget that I always cherish.

Also, I teach as an adjunct at a local university and I still use an initiative I did as a participant. There are so many things you can talk about in terms of decision making and communication. And I know it frustrates a lot of people in they think it doesn't have an answer or a solution, but there's so many ways of processing that initiative. I still use it 20 years later, and it still works!

Austin: We had a guy on our team whose take on things was not gelling. Everybody else had been really trained on PLCs and so there's lots of collaboration, but he was not down with that. I just remember that as one experience where we really had to try to work on a guy to get him to come around to that line of thinking, and eventually worked out. In another group, there was a lady from St Louis and she worked in a central office position and she had never been in a building leadership role. She had come from the business world and was like a CFO or something. She didn't participate a whole lot. During that puzzle experience the team was struggling with it. Finally, I mean it took a long time, but she finally spoke up and gave her two cents. And it was the key to the whole puzzle. That changed her whole take on things for the rest of the time. She was more of a participant than a casual observer. 
Judah: It wasn't incredibly impactful for me as a participant. I think I was in my fourth year of administration. I definitely grew upon that experience. But also I think I continue to learn.

Jamie: We had a woman in our group from St. Louis. It was a very interesting experience for her, a very challenging experience for her. Our group struggled a lot, but came together. In June, when we had graduation, she came up to me and said she wanted to know how you could maybe come back and intern to be a facilitator. And I think you guys have had those moments, too, where a lot of people want to come back and facilitate. But for someone who struggled that much, and who we thought absolutely hated every minute of it, to come back and say I got so much out of it upon reflection later. How can I be part of that? I think that's something also that makes an impact as far as seeing that it did really impact them in a different way than you thought. Because honestly I thought she just hated it. So I think they reflect beyond those three or four days and learn things from it. And that's important whenever you see that happen.

Mitch: We had some turmoil on our team on whether to go for a flag. And everybody was worried about a certain woman. But nobody gave this woman a voice. Everybody was talking around her. And then when we brought everyone into the circle, she was like, 'Well, why aren't we going for it?' So I think for me that was big. Making sure we talked about how everybody has a voice and that was super impactful for me.

Tim: Seeing those people be successful and branch out and do those different things. And even the ones that are just staying and are still at the same school district they were when they went through Leadership Academy. When they're running a darn good school and you can see good things happening. And you know, that's just, that's why we want all of 
those people that come in contact with those kids especially to have good experiences. And I think Leadership Academy helps them to pay it forward to their school districts that they serve.

Chad: The team that we were working with facilitating just seemed like the initiatives, they just went through them like nothing. We tried to make it tougher, we tried to silence some people and not let them lead. We did all those things, but they just seemed to be successful time and time again. Then we go on the orienteering and they're breezing through the first four flags and get to the campfire. And then it happened. You sense this overconfidence a little bit, where some of them were just relaxing, not paying attention, and it happened. They were lost. And they were lost for a good 45 minutes. To watch grown leaders neural downshift where all common sense and rational thinking go out the door. I knew eventually it was gonna work out, but it was really fun to watch that. Had they not had that experience it would've ended differently because it brought them together at a whole different level. A silent voice to the group, even though they were speaking it, and it finally was heard. And it was the correct direction to go and it was an eye opening experience for everybody in that group. That we need everybody, it can't just be one or two, we need everybody. That group became extremely close because of that. And that person that wasn't heard, by the time we were done, couldn't wait to get their shoes off. They had blisters everywhere. We had to stop and, and give him bandages and all those things. So that's probably one of my most memorable experiences, although every one of them has been that way.

Question 7: How would you characterize the elements of OLE? Those big overarching themes? 
Casey: Well, for me it was always exploration of self, collaboration and teamwork, of which trust is a part of. I would tell people, because I had principals that were nervous about it, you know you have to do OLE. You will come back with a whole new appreciation of who you are, who others are, and working together to accomplish a goal. Tyler: Trust for sure, empathy, communication, and a butterfly effect as well. Starting to see how a decision you make or a process you put in place as a leader could have a ripple effect or a butterfly effect. Understanding risk taking and vulnerability as an exploration of self. Well, and in the impact that self has on the community. So, whether it goes to more internal biases or judgments or experiences. They can become exposed. You can't hide them, if you're truly engaging in the process. But you're able to experience the impact of those in a safe place, and then be reflective of how that could impact a bigger community.

Austin: I think more of vulnerability based trust because it's all about getting out of your comfort zone. It really is all about community and all about relationships. And how you develop those relationships to form a community at large.

Skip: I think that the idea of support is critical to learning, and that may be verbal it may be physical. There's always other ways we can support others. And, you know, within that the idea of listening is such a critical piece, and we struggle often as leaders to listen to all those around us, as opposed to directing. I think that's a big piece that occurs in all the veins as well, is that idea of active listening.

Judah: It's an experience that's both visceral and academic that carries with you. I think it's an igniter, not only of ideas but a passion. And I think facilitation skills development. 
But there's a huge piece of trust, a huge piece and reflection, and I think also an interdependence that is a really important piece as well.

Harley: I'd say: camaraderie, reflection and friendships, because I think that I've taken out of this some lifelong friends that I will keep in contact with no matter if that's professionally or personally.

Jonah: Personal awareness and development. And then collaboration and learning. I mean the whole thing is still geared about learning, but having learning through different experiences.

Jamie: One is failing forward. Because I think part of OLE is that we set them up to fail in certain ways because they need to experience that. And I think we have to experience that. We also have to be forced to remember what that feels like because it's so important for our students to fail forward. I mean, that's what life's all about. We're gonna fail. But what do you do when you fail? And I think that's one of the top things that has to be instilled in everyone. And we need to be better about instilling in students what to do when you fail and how to go through that process. But the other thing is the power of reflection, because built within OLE (and built within the year long Leadership Academy program) we encourage reflection. We give them time for reflection, we reflect with them. We do a lot of reflection and I think that's one of the things people comment on all the time. They say they are not good about reflecting because we don't take the time. And I think it forces them to take the time and realize how powerful it is. They've got to do that more. That's one reason that the experience is valuable because they do reflect so much. That drive home you're really reflecting and thinking about what you do, how you're going to apply it, and what you got out of it. I think that's powerful. 
Mitch: The first word that I thought of was trust, but I think maybe in a different way. So I look at it as if you look at our participants, a lot of them come out with the same thing. They have this renewed re-energized education, ready to take things on. But I think part of that is how OLE is designed with the facilitators. So we're given a lot of tools. So if you compare that to schools or teachers, we're giving them standards to teach, where they trust us and how we deliver those tools. And then we also as as leaders, we need to trust teachers and how they deliver those standards. Right? In the end, people are coming out doing really well. So I think what that tells us is, maybe this is like some type of metaphor for just, let's give teachers standards and get the hell out of their way. Tim: We encourage out of the box thinking. A lot of us come to OLE with thoughts in our mind about how something should be done or the way it should be approached. I think a lot of our activities destroy all of those preconceived notions and force us to look at problems in a new way. I use this word a lot when I work with our principals in our region, but you have to make that transferal from what you're gonna get to the reality of your situation. Sometimes, if we're caught in that box that we're living in, we're not going to be able to do that. OLE and Leadership Academy forces people to give up the usual and look at some of the unusual ways to solve problems, which might be more valuable for the people that they work with, and the kids that they serve.

Chad: Confidence, you can see that growth in a three day event. Somebody that comes there, thinking they're too cool, or someone that comes in and they're just dead silent. And they're shy and don't want to be involved. And then by the end they're just right there with them. Also, I think the word that comes to mind is diversity. Because within a team, you can have a building leader from the smallest school in the state, to the largest 
building in the state. And so the diversity that they are able to get exposed to the problems that they deal with, we always tie it back to their school setting and how this applies to them, where they're at, not only in their personal life, but within their job back at their school. They quickly find that there's a lot of different problems that their colleagues deal with that they don't see where they live. So I think diversity.

Question 8: What is it that draws you back to facilitate each year?

Casey: You learn more as a facilitator than I did as a participant. I went through my first year in administration and I didn't know what I didn't know. Leadership Academy allowed me to muddle through that year to some degree of success I think, but it was that first year back as facilitator where things really started to lock in place. After that I was just up to go back every year. Doug Miller used to talk about being a renewal. I don't know that I ever waxed as poetically as Doug did but it was certainly a renewal for me. Also, I was fortunate enough to be Superintendent long enough that all of our principals went through Leadership Academy, as well as many teacher leaders. We accomplished a lot of things and I attribute that to the common shared language and experience. We all didn't go through at the same time, but we had more or less the same experience and it helped ground us as an administrative team and as district leadership.

Tyler: I see it as two sides of a coin for me. For me, there's a selfish component. I selfishly want that for me because of what it does for me. Instead of treating myself to a weekend getaway, I'd rather go there. I know that it could be taken as a negative but I mean it in the most positive of aspects, when it comes to that selfish piece. But the other piece of it is the service mindset because of my belief in it, and what it can do. It's like leaving leadership better than the way you found it. I'd rather dedicate my time to that 
type of mission than a lot of other things. It's a give and take. I get as much as I hope to give. Leave this place better than what you found it in terms of leadership. If people are committed to all those processes and those things that take place at OLE, and they can dive into it, you will be better. If it makes you better and it makes other people better, it's a win-win type of situation. There is no negative. I love when I'm able to involve myself in those types of situations.

Austin: You know, it's a life changing experience, and to have a small part in doing that for other people. You know, that's, that's really what it's all about. I mean we're all in this job to be life changers and that is a way to do it for your fellow administrators.

Skip: I get the opportunity to interact and learn from and share with administrators across the state and across demographic groups. There's just no other opportunity to really dig into multiple hours experiences that are both funny and serious. It doesn't occur anywhere else, and that that can't be minimized. It is a phenomenal opportunity because many of us grow up or work in fairly similar areas. So that's a huge proponent for me. And I just think that it is a great equalizer in terms of being able to share space in the outdoors. That is an opportunity many of us don't get, to really have that quiet space is an awesome opportunity for all of us.

$\underline{\text { Judah: }}$ So I want to give back, but at the same time I'm also learning quite a bit from others. It's the whole sharpening the saw piece. I'll also tell you the networking piece is incredible. I can't tell you how many times I've called upon people that I've met via OLE for advice on how to get through things, or how to handle things and vice versa. I think the skill development and skill honing is incredible. I think the importance for leadership in our state is an incredibly important thing and to be able to participate and give back to 
that is a calling that I'm happy to fill, but it's also renewal for me, not only skill wise but also energy wise. It's why journaling is so important and I love the fact we have an hour long solo built into OLE for that purpose. I think that change of pace is incredibly important. I think it's a renewal piece, but I think the setting and the pace is just a total difference, and it's very important for people.

Harley: Just what I got out of it going through the process the first time I decided I have to come back and I have to do this over. The networking and the people that I met were huge. But there's also a piece of OLE where it is going back and finding that child-like feeling, to be able to relate with kids to that camp atmosphere. And then knowing how to socially interact with others and people that are different from you. All of those pieces and working together as a team. I love going back to and putting myself into my kids' shoes and what it's like to be a kid again. I want to continue to go back to and just meet new people and get their perspectives and just learn. The outside the box thinking that I'm able to incorporate in any of our normal professional development is fun, it gets our team together.

Jamie: It really energizes me and the fact that it makes me remember why I'm in the business I'm in and why I love the business I'm in. And it helps me be a better leader, because it empowers me to be as you know, I learned new things and I meet new people that are doing the same things I'm doing and it really empowers me to push harder and want to be better because I'm meeting so many people who just amaze me. You just really learn a lot about people through that experience and it empowers me to be a better person and do better at what I do. 
Mitch: I think the hard thing about this is it's hard to quantify why we come back. For me, it's just the quality of the relationships and the quality of seeing growth in people. So often in education, you have to wait so long to see results in certain things. And this is one of those almost guaranteed times to see results over a three day period with a small group of people. And I think that's the big thing for me is just knowing every year I go, you're going to see these results that maybe aren't necessarily quantifiable.

Tim: The word I had ready to go was energy. Even the leaders that start out uninvolved or stepping back a little bit and by the end of day one they're in there digging through how can we make this happen? By the end of the night, they're right there with the same energy that everybody else has. That energy, it's hard not to have it and take it back with you. I always come back excited about what I'm doing again.

Chad: I think it was mentioned earlier about giving back to others the experience that you had. It is rewarding to watch the growth within the team that you get to facilitate and work with. And just see the coming together of a team and the development of a team. And the characteristics of that team. Every one of them, each time, is unique and different. It's just rewarding to see the growth in just a short period of time in all of those individuals.

Question 9: What would you tell the leaders of OLE as far as the design? What would you keep, take away, or add?

Casey: In many ways it's gotten easier right and that's, you know, a reflection of society as a whole, you know the facilities are definitely much more comfortable. I feel like we have lost a little bit of the focus on the facilitating of adults in this experience. When Hank and Doug put all this together it was stuff that Hank was doing with kids, but they 
really made the focus on facilitating adults through this experiential experience and not kids. There was a time when, when many of the facilitators went to Lahey training and did some other things where they really focused on adults. Hank and Larry kept that up, but now that they're both out of the picture. We're not doing that focused training for facilitators anymore. We're just relying on that they go as participant, they come back as an intern, and that's the training they get. I think we need training in order to ensure the viability of the experience into the future.

Tyler: Go back to the way it used to be before we went through all the changes in cuts and however it looks now. There's simple things. There's a poetic thing about camp Rising Sun. It's almost like I wish instead of taking money away from it, pour more money into it to design things. For instance there's nothing better than a canoe crossing at sunset to bring your mind back to a certain place. But to have opportunities like that. To figure out orienteering as a team, because there's like eight different ways to do this depending on the group dynamics, to how you're going to cook dinner. What are the strengths, weaknesses, and obstacles that each team uniquely faces. So I'd want to keep those elements. If they scaled back on something over the years because of restrictions or worries or insurance or whatever else, and I can only imagine that some things have been restricted. But there's always these things that are intentionally challenge by choice. There's low challenge by choice and there's high level challenge by choice.

Austin: I think they have really tried to tie OLE to current things that are going on in education, which is good to make it real, but I think that might seem a little forced sometimes because not everything lends itself to RTI, PLC, that stuff. And facilitators don't get a lot of training, other than you just come back and settle in. 
Skip: There's a history of OLE that is not contingent upon that place. I think being cognizant of how to structure that with who we are as an entity.

Judah: Every OLE is different. It's not yours, it's going to be a unique experience. You're there to facilitate it, not to recreate what you had before. And make sure we take care of people. We want a sense of belonging. And so if you're using sarcasm or you're solving the problem for them or whatever it might be, that can be detrimental to the group you're facilitating. So I think those are important pieces. I think actually the OLE experience at Camp Rising Sun and Camp Lakewood are very similar in a lot of respects. I think they're not roughing it as much. But I also don't think the roughing it part was always value added for everybody. At Camp Lakewood, the pace between flags is fast. And then if you end up having a physical challenge for the hike they become even more so, and people can stretch out. Whereas, it was hard to stretch out too far as a group at Camp Rising Sun because you were never oriented well enough to get to spread out. And that means you have less collaboration because there is a lot of collaboration, knowledge, and skills to get from flag to flag, but also just about your district, about your experience, about leadership, and about education that happens in those quiet spots. Harley: I really like afterwards when all the facilitators get together and reflect over that time and have the ability to discuss changes that need to take place in the future. How we can make it better. So I think that that's a key piece to each year to getting better.

Jonah: The networking. The progression of self-awareness, with the self assessments and all the little pieces that come together. The regional collaboration but I just think that's huge and then OLE itself is so well designed with the activities and the interaction. 
There's no pressure in any of it, but it all pushes you just a little bit to a greater awareness.

Jamie: I really think previous OLE experiences at Camp Rising Sun gave a little different experience, a little bit more. I think the teams built a little stronger, just because of the location, the setting, it was just a different feel there. And I don't know if that's because it was more primitive than Camp Lake Wood or not, but I do think a little bit was lost when we had to move. Not that that changed the overall purpose or anything like that. But I do think that changed just a little bit. I've always been an advocate for wanting to move it back there. But that's not going to happen. But I do think that changed it a little bit. Mitch: I think also the location is an equity thing. When you think about people in the northwest of Missouri who have to travel 6-7-8 hours. But I can be there in 52 minutes, and I live as far east in Missouri as anybody else. So I think it's just an equity issue. When some of that isn't even the participant. Right? Some of it is I'm mandated to be back for homecoming. And so I think part of it is the commitment on the partner districts that they know if they send somebody that they need to be willing to say they may miss something on that Friday night, or they may miss something on that Saturday night.

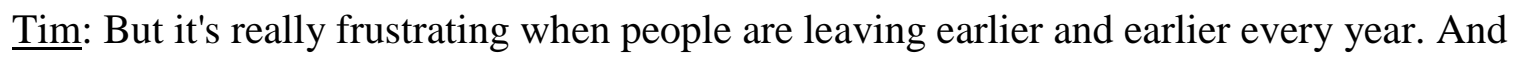
I think about what some of them miss out on by leaving early. I think they're missing out on some of the experiences that you can have. Can you attach a condition to it that if you are going to participate in OLE, you are there from Thursday evening until Saturday noon? If not, if you can't be there. We'd rather wait until next year, or a time that you could be there the entire time. I don't know the answer. It's just really frustrating. I think it's gotten a little bit worse every year, where more people leave on Friday evening, or 
don't hang around for any on Saturday and miss out some of the experiences that are in my mind some of the more valuable ones. Because it seems like the world is not slowing down any. And we need them to slow down for three days and ignore everything that's going on around them. And that's easy for us to say, but there's not a lot of school districts that will say that same thing.

Chad: Yeah, I don't know that I would change or add anything to OLE. I agree that I like Ozarks location better. That's where I went through as a participant. The only other thing is that the last year the flag issue and setting that course up, it seemed pretty disorganized. But we know that was a problem. And that's something that happens when you seek improvement.

Question 10: Is there anything else you feel I should know about your experience at the OLE?

Casey: So I just worry about that for the future and for it to continue to be viable and as impactful as it was.

Austin: I agree with Casey. I wouldn't want it to get watered down. I think that's the fear of trying to integrate into MLDS. I think the approach of this is a whole separate experience that may or may not fit with what's being taught in MLDS. I think that's how it has to be approached because they're trying to make that square peg fit in that round hole.

Judah: We didn't know when he came to OLE but basically that day his wife said she's going divorce him. So he actually loaded up his car and had no idea where he was going to go to after OLE. You can imagine he was not the most pleasant person, but none of us knew why. I can remember there's some wonderful people, who would say, 'darn it, you 
know x person ready circle' on our hike. I think we got in at two in the morning. We never missed a single flag. We hit them all dead on but we probably did 30 ready circles, because he was so caustic. But he was so hurting and by the end of it the group just kept loving him, holding him accountable, loving him, holding him accountable, loving him. He would say even though wasn't a pleasant time for him. He learned a ton from that and our last morning he shared out what was going on and, and of course it put everything in context. So, even if it's not a pleasant experience, you can still learn a ton. I can't tell you how many people I've also known say they did not want to go. You and I were just talking about somebody. He didn't want to go. I had multiple employees that worked for me that didn't want to go, but all of a sudden they got there, and experienced it saying, 'Oh, this is amazing.' So I think the mystique of it is one thing, but I also think the reality is it's so foreign to some folks, but we have to wrap around and make it purposeful. I think it's so purposeful, whether you enjoy the outdoors or not, you're going to enjoy the experience. Kudos to everyone who, who helps facilitate year in and year out.

Skip: The facilitators themselves, the folks who have been experienced and want to come back and give back, is a critical element. The practitioners who have experienced OLE and have come back year after year, to give back to that space. Rest assured, I get from it. It grows me. It builds me. It gives to me. But the importance of practitioners, of past participants, coming back to give back, is just a critical element of OLE. And I think the other thing I want to share is your willingness to do this is a really big deal. It means a lot. I think that there's a rich history. And you being willing to take on what are those parts is a big deal for a lot of people who aren't here now. And they have given us so much in the past, and for those who will come after us. And even then... who's coming 
next. I don't know, but I want to be there to make sure that somebody else has those same tools that were freely given to me to be a better human being. I really appreciate you taking this on and find the value that we all see.

Jonah: And the significance of growing new leaders internally, that you go out as a cofacilitator and you watch, you get mentored, and you do it for a year to understand the dynamics. Because working with adults, there's something to that besides having passion, you've got to have a level of expertise. 


\title{
Appendix C
}

Consent Form to Participate in Study

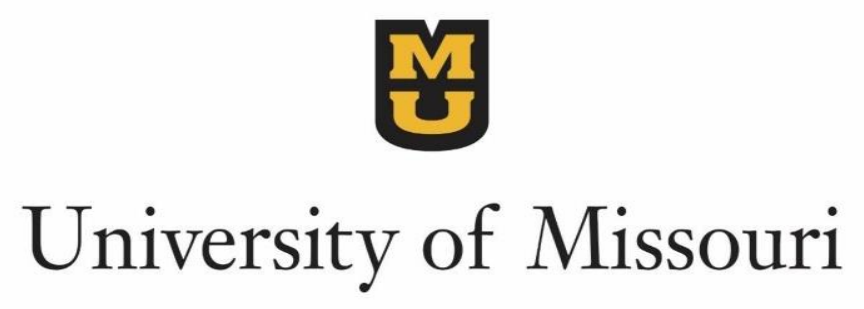

CONSENT FORM TO PARTICIPATE IN A RESEARCH STUDY

\author{
Researcher's Name: Jenni Hayes \\ Project Number: \\ Project Title: School Leaders' Perceptions of Missouri's Outdoor Leadership \\ Experience
}

\section{STUDY SUMMARY:}

You are being asked to participate in a research study. This research is being conducted to understand participants' perceptions of Missouri's Outdoor Leadership Experience and in what ways the skills learned at the outdoor leadership experience are perceived to impact school leader effectiveness. You have the right to know what you will be asked to do so that you can decide whether you would like to participate. Your participation is voluntary. If you decide not to participate, you will not be penalized in any way. You can also decide to stop at any time without penalty. If you do not wish to answer any of the questions, you may simply not answer them.

\section{PURPOSE OF THE STUDY:}

The purpose of this study is to understand in what ways the skills learned at the outdoor leadership experience are perceived to impact school leader effectiveness.

\section{REQUEST FOR PARTICIPATION:}

I am inviting you to participate in a study on your perceptions of Missouri's Outdoor Leadership Experience. You are being asked to complete an interview.

\section{QUESTIONS, CONCERNS, OR COMPLAINTS:}

Please contact Dr. Sandy Hutchinson, dissertation chair, at hutchinson@ucmo.edu, if you have questions about the research. Additionally, you may ask questions, voice concerns, or register complaints to the researcher, Jenni Hayes at jhkdz@ mail.missouri.edu. There is also IRB which is a group of people who review research studies to make sure the rights of participants are protected. Their phone number is (573) 882-3181 or email irb@missouri.edu. 


\section{Appendix D}

\section{Recruitment Script}

Identification of Researcher: This research is being conducted by doctoral student Jenni Hayes, from the MU Cooperative EdD program.

Hello, My name is Jenni Hayes and I am a doctoral student from the University of Missouri Cooperative EdD program. I am conducting a study to understand participants' perceptions of Missouri's Outdoor Leadership Experience and in what ways the skills learned at the outdoor leadership experience are perceived to impact school leader effectiveness. I would like to conduct focus groups and interviews about your thoughts on Missouri's Outdoor Leadership Experience. I would like for you to join me for either an interview or focus group, or possibly both. If you would be willing to help, I will conduct a focus group

\section{$\mathrm{AM} / \mathrm{PM}$}

and interviews

AM/PM. 


\section{VITA}

Jenni Hayes holds a Bachelor of Science in Education, Early Childhood and Elementary Education, as well as a Master of Science in Education, Elementary School Administration. A doctor of Education in Educational Leadership and Policy Analysis is expected from the University of Missouri in May of 2021. She has been an educator for 18 years. She spent 10 years as an Elementary Teacher and the last eight years as an Elementary Principal. Jenni’s passion for helping others learn continues to lead her in new directions in education with both children and adults. 